\title{
The Business Method Patent Myth
}

\author{
By John R. Allison and Emerson H. Tiller ${ }^{t}$
}

\begin{abstract}
Internet business method patents have been roundly criticized by most observers as being singularly inferior to most other patents. Many have even argued that business methods should not be patentable subject matter. As a result, Congress and the Patent and Trademark Office ("PTO") singled them out for special treatment. All of these criticisms were, however, voiced without empirical support.

We gathered data on most Internet business method patents issued through the end of 1999 and compared them with a large contemporaneous data set of patents in general. We also compared them with patents in fourteen individual technology areas within the general patent data set. Our comparison focused on several metrics that we believe serve as good proxies for patent quality and value. We found that Internet business method patents appear to have been no worse than the average patent, and possibly even better than most. They also appear to have been no worse, and possibly even better, than patents in most individual technology areas.

These findings lead us to question the conventional wisdom that Internet business method patents were uniquely deficient. We briefly explore some possible explanations for the chasm between the accepted
\end{abstract}

\section{(C) 2003 John R. Allison and Emerson H. Tiller}

$\dagger$ John R. Allison is the Spence Centennial Professor of Business Administration, McCombs School of Business, and Professor of Intellectual Property Law, McCombs School and the College of Engineering, University of Texas at Austin. Emerson H. Tiller is Professor of Law, Northwestern University School of Law.

Partial funding for this study was provided by the National Academy of Sciences ("NAS"), Science, Technology, and Policy Board ("STEP"). We appreciate the ideas and suggestions offered by several members of STEP's Committee on Intellectual Property Rights in the Knowledge-Based Economy.

The authors thank Thomas Bohman and Xinlei Wang of the Information Technology Services at the University of Texas for statistical consulting. The authors also thank participants at the University of Chicago Law School's Law and Economics Workshop, University of California at Berkeley, Workshop on Institutional Analysis, Northwestern Law School's Faculty Workshop, the University of Southern California Law School's Workshop on Law, Economics and Organization, and the Huber-Hurst Research Seminar, University of Florida, for comments on this Article or portions thereof, as well as several individuals who provided especially helpful comments on earlier drafts, including Connie Bagley and Mark Lemley. 
view and what we believe to have been the reality, including the possibility that negative opinions about these patents may have been the result of an information cascade. More importantly, we believe that efforts to single out these patents for special treatment not only lacked sound justification in the particular case but also reveal more fundamental problems associated with ex ante definitions to carve out any particular technology area for different treatment.

\section{TABle of Contents}

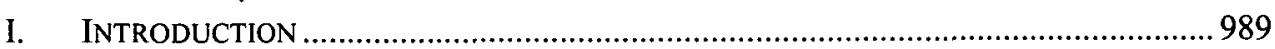

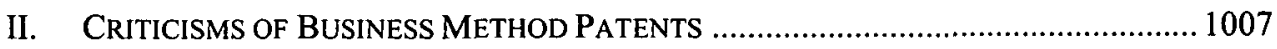

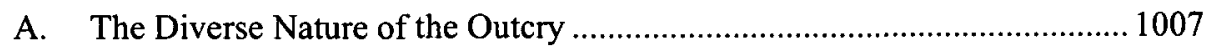

B. A Bit of Software Patent Déjà Vu ..................................................... 1012

C. Prior Art-Related Criticisms Migrating from Software to Business Method

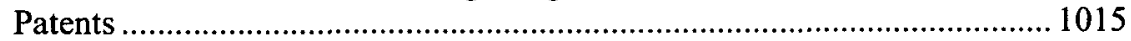

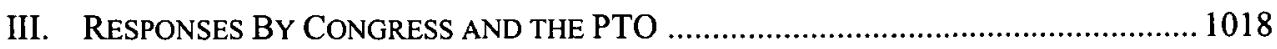

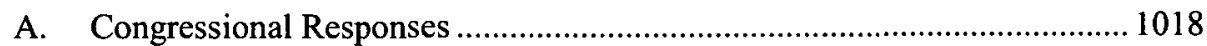

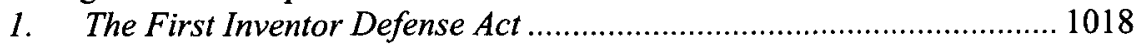

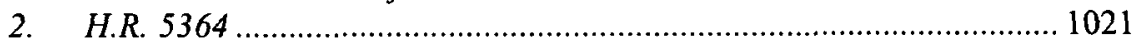

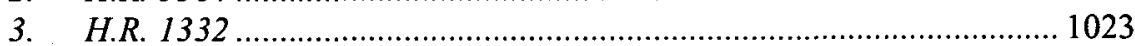

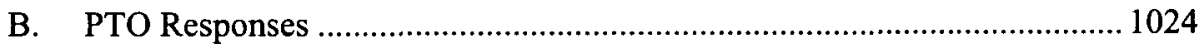

IV. DATA ON INTERNET Business METHOd PATENTS AND GENERAL PATENTS ......... 1026

A. The General Patent Data Set ................................................................ 1026

1. Defining the Technology Areas ..................................................... 1027

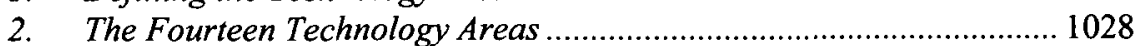

B. The Internet Business Method Patent Data Set ........................................ 1031

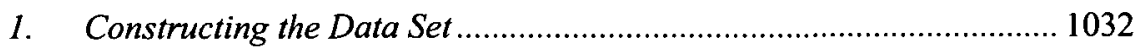

2. Categorizing Internet Patents ........................................................ 1034

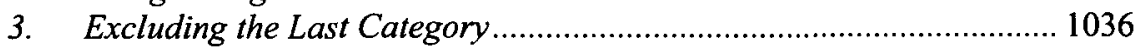

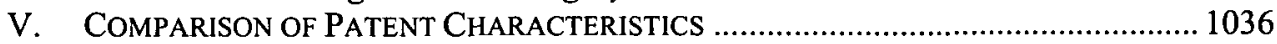

A. Number of Prior Art References............................................................ 1036

1. Internet Business Method Patents Compared With the Average Patent 1039

2. Internet Business Method Patents Compared With Patents in Individual Technology Areas ..................................................... 1043

B. Types of Nonpatent Prior Art References ............................................. 1045

1. Internet Business Method Patents Compared With the Average Patent 1048

2. Internet Business Method Patents Compared With Patents in Individual Technology Areas ......................................................... 1050

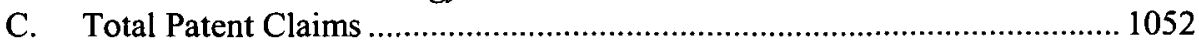

1. Internet Business Method Patents Compared With the Average Patent 1057

2. Internet Business Method Patents Compared With Patents in Individual Technology Areas ......................................................... 1057

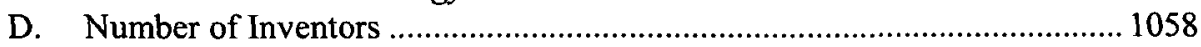

1. Internet Business Method Patents Compared With the Average Patent 1060

2. Internet Business Method Patents Compared With Patents in Individual Technology Areas ......................................................... 1061

E. Time Spent in the Patent Office .......................................................... 1063

1. The Effect of Ancestor Applications on Average Pendency Times...... 1063 
2. Other Reasons for Variation in Pendency Times

3. Method of Comparison

4. Pendency Times from the Original Priority Filing Date: Internet Business Method Patents Compared With General Patents and With Patents in Each Technology Area.....

5. Pendency Times from the Most Recent Filing Date: Internet Business Method Patents Compared With General Patents and With Patents in Each Technology Area

VI. SUgGested EXPlanATIONS FOR THE GAP BETWEEN CONVENTIONAL WisdoM AND REALITY

A. Possible Explanations

B. An Information Cascade of Negative Opinion

VII. CONCLUSION 1081

\section{INTRODUCTION}

A patent represents a bargain with society. In return for the right to exclude others from making, using, or selling an invention for twenty years, the inventor must disclose the invention's details to the public instead of keeping them secret. ${ }^{1}$ To justify such a grant, the inventor must introduce and reveal a technological advance that is both different from what has been done before - the requirement of "novelty"-and different enough so that it represents more than a trivial extension of what is already in the public domain - the requirement of "nonobviousness." Although it is the exceedingly rare patent that, by itself, confers significant market power on its owner, such exclusive rights to control knowledge that is otherwise free for the taking may cause a number of economic distortions. $^{3}$ Thus, there is cause for concern when patents are granted erroneously. ${ }^{4}$ If patents are issued that should not be, the public does not

1. 35 U.S.C. $\S 112$ (2000) (disclosure requirement).

2. Id. $\S 102$ (novelty requirement); id. $\S 103$ (nonobviousness requirement).

3. There is a vast literature on the economics of patents. One example is the increasingly large theoretical literature on various approaches to the proper scope and allocation of patent rights, thoroughly surveyed in Dan L. Burk \& Mark A. Lemley, Policy Levers in Patent Law, 89 VA. L. REV. 1575, 1595-1630 (2003).

4. We assume, as do most observers, that patent quality matters. Staking out a distinctly minority position, Mark Lemley has argued that issuance of substandard patents by the PTO does not cause enough economic harm to warrant the expenditure of additional resources to increase patent quality, because only a very small portion are ever licensed or enforced and the federal courts are better equipped to assess patent validity in depth. Mark A. Lemley, Rational Ignorance at the Patent Office, 95 Nw. U. L. REV. 1495 (2001) [hereinafter Lemley, Rational Ignorance]. Although exploring his arguments is beyond the scope of this Article, we observe in passing that he does condition them on significant reforms in patent litigation, such as lowering the burden of proof for one challenging the validity of a patent from "clear and convincing evidence" to "preponderance of the evidence." Id. at 1528-29. Even with such litigation reforms, we remain uncon- 
receive the benefit of technological advancement in return for the patentee's exclusive right.

Of late, there has been a great deal of negative commentary about patents on "methods of doing business," as well as targeted action against such patents by both Congress and the PTO. Although the criticism and action have focused on business method patents generally, the majority of these patents entail business processes and techniques implemented on the Internet. Moreover, those business method patents tailored for Internet usage are the most controversial and the most likely to cause economic harm if they are granted when they should not be because of their potential for impeding electronic commerce while it is still maturing.

In this Article, we present the findings of our empirical study comparing two sets of patent data. We compared Internet business method patents issued through December 31, 1999 with a large random sample of general patents issued during a contemporaneous time period. We find that Internet business method patents actually fare quite well statistically, contrary to the conventional wisdom that Internet business method patents issued during the early years of their recognition were much worse than others-that they were somehow exceptional.

In the now famous State Street Bank \& Trust Co. v. Signature Financial Group, Inc., ${ }^{5}$ the United States Court of Appeals for the Federal Circuit $^{6}$ held that business methods can be patentable subject matter. ${ }^{7}$

vinced. Overall, however, Lemley's assertions are sufficiently serious that a number of his assumptions and estimates warrant further empirical research, as he himself suggests. Id. at 1531 .

5. 149 F.3d 1368 (Fed. Cir. 1998) (holding that there is no patentable subject matter exception for methods of doing business).

6. The Federal Circuit is the court of appeals having exclusive appellate jurisdiction over patent cases. 28 U.S.C. $\S \S 1295(a)(1), 1338(a)(2000)$.

7. The Federal Circuit actually concluded that there never had been a patentable subject matter exception for business methods, despite much contrary conventional wisdom supported by dicta in several older cases. In State Street, the court explained that earlier decisions referring to such an exception were decided on other grounds. 149 F.3d at 1375-76. For a discussion of the widespread pre-State Street assumption among practicing patent attorneys that there was a patentable subject matter exception for business methods, and the absence of a basis for this assumption, see Rinaldo Del Gallo, III, Are "Methods of Doing Business" Finally Out of Business as a Statutory Rejection?, 38 IDEA 403 (1998).

Quickly demonstrating that State Street was not a fluke, as some observers believed might be the case, the Federal Circuit followed that decision one year later with AT\&T Corp. v. Excel Communications, Inc., 172 F.3d 1352, 1355 (Fed. Cir. 1999), in which the court reemphasized the absence of any subject matter exception to patentability for methods of doing business. 
Although the PTO had issued patents on software-embodied business methods ${ }^{8}$ before the State Street decision in $1998,{ }^{9}$ the number exploded thereafter. ${ }^{10}$ Along with the increased patenting activity came a chorus of criticism. Some observers expressed alarm at the very idea of patenting software-embodied business methods. ${ }^{11}$ A larger number of

In both State Street and $A T \& T$, the Federal Circuit also reiterated its 1994 holding in In re Alappat, 33 F.3d 1526, 1544 (Fed. Cir. 1994) (en banc), that mathematical subject matter should be treated no differently in patent law than any other subject matter, and therefore, software is patentable subject matter despite the fact that it consists of mathematical algorithms. Algorithms are only unpatentable in the abstract, but are patentable subject matter if they achieve a "useful, concrete, and tangible result." $A T \& T, 172$ F.3d at 1356-58; State Street, 149 F.3d at 1373-75. Although the Federal Circuit spoke in terms of patentable subject matter, the distinction between abstract and useful really implicates the utility requirement of patent law rather than the patentable subject matter requirement. See 35 U.S.C. $§ 101$ (2000).

8. The holding in State Street that business methods are patentable subject matter was not limited to those implemented by software, but when people speak of business method patents they ordinarily refer only to software-embodied ones. The ones we studied that envision Internet-related use are necessarily implemented by software. Thus viewed, business method patents are a subset of software patents. To distinguish business method patents from other kinds of software patents, we use the term "software patent" to refer to the broader set minus business method patents.

9. The patent at issue in State Street is but one example. The patent covered software described (and "claimed," using patent law terminology for the structure of the claims that follow the written description) as a data processing system for implementing an investment structure whereby mutual funds pooled their assets in an investment portfolio organized as a partnership in a way that assertedly achieved economies of scale in administration coupled with tax advantages. See U.S. Patent No. 5,193,056 (issued Mar. 9, 1993) ("Data Processing System for Hub and Spoke Financial Services Configuration").

10. Although business method patents may be found in several classifications within the PTO's classification scheme, Class 705, "Data processing: financial, business practice, management, or cost/price determination," consists almost exclusively of them. The PTO placed 469 patents in classification 705 in 1998, 833 in 1999, and 1,006 in 2000.

Many have commented on the large number of business method patents issuing in a relatively short time. See, e.g., Michael J. Meurer, Business Method Patents and Patent Floods, 8 WASH. U. J.L. \& POL'Y 309 (2002) (pointing to the existence of a patent flood in the area of business methods, predicting that the flood will worsen, and describing the economic harm caused by patent floods); Arti Rai, Addressing the Patent Gold Rush: The Role of Deference to PTO Patent Denials, 2 WASH. U. J.L. \& POL'Y 199, 211 (2000) (documenting and discussing dramatic increase in filings of business method patents, and calling for more deference by the Federal Circuit to PTO application rejections).

11. See, e.g., John R. Thomas, The Patenting of the Liberal Professions, 40 B.C. L. REV. 1139, 1185 (1999) [hereinafter Thomas, Liberal Professions] (observing that recognizing the patentability of business processes opens the door for patenting new developments in all of human experience, and that patents should remain grounded in science and engineering); see also Alan L. Durham, "Useful Arts" in the Information Age, 1999 BYU 
commentators, however, maligned business method patents for their purported lack of quality, devoting much of their attention to the perceived failure of patent applicants and the PTO to adequately take into account the "prior art." 2 The argument is that patents granted without proper consideration of the prior art are not as likely to meet the statutory requirements of novelty and nonobviousness. ${ }^{13}$

L. REV. 1419, 1526-28 (similarly arguing that software-embodied business method patents should not be patentable subject matter).

12. For present purposes, prior art consists of prior patents and other printed publications relevant to the invention in question, for example, "patent prior art" and "nonpatent prior art." There are other types of prior art, but these are the only ones that can be analyzed in a study like ours.

13. Most of the prior art-based criticisms represent extensions of similar complaints about software patents generally. It has been observed, for example, that much fundamental programming knowledge was developed long before software was recognized as a candidate for patenting and that, consequently, this knowledge was kept as trade secrets and is not available to those searching for prior art. See, e.g., Julie E. Cohen, Reverse Engineering and the Rise of Electronic Vigilantism: Intellectual Property Implications of "Lock-Out" Programs, 68 S. CAL. L. REV. 1091, 1177-79 (1995) [hereinafter Cohen, Electronic Vigilantism]; Simson L. Garfinkel, Patently Absurd, WIRED, July 1994, available at http://www.wired.com/wired/archive/2.07/patents_pr.html (1ast visited Nov. 9. 2003). We explain later that previous inventions in many fields are secret, and thus do not create prior art because companies of all kinds often prefer trade secret protection over patent protection, especially for methods (techniques and processes).

Generally speaking, prior art refers to past revelations about the technology being patented. The types of prior art cited in patent applications and issued patents are prior U.S. and foreign patents and prior printed publications from anywhere in the world. Printed publications include those from a vast array of hard copy and electronic sources, including academic and trade journals, company and industry-sponsored publications, university and government reports, software and its documentation, the popular press, published patent applications and search reports, various web sites, and so on. In almost all cases, prior art must have been accessible to interested members of the public, although the patent statute provides for one instance in which "secret prior art" may be used to prevent a patent from issuing or to subsequently invalidate it in court. If $X$ filed a patent application before $Y$ invented, and $X$ later received a patent, $X$ 's patent can be prior art against $Y$ 's application for a patent even though $X$ 's application was held in secret by the PTO at the time Y invented. 35 U.S.C. $\S 102$ (e) (2000 \& Supp. 2003).

Other types of prior art, which are typically discovered by an accused infringer seeking to invalidate the patent rather than by the PTO, include evidence of a prior public (nonconfidential) use of the invention or evidence that the invention had been placed on sale. Regarding the "critical date," if a piece of prior art reveals all of the elements of the invention now in question, and if the prior art became accessible either (1) before this inventor invented or (2) more than one year before this inventor filed her patent application, the inventor cannot receive a valid patent. If the prior art became accessible before this invention, we say that this invention lacks novelty. Id. $\S 102(\mathrm{a})$. If the prior art became accessible more than one year before this inventor filed a patent application, we say 
Two of the business method patents often cited as probably failing the requirements of novelty or nonobviousness are Amazon.com's patent on its "one-click" technique for more efficiently ordering merchandise online, ${ }^{14}$ and Priceline.com's patent on the reverse auction technique for buying airline tickets on the Internet. ${ }^{15}$ Although patents in other areas of technology have brought forth complaints from various quarters, ${ }^{16}$ the

that there is a statutory bar to patentability. $I d$. $\S 102(\mathrm{~b})$. Obviously, $\S \S 102(\mathrm{a})$ and (b) can sometimes overlap.

Even if no single piece of prior art revealed all of the elements of the invention in question, two or more pieces of prior art in the relevant field of technology, or in a closely related field, may be combined by the PTO or a court to reach a conclusion that this invention is "obvious." The requirement that an invention have been nonobvious at the time the invention was fully conceived is found in 35 U.S.C. $\S 103$ (a) (2000). From the perspective of a hypothetical "ordinarily skilled practitioner in the art," the invention must not have been merely a trivial, or obvious, extension of the cumulative prior art. According to $\S 102$, this invention must be different from any single piece of prior art, and according to $\S 103$, this invention must be different enough from the cumulative prior art.

14. U.S. Patent No. 5,960,411 (issued Sept. 28, 1999) ("[M]ethod and system for placing a purchase order via a communications network"). Amazon sued Barnesandnoble.com for patent infringement and won a preliminary injunction. Amazon.com, Inc. v. Barnesandnoble.com, Inc., 73 F. Supp. 2d 1228, 1249 (W.D. Wash. 1999). On appeal, however, the Federal Circuit reversed, noting that there were sufficient obviousnessbased doubts about the patent's validity to preclude a finding of substantial likelihood of success on the merits. Amazon.com, Inc. v. Barnesandnoble.com, Inc. 239 F.3d 1343, 1366 (Fed. Cir. 2001).

15. U.S. Patent No. 5,797,127 (issued Aug. 18, 1998) ("Method, apparatus, and program for pricing, selling, and exercising options to purchase airline tickets"). The reverse auction is sometimes referred to as a Dutch auction. See, e.g., Eugene R. Quinn, Jr., The Proliferation of Electronic Commerce Patents: Don't Blame the PTO, 28 RUTGERS COMPUTER \& TECH. L.J. 121, 122 n.5 (2002).

16. Gene patents appear to be the only type that has garnered more publicity than business method patents. A survey of articles in the Lexis "News Group File, All" using the simple "patent $w / 10$ gene" search request reveals that comparable or even greater publicity has been given to patents on isolated, purified genes. This publicity in the popular press has been mixed, and most negative comments reveal the perception that such patents reward mere discovery rather than invention. This is not the case, however, because in their natural state, genes cannot exist in isolation. It is only through human intervention that genes can be isolated, purified, and put to use in medical and pharmaceutical research. See, e.g., John M. Golden, Biotechnology, Technology Policy, and Patentability: Natural Products and Invention in the American System, 50 EMORY L.J. 101, 122-28 (2001).

Regardless of the reasons stated in objections to gene patentability, the magnitude of reported comment, criticism, and opinion on the subject likely results not so much from the expressed concerns or even from the relative newness of the technology as from underlying fears about privacy, the morality of private ownership of the basic building blocks of life, the uncertain consequences of genetic alterations that may pass to progeny, 
magnitude of adverse commentary and reportage on business method patents has been unprecedented. ${ }^{17}$

In 1999, Congress responded to the outcry with the First Inventor Defense Act, ${ }^{18}$ which creates a special patent-infringement defense for a prior business-method inventor who used it in secret and was later sued for infringement by a second comer who obtained a patent. U.S. patent law provides no such defense for similarly situated "secret" first inventors in other areas of technology, and Congress usually does not provide special treatment for any category of technology. ${ }^{19}$

Late in the 2000 congressional session, Representatives Howard Berman and Rick Boucher introduced H.R. 5364, "The Business Method Patent Improvement Act of 2000."20 H.R. 5364 sought to significantly raise the patentability bar for business method patent applications. Among other features, the bill proposed to increase the difficulty of satisfying the requirement that an invention be nonobvious, and called for post-grant

and other similarly unsettling ideas. See generally Leon R. Kass, Triumph or Tragedy? The Moral Meaning of Genetic Technology, 45 AM. J. JURIS. 1 (2000). These are quite different concerns than those regarding business method patents, but certainly help explain the vast amount of public discourse on biotechnology patents. II.A.

17. We thoroughly explore the nature and magnitude of this criticism infra at Part

18. First Inventor Defense Act of 1999, Pub. L. No. 106-113, 113 Stat. 1536 (codified as amended at 35 U.S.C. $\S 273(2000)$ ).

19. Though unusual, congressional action to single out a particular technology is not completely without precedent. For example, since 1996, physicians, hospitals, and other health care providers have been immunized from infringement liability for using patented medical procedures. 35 U.S.C. $\$ 287$ (c) (2000). Also in 1996, Congress relaxed the standard for nonobviousness of biotechnology processes such that, if either the starting material or the product of the process is novel, the process is presumed to have been nonobvious in light of the prior art. $I d . \S 103(\mathrm{~b})$. In the mid-1980's, Congress created sui generis protection for semiconductor mask works including concepts from both copyright and patent law. It was obsolete upon or shortly after taking effect because it had become impractical for copyists to use the proscribed methods. Semiconductor Chip Protection Act of 1984, 17 U.S.C. $§ 901$ (2000); see also Steven P. Kasch, The Semiconductor Chip Protection Act: Past, Present, and Future, 7 HIGH TECH. L.J. 71 (1992); John G. Rauch, The Realities of Our Times: The Semiconductor Chip Protection Act of 1984 and the Evolution of the Semiconductor Industry, 75 J. PAT. \& TRADEMARK OFF. SOC'Y 93 (1993); Pamela Samuelson, Intellectual Property and Contract Law for the Information Age: Foreword to a Symposium, 87 CALIF. L. REV. 1, 16 n.16 (1999). Congress has also provided for limited extensions of the patent term for pharmaceuticals to allow drug companies to recoup some of the time lost during the lengthy process of securing marketing approval from the Food and Drug Administration. 35 U.S.C. $\S 156$.

20. Business Method Patent Improvement Act of 2000, H.R. 5364, 106th Cong. (2000). 
opposition proceedings. ${ }^{21}$ Early in the 2001 session, Berman and Boucher introduced H.R. 1332, which was very similar to the previous year's bill. ${ }^{22}$ One day after the introduction of the second bill targeting business method patents for heightened PTO scrutiny, Congress conducted oversight hearings on business method patents that focused on whether such legislation was needed. ${ }^{23}$

In March of 2000, the PTO-perhaps moved by the public outcry, the dread of legislation that might be difficult to implement, or the crush of the increasingly large number of business method patent applicationsundertook new procedures for examining business method patents. The PTO initiative sought to hire more examiners with qualifications suited for examining business method patent applications, provide more training for such examiners, require examiners to search specifically identified prior art sources for particular subclasses of business method patents, subject business method patents having 705 as their main classification to a second-level review after allowance, and, once issued, select a sample of these patents for review by the Office of Patent Quality Review that is larger than the samples selected for periodic quality review in other technical areas. ${ }^{24}$ The initiative represented a rare commitment of resources by the PTO to a single subset of the patenting enterprise. ${ }^{25}$

21. Post-grant opposition provisions exist for all patents in many countries other than the United States. Such proceedings probably make much more sense in these other nations, because their courts, unlike ours, cannot rule on the validity of an issued patent. See John R. Thomas, Collusion and Collective Action in the Patent System: A Proposal for Patent Bounties, 2001 U. ILL. L. REV. 305, 326-42 (2001) [hereinafter Thomas, Collusion and Collective Action] (critiquing proposed reforms of patent system, especially relating to business method patents, and rejecting European-style post-grant oppositions in favor of a system of bounties to third parties who submit relevant prior art to the PTO).

22. Business Method Patent Improvement Act of 2001, H.R.1332, 107th Cong. (2001). No such legislation was introduced in 2002.

23. Business Method Patents: Hearings on H.R. 1332 Before the House Comm. on the Judiciary, Subcomm. on Courts, the Internet, \& Intell. Prop., 107th Cong. (2001) [hereinafter Hearings on H.R. 1332], available at http://commdocs.house.gov/ committees/judiciary/hju72299.000/hju72299_0f.htm (April 4, 2001) (last visited Nov. 19, 2003).

24. U.S. PAT. \& TRADEMARK OfF. [hereinafter USPTO], A USPTO White PAPER: automated financial or Management Data Processing Methods (Business METHODS) 8-22 [hereinafter BUSINESS METHODS WHITE PAPER], available at http:// www.uspto.gov/web/menu/busmethp/whitepaper.pdf. (last visited Nov. 9, 2003). The action plan, discussed in detail at these sites, is summarized at http://www.uspto.gov/ web/offices/com/sol/actionplan.html. USPTO, Business Methods Patent Initiative: An Action Plan, http://www.uspto.gov/web/offices/com/sol/actionplan.html (last visited Nov. $9,2003)$. The sets of specifically identified prior art sources for particular subclasses of business method patents that examiners are now required to search are necessarily very 
Patent quality is an elusive concept, but it essentially consists of the likelihood that a patented invention meets the requirements of novelty and nonobviousness, and thus will be found valid if challenged in litigation. Although most of the complaints about Internet business method patents have been couched in terms of perceived low quality, we believe that it is also important to examine indicators of value. ${ }^{26}$

Knowing more about patent value is important for several reasons. Given the limitations of any inferences one might draw from the evidence on patent quality, additional information about patent value may buttress those inferences about quality because patent owners (patentees) are more likely to care about quality when they perceive high value. Patentees' perceptions about value should be relatively accurate. Patentees should have more relevant information about their patents' value than anyone else and, on the average, can be expected to act rationally to increase patent quality when they perceive that value is high. ${ }^{27}$ Patent value is also important independent of the effect it may have on quality. For example, perceptions of patent value affect license negotiations, the decision to

incomplete, but do represent a good faith effort by the PTO to meet criticisms aimed at perceived deficiencies in the amount of nonpatent prior art cited in business method patents. See USPTO, Non-PATENT LiteratuRE DATABASES FiguRES FOR WhITE PAPER ON BUSINESS METHODS PATENTS, available at http://www.uspto.gov/web/menu/busmethp/ figurenpl.htm (last visited Nov. 9, 2003). For a general summary of post-State Street developments, see Peter R. Lando, Business Method Patents: Update Post State Street, 9 TEX. INTELL. PROP. L.J. 403 (2001).

25. The PTO has previously made special efforts to clarify patenting standards in specific technology areas. It has, for example, issued guidelines for examiners of software patents. USPTO, Examination Guidelines for Computer-Related Inventions: Training Materials Directed to Business, Artificial Intelligence, and Mathematical Processing Applications, http://www.uspto.gov/web/offices/pac/compexam/examcomp.htm (last visited Nov. 9, 2003). It has also issued examination guidelines on the utility requirement for biotechnology patents. Utility Examination Guidelines, 66 Fed. Reg. 1092 (USPTO Jan. 5, 2001), available at http://www.uspto.gov/web/offices/com/sol/notices/utilexmgu ide.pdf (last visited Nov. 9, 2003). Guidelines such as these are intended to serve an explanatory purpose for examiners and applicants. The PTO measures targeting business method patents for additional scrutiny seek to codify disparate treatment rather than to merely clarify an existing patentability requirement in a technology area.

26. We speak only of private value and not of social value. The former is the value of patents to their owners and the latter is the value of patents to society. The two are obviously correlated because the characteristics of invention novelty and nonobviousness that contribute so much to private patent value are the sine qua non of innovations that benefit the public in the long run.

27. We know that not everyone will behave this way. There may be a few patent applicants who knowingly seek and receive low quality patents with the idea of using them in an extortionate way, but we believe that our assumption holds true for most patent applicants in most circumstances. 
settle or litigate an infringement claim, and the assessment of whether private or public resources expended in the patenting enterprise are being properly allocated.

Furthermore, because patent quality and value are interwoven in inextricable ways, one seeking a definition of patent value would in most cases be wise to start with patent quality. On average, value can probably be characterized as quality plus other factors. We recognize that situations exist in which a patent may be valuable to its owner despite its low quality. For example, it is possible for a single patent to have little, if any, value on its own, and even be of highly questionable validity, but to form part of a patent portfolio with a value far greater than the sum of its parts. Portfolio value can manifest itself in licensing negotiations, especially cross-licensing, or merely in the greater in terrorem effects it creates for competitors. ${ }^{28}$

Many other variables can affect the degree to which a patent has worth to its owner. Ascertaining those factors, much less measuring them, is challenging. For instance, if other things are equal, a patent that helps launch a new technology should be more valuable than one that adds to an already mature technology. There is neither a generally accepted definition $^{29}$ nor a unified theory of patent value. Instead, researchers have

28. One of several manifestations of portfolio value is in a "patent thicket," what Carl Shapiro has called "a dense web of overlapping intellectual property rights that a company must hack its way through in order to actually commercialize new technology." Carl S. Shapiro, Navigating the Patent Thicket: Cross Licenses, Patent Pools, and Standard-Setting, in 1 INNOVATION POLICY AND THE ECONOMY 1-2 (Adam Jaffe et al. eds., 2001), available at http://faculty.haas.berkeley.edu/shapiro/thicket.pdf. (last visited Nov. $19,2003)$. In other words, many closely related patents may cover a single product, making it much more difficult for competitors to invent noninfringing substitutes. Patent thickets increase the probability of "hold-up" licensing, that is, exercising the ability to charge a premium for patent licenses in the case of technologies in which competitors have already invested heavily. Id. A patent thicket is just one instance of portfolio value, because a group of patents on related technologies can have a value greater than the sum of its parts even if the patents do not create overlapping rights in the same product. Regardless of the particular manifestation of portfolio value, previous research has not captured this aspect of patent value, and we have not ascertained a way to estimate the effect of a patent's contribution to a portfolio apart from whatever stand-alone value it may or may not have.

29. In the course of showing how the number of times a patent is cited as a reference in later patents may be an indicator of patent value or importance, Manuel Trajtenberg stated: "By value I mean the social benefits generated by the innovation in the form of the additional consumer surplus and the profits stemming from the innovation." Manuel Trajtenberg, A Penny for Your Quotes: Patent Citations and the Value of Innovations, 21 RAND J. ECON. 172, 173 n.1 (1990). Here, Trajtenberg seems to refer to both private value and social value in the same sentence. 
simply proposed and tested value indicators. ${ }^{30}$ We can only do the same by seeking to measure several indicators suggesting patent quality and value.

We propose and test five value indicators in comparing Internet business method patents with other types of patents: the number of prior art references, type of prior art references, number of claims within the patents, number of inventors, and time spent in the PTO before issuance. We examine the number and type of prior art references in both patent data sets for two reasons. First, the number and type of prior art references appear to relate directly to patent quality (and thus value). ${ }^{31}$ Second, the alleged failure of business method patents to properly cite prior art served as a centerpiece for much of the criticism of business method patents. In addition to analyzing the number and type of prior art references, we also examine the total number of claims within these patents, because number of claims is another variable that may relate to patent value. ${ }^{32}$ On average,

Economists sometimes even use the term patent "quality" as being synonymous with the private value of patents to their owners, without providing useful definitions of either quality or value. See, e.g., JEAN O. LANJOUW \& MARK SCHANKERMAN, THE QUALITY OF IDEAS: MEASURING INNOVATION WITH MULTIPLE INDICATORS 1 (Nat'l Bureau of Econ. Research, Working Paper No. 7345, 1999) [hereinafter LANJOUW \& SCHANKERMAN, QUALITY OF IDEAS]; Mark Schankerman \& Ariel Pakes, Estimates of the Value of Patent Rights in European Countries During the Post-1950 Period, 96 ECON. J. 1052, 1052 (1986).

30. Josh Lerner has, for example, used the valuation of patent-dependent biotechnology start-ups by venture capital firms during multiple rounds of financing as such an indicator. Joshua Lerner, The Importance of Patent Scope: An Empirical Analysis, 25 RAND J. ECON. 319 (1994) [hereinafter Lerner, The Importance of Patent Scope]. For further discussion of patent value indicators, see John R. Allison et al., Valuable Patents, 89 GEO. L.J. (forthcoming Jan. 2004) [hereinafter Allison et al., Valuable Patents], available at http://papers.ssrn.com/sol3/delivery.cfm/SSRN_ID426020_code030722630.pdf? abstractid $=426020$.

31. Patent lawyers speak of prior art references, whereas economists typically speak of "backward citations" to refer to the same thing. The amount and type of prior art in a patent is associated with the extent of the applicant's effort to differentiate its invention from what has gone before. Thorough prior art searches also are costly. Moreover, previous research has shown that prior art found by the accused infringer that was not cited in the patent and, thus, not considered by the PTO in its examination prior to issuance, is one of the most common reasons for judicial declarations of patent invalidity. See John R. Allison \& Mark A. Lemley, Empirical Evidence on the Validity of Litigated Patents, 26 AM. INTELL. Prop. ASS'N Q.J. 185, 231-34, 251 (1998) [hereinafter Allison \& Lemley, Validity of Litigated Patents] (examining litigated patents leading to final written decisions on validity or invalidity during 1989-96). The amount and type of prior art should thus be associated with patent quality and value.

32. Section 112 of the Patent Act requires that a patent application have a thorough and concise description of the invention coupled with drawings (engineering and/or con- 
patents that become the subject of infringement litigation appear to be more valuable than those that do not, ${ }^{33}$ and prior research shows that litigated patents have more claims than unlitigated ones. ${ }^{34}$ There also are strong intuitive reasons to believe that the average number of claims in a group of patents is associated with patent value. Finally, we examine two other variables that may impart information about patent value: the number of inventors, and the amount of time that applications spend in the PTO before issuance as patents. Although previous research has not tested the possible relationship between the number of inventors and patent value, we believe that there is sufficient reason to suspect an association at least warrant investigation. ${ }^{35}$ The amount of time an application spends in

ceptual). The description and drawings must be "enabling," that is, they must reveal information about the invention that is sufficient to enable a hypothetical ordinarily skilled practitioner in the art to make the invention without undue experimentation. 35 U.S.C. $\S 112(2000)$. Following the description, the application must contain "claims" that precisely delineate the intangible property interest being sought by the applicant. $I d$. The claims define the invention. When a patentee sues for patent infringement, it actually sues for infringement of one or more of the claims within the patent. The total number of claims is thus likely to be correlated to the likelihood of proving infringement.

33. Patent infringement litigation is frightfully expensive, and one would generally expect patent owners to resort to it only when the stakes are relatively high. The American Intellectual Property Law Association recently estimated the median expense of patent infringement litigation for cases with between \$1 million and \$25 million at stake as $\$ 1.001$ million through pretrial discovery and \$2 million through trial and appeal. AM. INTELl. PROP. LAW ASS'N (AIPLA), 2003 REPORT OF THE ECONOMIC SURVEY 21-22 (2003) [hereinafter AIPLA, 2003 ECONOMIC SURVEY]. Factors other than the size of the stakes also affect the propensity to litigate patents, however. See, e.g., JEAN O. LANJOUW \& MARK SCHANKERMAN, ENFORCING INTELLECTUAL PROPERTY RIGHTS (Nat'l Bureau of Econ. Research, Working Paper No. 8656, 2001) [hereinafter LANJOUW \& SCHANKERMAN, ENFORCING INTELlECTUAL PROPERTY RIGHTS] (finding several variables to be correlated with the fact of patent litigation, and finding that the fact of litigation, but not the outcome, is significantly correlated with patent value); Jean O. Lanjouw \& Josh Lerner, The Enforcement of Intellectual Property Rights: A Survey of the Empirical Literature, 49/50 ANNALES D’ECONOMIE ET DE STATISTIQUE 223-46 (1998) [hereinafter Lanjouw \& Lerner, Literature Survey on I.P. Rights Enforcement] (surveying empirical studies in economics on intellectual property litigation, including the relationship between patent litigation and patent value).

34. See, e.g., Jean O. Lanjouw \& Mark Schankerman, Characteristics of Patent Litigation: A Window on Competition, 32 RAND J. ECON. 129 (2001) [hereinafter Lanjouw \& Schankerman, Characteristics of Patent Litigation]. Another far more comprehensive study of litigated and unlitigated patents by one of the authors, John Allison, along with Mark Lemley, Kimberly Moorc, and Derek Trunkey, finds that litigated patents have significantly more claims than unlitigated ones. See generally Allison et al., Valuable Patents, supra note 30.

35. The number of inventors may be an indicator of resources committed to the inventive endeavor, complexity of the technology, and costs associated with patenting, thus 
the PTO before issuance is often referred to as "pendency time" or "timein-prosecution." Another previously untested variable, average pendency time is likely to reveal several types of information, including some that may relate to patent quality and perhaps value. Although the time a patent application spends in the PTO prior to issuance affects the term of patent protection, we believe that average pendency times are far more important because they reveal information about the seriousness of the applicant and the thoroughness of the PTO's examination. ${ }^{36}$

Others have proposed several additional indicators of patent value that we do not measure. For example, some have suggested that the number of International Patent Classifications ("IPCs") into which the PTO places a patent correlates with its value. ${ }^{37}$ The argument is that because each IPC defines a technology area, the more IPCs a patent is assigned to, the more technology areas it touches upon and the larger the number of potential infringers. If the average number of IPCs is a useful measure of patent scope, one might expect it to be correlated with private patent value and litigation propensity. The relevance of this variable as a measure of patent value is highly questionable, however, and we were, in any event, unable to employ it. ${ }^{38}$ Others have also found that the number of different nations

suggesting a perception by the patent applicant that the invention has substantial value, such perception often affecting the reality. See infra Part V.D.

36. Prior to June 8, 1995, the term of patent protection was seventeen years from the date of issue. For applications originally filed after that date, the term of a patent issued from such application is twenty years from the original filing date. For patent applications pending on June 8,1995 , or for patents currently in force on that date, the patentee was given a choice of the two patent terms. 35 U.S.C. $\S \S 154(a)(2)$, (c). When a patent's term is calculated from the original filing date, pendency time obviously affects the length of the term.

37. See Lerner, The Importance of Patent Scope, supra note 30, at 320-21. Professor Lerner found a positive association between the values assigned to patent-dependent biotechnology start-ups by venture capital firms in multiple rounds of financing and the average number of four-digit IPCs into which the biotechnology firms' patents had been placed by the PTO. Lerner thus suggested an association between the number of fourdigit IPCs and patent value. The PTO assigns patents to both its own classifications and to IPCs, and Lerner offers explanations for why he believes the IPC system is superior to the PTO's own system for this purpose. Id.

38. See Jean O. Lanjouw \& Mark Schankerman, Stylized Facts of Patent LITIGATION: VALUE, SCOPE AND OWNERSHIP (Nat'l Bureau of Econ. Research, Working Paper No. 6297, 1997) [hereinafter LANJOUW \& SCHANKERMAN, STYLIZED FACTS OF PATENT LitigATION] (finding that the average number of IPCs is not correlated with propensity to litigate); Dominique Guellec \& Bruno Van Pottelsberghe de la Potterie, Applications, Grants, and the Value of Patent, 69 ECON. LETTERS 109 (2000), available at http://www.ulb.ac.be/cours/solvay/vanpottelsberghe/resources/Pap_Econ_letters_1.pdf (last visited Nov. 9, 2003); Dominique Guellec \& Bruno Van Pottelsberghe de la Potterie, 
in which patent protection has been obtained for the same invention is associated with value. ${ }^{39}$ Because of the large expense required to obtain patent protection in multiple countries, an association with patent value is to be expected, but we were not able to make use of the statistic because the business method patent phenomenon is purely an American one.

We used two data sets in our research. The first was a set of 1,000 randomly selected patents of all kinds that were issued between mid-1996 and mid-1998. These data were developed by John Allison and Mark

The Value of Patents and Patenting Strategies: Countries and Technology Areas Patterns, 11 ECON. INNOVATION \& NEW TECH. 133 (2002) (reasonably assuming that issued patents in Europe reflect more valuable inventions than published patent applications that were then either abandoned or finally rejected, finding that issued patents actually were characterized by a smaller average number of four-digit IPCs than abandoned or rejected applications). Although Professor Lerner was undoubtedly correct in finding the association he did, we believe it to have been idiosyncratic to his set of data and not generalizable. Allison et al., Valuable Patents, supra note 30 (manuscript at $12 \mathrm{n} .36$ ) (finding that the number of IPCs is not a significant predictor of litigation, and is actually negatively correlated with litigation propensity).

The average number of technology areas per patent probably is an indicator of patent value, but IPCs simply do not do a good job of identifying technology areas at a conceptual level for the same reasons PTO classifications do not do a good job of identifying technology areas at a conceptual level. Each classification system is designed to aid in prior art searching and thus operates at a functional rather than conceptual level, and at a very low level of abstraction. Using the same fourteen subjectively identified technology areas that we employ in this Article when we compare Internet business method patents to other patents, another study has found that the average number of technology areas per patent is highly related to the propensity to litigate, litigated patents clearly being more valuable on average than unlitigated ones. Allison et al., Valuable Patents, supra note 30 . It was found in that study that litigated patents averaged 1.99 technology areas per patent, and unlitigated patents 1.59 , a difference that is statistically significant far beyond $99 \%(\mathrm{p}<0.0001)$.

Even if the average number of IPCs were a value indicator, in our study it is not meaningful to compare the number of IPCs into which Internet business method patents have been placed with the average patent in all technology areas because business method patents all lie in a very narrow technical field whereas the "average" patent often will involve multiple areas of technology. It likewise is not useful to use this indicator for comparing Internet business method patents with patents in each of our defined technology areas because the former also are innately narrower than any of the latter.

39. See, e.g., LANJOUW \& SCHANKERMAN, QUALITY OF IDEAS, supra note 29, at 12. Economists have referred to the existence of protection in multiple nations as a "patent family." Patent Information Users Group, Inc., Patent Families, http://www.piug/org/ patfam.html (last visited Dec. 10, 2003). What they measure, however, is geographic scope, and the term "patent family" probably would be better used to describe multiple patents on closely related inventions rather than patents in multiple countries on the same invention. 
Lemley for use in two previous studies, ${ }^{40}$ although more data were added for the instant study. The second data set of Internet business method patents was developed especially for this study and mirrors the data categories from the set of general patents. The data set of business method patents consists of those that were clearly aimed at use with the Internet. ${ }^{41}$ The characteristics of these two data sets, as well as our data mining techniques, are more fully described below.

Using bivariate and multivariate statistical methods, ${ }^{42}$ we obtained statistically significant findings that both defied conventional wisdom and surprised us. Our findings are listed below:

40. John R. Allison \& Mark A. Lemley, The Growing Complexity of the United States Patent System, 82 B.U. L. REV. 77 (2002) [hereinafter Allison \& Lemley, Growing Complexity] (comparing many variables in a randomly selected set of one thousand patents issued during a two-year period in 1996-98 with counterpart variables in an identical sample drawn from patents issued during a two-year period twenty years earlier, revealing that the patenting enterprise had grown more complex over twenty years in all dimensions); John R. Allison \& Mark A. Lemley, Who's Patenting What? An Empirical Exploration of Patent Prosecution, 53 VAND. L. REV. 2099 (2000) [hereinafter Allison \& Lemley, Who's Patenting What?] (exploring empirically, among many other things, the types of entities receiving patents, the geographic origin of patents, and technology areas in which patents are granted).

41. Although not all business method patents are so targeted, we chose to collect those that are Internet-related because (1) the great bulk of patents one may characterize as covering business methods are Internet-related; (2) the business method patents receiving the most attention and criticism in recent years are Internet-related; and (3) any relevant policy concerns about the quality of business method patents are allegedly most acute in the case of those aimed at Internet usage because of their potential for unduly propertizing and thus creating stenoses in the Internet. See LAWRENCE LESSIG, THE FUTURE OF IDEAS: THE FATE OF THE COMMONS IN A CONNECTED WORLD 204-17, 316-24 (2001) [hereinafter LESSIG, FUTURE OF IDEAS] (arguing that the granting of patents on Internet-related software threatens to fence off large areas of the Internet); see also JAMES BOYle, Shamans, SPleENS, AND SofTWARE (1996) (offering a wide-ranging objection to the growing propertization of information).

42. Bivariate methods, such as the independent groups $t$-test or $z$-test for comparing means from two samples, seek to ascertain whether differences in a variable in two data sets are statistically significant. See, e.g, WILLIAM E. BECKER, STATISTICS FOR BUSINESS \& ECONOMICS 400-46 (1995). Multivariate methods are used to simultaneously analyze data on several variables. See, e.g., AMIR D. ACZEL, COMPLETE Business STATISTICS 895-963 (1989). Thus, when we compare several variables in one sample or population with counterpart variables in another sample or population, we use bivariate methods to determine whether there are statistically significant differences between a given variable in one set and its counterpart variable in the other set. When we speak of a statistically significant difference, we use the standard " $95 \%$ confidence" level; in other words, a difference is viewed as statistically significant if we are at least $95 \%$ confident that the difference is not due to chance. Stated somewhat differently, we report statistical significance when the $p$-value is 0.05 or less. In all instances in which we report statistical sig- 
- First, with respect to prior art, Internet business method patents had significantly more patent references, nonpatent references, and total references than patents in general. They also had significantly more of all types of references than patents in most of the fourteen individual technology areas within the general patent data set that we identified. ${ }^{43}$

- Second, although it was impossible to directly measure the relevance or informational value of prior art references, we developed a taxonomy of nonpatent prior art that allowed us to make rough comparisons of the likely quality of these nonpatent references in the two data sets. Internet business method patents appear to have cited nonpatent prior art of a similar quality to that in the average patent. ${ }^{44}$

- Third, Internet business method patents had significantly more claims than patents in general, and significantly more than in all but one individual technology area. ${ }^{45}$

- Fourth, Internet business method patents had significantly more inventors than patents in general, although this finding is weaker than the findings pertaining to references and claims.

- Fifth, applications for Internet business method patents spent much more time in the PTO's examination process than we expected. ${ }^{46}$ There is thus no evidence that Internet business method patent

nificance, the $p$-value is actually far below 0.05 . Multivariate methods then provided general confirmation of the bivariate results by revealing that significant differences between variables in the two data sets were not rendered insignificant by interactions among variables within each data set.

43. We emphasize that the Internet business method patents in our data set were all issued before the PTO initiated its program of greater scrutiny for certain business method patent applications.

44. Only chemistry, semiconductor, and pharmaceutical patents out of our fourteen technology areas appear to have cited higher quality prior art than Internet business method patents, and only pharmaceutical patents cited prior art that is better when taking into account both quantity and quality.

45. Internet business method patents actually had substantially more claims than patents in this technology area, acoustics, but the fact that this area included a relatively small number of patents and that acoustics patents did have more claims than the other technology areas caused the difference to be statistically insignificant.

46. For several reasons, we anticipated that other kinds of patents would have had much longer pendency times than Internet business method patents, especially when measuring from the original priority filing date. These reasons are explained infra in Part V.E 
applications received less examination than other patents, or that their owners committed fewer resources to obtain them. ${ }^{47}$

Overall, our data demonstrate that Internet business method patents were no worse than patents in general in the late 1990s. Indeed, our empirical evidence suggests that they may have been better than average. ${ }^{48}$

Why, then, have these patents been so widely disparaged and singled out for disparate treatment? Stated differently, why is there a wide gap between the conventional wisdom and the apparent reality shown by hard data? There are several possible explanations.

One possibility is that all of the alleged deficiencies in Internet business method patents resulted from the patent system trying to cope with a new subject matter that had been recognized only recently as patentable. Although superficially appealing, such an argument quickly collapses upon further consideration. We studied Internet business method patents when they were still new-patents issued through the end of 1999 - and found that they compared favorably with patents generally.

One might also argue that the approach used by the PTO and the courts for addressing the requirement of "nonobviousness" provides an explanation. ${ }^{49}$ The mere fact that an invention appears trivial after a quick look does not mean that it is obvious for patentability purposes. ${ }^{50}$ The PTO or a challenger in litigation must produce prior art showing that the invention represents only an obvious advance over the prior art. This legal attitude toward the nonobviousness requirement may explain why we find patents in all areas that appear questionable, but it does not support an

47. The average patent did spend slightly more time in the PTO than did Internet business method patents, but the significance of the difference disappeared when we accounted for the influence that the number of references and claims have on pendency time. Moreover, patents in only four of the fourteen technology areas had longer pendency times. When we removed the effect of multiple applications in a chain and considered only those applications leading most directly to the patents in question, Internet business method patents surprisingly spent a lot more time in the PTO than the average patent and than those in most technology areas. These differences remained statistically significant even after taking account of the effect that the number of references and claims each have on pendency times.

48. If there are serious problems with the quality of issued U.S. patents, they appear to be systemic rather than specific to a certain technology. We realize that this statement has negative implications for the patent system as a whole, but examining the entire system or the work quality of the PTO is a task left for others.

49. 35 U.S.C. $\S 103(2000)$.

50. See, e.g., Panduit Corp. v. Dennison Mfg. Co., 774 F.2d 1082, 1093-96 (Fed. Cir. 1985), vacated by 475 U.S. 809, 810 (1986), remanded to 810 F.2d 1561 (Fed. Cir. 1987). 
inference that patents in one area are inferior to those in other areas. Many have contended that more patents were issued on obvious Internet business methods than in other areas because many of these methods had been previously practiced but kept secret so that little accessible prior art was created. Not only was this intuitively attractive argument not borne out by the data, but it is far from clear that prior secret innovations are substantially more common in the area of business methods than in other areas. $^{51}$

The possibility also exists that our analysis of prior art cited in patents overemphasizes quantitative measures and fails to adequately account for variations in the relevance and content quality of those references. We will show, however, that the quantitative measures we use say a great deal about patent quality and value. We also attempt a reasonable assessment of the caliber of the prior art cited in the patents we study. A complete qualitative study of the cited prior art takes money and time, and would require the employment of experts in every technology area and sub-area.

A final possibility, which we believe to be the most likely, is that negative opinions about business method patents and consequent actions to further spread this impression are the subject of a classic information cascade. Such phenomena are pervasive in all parts of society and can be found in various fads and fashions, in riots and mobs, and in the herd behavior of stock market investors. ${ }^{52}$

51. Despite rapidly increasing rates of patenting in practically all industries, most research and development executives view trade secrets and other means as superior to patents in appropriating returns on R\&D investment. See WESLEY M. COHEN ET AL., Protecting THEIR INTElleCtUAL ASSETS: APPROPRIABILITY CONDITIONS AND WHY U.S. MANUfacturing FIRMS PATENT (OR NOT) 9-11 (Nat'l Bureau of Econ. Research, Working Paper No. 7552, 2000) [hereinafter COHEN ET AL., WHY U.S. MANUFACTURING FIRMS PATENT] (showing that the importance of patents as a means for appropriating returns from research and development investments varies among industries and that patents are among the least favorite means in almost all of them despite the fact that patenting activity has increased dramatically); Richard C. Levin et al., Appropriating the Returns from Industrial Research and Development, in 1987 BROOKINGS PAPERS ON ECON. ACTIVITY 783, 794-97 (1987) (showing, in a seminal study, that the importance of patents as a means for appropriating returns from $R \& D$ investments varies among industries, and that they are among the least favorite means in most of them).

52. They go by many other names, as well, such as "bandwagon effects," and occur when a critical mass of information is reached and leads to rapid acceptance of a norm or belief and similar action by large numbers of people. People's own actions can come to depend to an increasing degree on the information conveyed by the actions of others. The phenomenon can occur regardless of whether the information on which it is based is correct or incorrect. See, e.g., Sushil Bikhchandani et al., A Theory of Fads, Fashion, Custom, and Cultural Change as Informational Cascades, 100 J. POL. ECON. 992 (1992) 
In a closely related vein, the "confirmation" bias, which has been found by researchers in behavioral decision theory to be a pervasive psychological phenomenon, may have played a part in perpetuating the view that Internet business method patents were uniquely bad. ${ }^{53}$ Further supporting the idea that surface perceptions may have overwhelmed the public debate is the fact that Internet business methods probably require much less capital investment and start-up time to reach the marketplace than many other inventions. As a result, by the time a business method patent issues, the product may already be quite familiar to the public. Such early familiarity may contribute to widespread perceptions that the method is obvious.

Part II of this Article outlines the most frequently voiced criticisms of Internet business method patents and notes the unusual volume and intensity of these complaints, especially in the popular, business, and legal press. Part III outlines steps taken by Congress and the PTO in response to the widespread panning of business method patents. Part IV describes our data mining techniques and the two data sets we developed for comparison. Part V describes the patent attributes we measured, the results of our statistical analyses, and the import of these results. Part VI offers some possible reasons for the differences between our findings and the general consensus that business method patents were worse than other kinds, including the likelihood that excoriating them simply became a fad. Part VII offers some concluding observations. We conclude that actions to single out Internet business method patents for special treatment were not only unjustified, but also were probably futile and counterproductive.

[hereinafter Bikhchandani et al., Theory of Fads] (showing how information cascades can often be mistaken even though individuals are acting rationally, how a few early individuals can have a disproportionate effect on the development of a cascade, and how people's beliefs and actions can depend to an increasing degree on information learned from the decisions of others).

53. Decision-making "heuristics," or short cuts, may be the most efficient means for processing information in many circumstances, but forming beliefs and making decisions based on beliefs so derived can also create systematic decision-making biases. Regarding the "confirmation bias," once relatively firm beliefs or theories are formed, most people tend to pay more attention to and indeed seek out further information that confirms preexisting beliefs. Such an approach is not the logical way to test a belief (or a hypothesis in statistical testing) and is diametrically opposed to the scientific method. Sometimes this tendency is referred to as a logical fallacy that produces "belief perseverance." See, e.g., ROBIN M. HOGARTH, EDUCATING INTUITION 119-21 (2001) (discussing the confirmation bias). Once firm beliefs were formed that business method patents were either inferior or should never have been recognized as protectible, many may have clung to those beliefs and paid far more attention to subsequent evidence confirming them, even if further evidence consisted merely of the unsubstantiated opinions of others. 


\section{CRITICISMS OF BUSINESS METHOD PATENTS}

\section{A. The Diverse Nature of the Outcry}

Business method patents antedated their official 1998 recognition by the Federal Circuit. ${ }^{54}$ However, the sprinkle became a deluge after State Street. ${ }^{55}$ Along with the accelerated patenting of business methods came a great deal of attention in the popular, legal, and business press, as well as in academic circles. In general, these patents received poor reviews. The substance of the criticism has ranged from the plausible to the puzzling, and the rhetorical means from the cautiously alarmed to the polemical. Some observers simply viewed business processes as an inappropriate subject matter for patent protection. A notable theme in this strain of criticism was that allowing such patents opened the door for patenting new developments in all of human experience, and that patents should remain grounded in science and engineering, a theme expressed especially well by John R. Thomas:

Each issue of the Patent Office Gazette seems to include proprietary processes from an unlikely collection of disciplines. Although we once might have relegated these claims to some popular compilation of unusual patents, the Federal Circuit opinion in State Street has imbued them with newfound vitality. With the Patent Office open for patents on business methods, the frontiers of the patent system appear virtually without limit. The patent system now seems poised to impact callings ranging from the arts, to the social sciences, to the law itself.

There is much to commend the adoption of the standard of industrial application in the United States patent law. Our patent law should comport with our perception of what technology is, not defy it. Restoring a patentability standard firmly grounded in industrial applicability, rather than equating technology with anything artificial, would enable us to maintain the integrity of our current patent system. Moreover, it would enable us to respect the boundary between the whole expression of our

54. See Business METhod White PAPER, supra note 24 , at 8,$10 ;$ see, e.g., U.S. Patent No. 5,664,115 (issued Sept. 2, 1997) ("Interactive Computer System to Match Buyers and Sellers of Real Estate, Businesses and Other Property Using the Internet"); U.S. Patent No. 5,664,110 (issued Sept. 2, 1997) ("Remote Ordering System") (an Internet-based system for building and using order-lists for remotely ordering goods and services).

55. See, e.g., Julia Angwin, 'Business Method' Patents, Key to Priceline, Draw Growing Protest, WALL ST. J., Oct. 3, 2000, at B1; see generally Meurer, supra note 10; Rai, supra note 10, at 211; Maeir, supra note 10. 
humanity and that small part of it that is properly called technological. However central to contemporary life and worthy of nurturing through the patent system, technology is but one manifestation of the human experience. ${ }^{56}$

Others have made similar arguments. After an exhaustive search for a definition of "technology," Alan Durham concluded that even if the art of computer programming is within the definition and should be treated as patentable subject matter, a software-embodied business method is not and should not. ${ }^{57}$ Similarly, the well-known science writer James Gleick observed that business method patents (as well as software patents generally) had crossed a crucial boundary between "a substantial, tangible, nuts-and-bolts world ... into the realm of thought and abstraction." Rochelle Cooper Dreyfuss opined against the patentability of business methods for slightly different reasons. Dreyfuss argued that, contrary to the situation in many other fields, patents are unnecessary to create incentives to innovate in business methods, and thus there is no social benefit to offset the social cost of exclusive rights. ${ }^{59}$ Commentators have also expressed particular concerns about lock-in effects and network

56. Thomas, Liberal Professions, supra note 11 , at 1185.

57. Durham, supra note 11, at 1525-28; see also, Joseph H. Sommer, Against Cyberlaw, 15 BERKELEY TECH. L.J. 1145, 1220 (2000) (stating in passing that business methods have nothing to do with technology, and that the patent system is going beyond technological innovation to protect social innovation). For allusions to the nontechnological nature of business method patents, rather than arguments, see Julie E. Cohen \& Mark A. Lemley, Patent Scope and Innovation in the Software Industry, 89 CALIF. L. REV. 1, 27 n.99 (2001) [hereinafter Cohen \& Lemley, Patent Scope and Innovation] (claiming " $[\mathrm{t}]$ he floodgates for non-technological patents were opened by State Street ... which allowed the patenting of pure business methods. A number of patents had already issued for such non-technological concepts as methods of holding a golf putter, however.").

58. James Gleick, Patently Absurd, N.Y. TIMES, Mar. 12, 2000, § 6 (Magazine), at 44; see also Angwin, supra note 55, at B1 (quoting Tim O'Reilly stating that business method patents give exclusive rights to pure ideas).

59. Rochelle Cooper Dreyfuss, Are Business Method Patents Bad for Business?, 16 COMPUTER \& High TECH. L.J. 263, 274-77 (2000). For similar arguments, see, for example, Jared Earl Grusd, Internet Business Methods: What Role Does and Should Patent Law Play? 4 VA. J.L. \& TeCh. 9 (1999); Robert A. Kreiss, Patent Protection for Computer Programs and Mathematical Algorithms: The Constitutional Limitations on Patentable Subject Matter, 29 N.M. L. REV. 31, 84 n.358 (1999); Leo J. Raskind, The State Street Bank Decision: The Bad Business of Unlimited Patent Protection for Methods of Doing Business, 10 Fordham INTEll. Prop. Media \& ENT. L.J. 61, 90-93, 101-02 (1999). 
externalities stemming from Internet business method patents. ${ }^{60}$ Arti Rai has said that, because of the relatively short Internet business cycle, first-

60. A lock-in effect may exist if a product or service user faces substantial switching costs, that is, costs of changing from one product or service to another. This may deter switching to a competitor, or even deter entry by a potential competitor, even if the latter offers better quality or a lower price. It has been posited that a user may be reluctant to switch to another Internet merchant because of the tedium of entering one's credit card and other information again at a competitor's web site. See Dreyfuss, supra note 59, at 271; Thomas, Collusion and Collective Action, supra note 21 , at $305,320-21$. We fail to see much in the way of sunk costs in using an Internet merchant that would significantly dissuade a user from switching.

Network externalities exist as a positive effect on the incremental value of a network-such as a telephone system, real estate multiple listing service, or operating system software-as additional users participate in the network. Such networks become more valuable to each user as the number of users increases. Although network economic effects are generally positive, they can tend toward monopolistic results when the network's basic technical standards are closed, as by software copyright protection, patent protection, or other standards-closing mechanisms. See, e.g., Dreyfuss, supra note 59, at 271; Thomas, Collusion and Collective Action, supra note 21, at 305, 318-21. There is little question that a proprietary network gives greater control than a proprietary nonnetwork technology, because competing alternatives to proprietary technical standards are much less likely to develop when large positive externalities draw users into the network and ultimately make them highly dependent on it. One only has to consider Microsoft's operating systems, the code for which is vigorously protected by copyright. On network externalities more generally, see Mark A. Lemley \& David McGowan, Legal Implications of Network Economic Effects, 86 CALIF. L. REV. 479 (1998); Howard A. Shelanski \& J. Gregory Sidak, Antitrust Divestiture in Network Industries, 68 U. CHI. L. REV. 1 (2001).

Opponents of patenting software in general, or software-embodied business methods in particular, would argue that the Internet would not have developed as it did had its basic standards been patented. We first note that these standards were technical software communications protocols, and not business methods. It is true, however, that if software generally had not reached patentable status, neither would software-embodied business methods. We agree that the Internet would have developed differently if these early protocols had been someone's personal property, and probably would not possess the marvelous end-to-end architecture that makes it what it is. Had today's standards of software patentability existed during the years leading up to development of the Internet, however, the basic protocols would not necessarily have been patented. Mark Lemley observes that some of the Internet's original standards were developed by government, and some were collaborative ventures among many different educational institutions such that sorting out patent rights would have been very difficult if not impossible. E-mail from Mark A. Lemley, Professor of Law, University of California at Berkeley, Boalt Hall School of Law, to John R. Allison (July 1, 2003) (on file with author). He also notes that many standards in telecommunications today are open because standards-setting groups agree to keep them nonproprietary. Id. Patents could be a cost to the Internet, Lemley believes, but it is far from certain. $I d$. He also notes that many standards in telecommunications today are open because standards-setting groups agree to keep them nonproprietary. $I d$. 
mover advantages may cause more economic harm than such advantages cause in other markets. ${ }^{61}$ Robert Merges stated that, although it was too early to tell whether business method patents as a class are worthwhile, "the increased volume of patent applications stemming from this newly patentable subject matter has pushed the patent system into crisis,",62 and Professor Thomas argued that low quality business method patents were further damaging the public perception of the patent system. ${ }^{63}$ One Forbes Magazine writer assumed that business method patents are bad and circularly attributed their badness to a PTO overtaxed by the huge number of business method patent applications. ${ }^{64}$ Others asserted that business methods are bad without providing any rationale, ${ }^{65}$ and one even argued that granting business method patents is unconstitutional. ${ }^{66}$

Recently, Michael Meurer argued that patent flooding in the area of business methods has already occurred and will get worse. This particular flood will produce more serious economic harm than similar phenomena in other fields, such as biotechnology, because previous patent floods were triggered by technological breakthroughs not present in business methods. ${ }^{67}$ Even more recently, Richard Posner observed that business

61. Rai, supra note 10 , at 212 . The reasoning here, which is related to concerns about lock-in effects, is that the relatively short duration of Internet business cycles prevents the market from having enough time to correct the anticompetitive consequences of ill-considered business method patents even if they are later deemed to be invalid.

62. Robert P. Merges, One Hundred Years of Solicitude: Intellectual Property Law, 1900-2000, 88 CALIF. L. REV. 2187, 2232 (2000) [hereinafter Merges, One Hundred Years of Solicitude].

63. See Thomas, Collusion and Collective Action, supra note 21, at 322 ("Another worrisome trend is that public perception of the patent system is in a rapid tailspin. Citing proprietary rights in electronic commerce concepts such as the one-click patent, major newspapers and magazines have once more found the patent system a convenient target of scathing criticism.").

64. Philip E. Ross, Patently Absurd, FORBES, May 29, 2000, at 180.

65. See, e.g., Larry A. DiMatteo, The New "Problem" of Business Method Patents: The Convergence of National Patent Laws and International Internet Transactions, 28 RUTGERS COMPUTER \& TECH. L.J. 1, 22-25 (2002).

66. Malla Pollack, The Multiple Unconstitutionality of Business Method Patents: Common Sense, Congressional Consideration, and Constitutional History, 28 RUTGERS COMPUTER \& TECH. L.J. 61 (2002) (attacking business method patents as unconstitutional because (1) common sense shows that they do not promote progress, (2) Congress has not said that business method patents promote progress, (3) the term "useful arts" as used in the Constitution's intellectual property clause does not contemplate business method patents, and (4) the generation that ratified the Constitution would have considered business method patents to be "an abuse of the rights of Englishmen"). Although we believe these to be really strange arguments, dissecting or challenging these or other arguments is not our purpose despite any faulty fact or logic they may display.

67. See Meurer, supra note 10 , at 321 . 
method patents create the potential to obtain enormous monopoly power and generate a reward greatly in excess of the cost of the invention. ${ }^{68}$ Lawrence Lessig asserted that software development projects are being rendered more costly because of business method and other software patents, ${ }^{69}$ and that business method patents work to the disadvantage of small businesses by imposing additional legal expenses that they can ill afford. ${ }^{70}$ Both Lessig and James Boyle cited business method patents as one of the prime threats to the Internet and the public domain, ${ }^{71}$ and Lessig predicted that business method patents, along with expanded copyright protection, will devastate the Internet, turning it into a big businesscontrolled institution "that will disable once again the independent, unaffiliated, critical, questioning creativity that the Internet of the last ten years produced." ${ }^{72}$ Comparing those attempting to enforce them to Mafiosi, ${ }^{73}$ and calling for a moratorium on their issuance, ${ }^{74}$ Lessig also

68. Richard A. Posner, The Law \& Economics of Intellectual Property, DAEDALUS, Spring 2002, at 5 . Posner apparently was serious about the totally implausible assertion pertaining to monopoly power. See also Declan McCullagh, Left Gets Nod From Right on Copyright Law, CNET NEWS.COM, Nov. 20, 2002 (reporting on lecture by Posner to the American Enterprise Institute in which he criticized recent expansions of copyright law and attacked the granting of "very questionable" business method patents), available at http://news.com.com/2100-1023-966595.html.

69. Controlling the 'Net: How Vested Interests Are Enclosing the Cybercommons and Undermining Internet Freedom, MULTINATIONAL MONITOR, Mar. 1, 2002, at 23 (interview with Lawrence Lessig).

70. Daniel S. Levine, One on One with Lawrence Lessig, Author, San Fran. Bus. TIMES, Nov. 30, 2001, available at http://sanfrancisco.bizjournals.com/sanfrancisco/ stories/2001/12/03/newscolumn 10.html.

71. Lessig, FUTURE OF IDEAS, supra note 41; James Boyle, Fencing Off Ideas: Enclosure \& the Disappearance of the Public Domain, DAEDALuS, Mar. 22, 2002, at 13; see also Anjana Ahuja, Patently It Doesn't Work, London TIMES, Features, Mar. 22, 2000 (quoting Lawrence Lessig that business methods are a disaster and the biggest threat to innovation in cyberspace).

72. Lawrence Lessig, The Death of Cyberspace, 57 WASH. \& LEE L. REV. 337, 34547 (2000). Lessig has expressed the same sentiments elsewhere many times. See, e.g., Lawrence Lessig, Foreword, 52 STAN. L. REV. 987 (2000).

73. Lawrence Lessig et al., Criticism of the US Patent \& Trademark Office, Transcript: Weekend All Things Considered (National Public Radio, Apr. 20, 2002). Lessig has, however, also made the far more sensible statement that the major problem today is the federal government's role in over-protecting intellectual property generally. See Lawrence Lessig, The Problem With Patents, Industry Standard, Apr. 23, 1999, previously available at http://www.thestandard.com/article/display/0,1151,4296,00.html (printed copy on file with authors). From what we have discovered in our data, he is on less firm ground in the same opinion piece when he asserts that business method patents provide the clearest example of bad patents. Id.

74. Lawrence Lessig, Online Patents: Leave Them Pending, Wall St. J., Mar. 23, 2000, at A22. Lessig took swipes at business method patents at many other times and 
referred to business method patents as "new monster[s] called forth from an old statute." 75

\section{B. A Bit of Software Patent Déjà Vu}

Software patents as a genus had been targeted for patentable subject matter criticism several years before the business method species became news. Some of these jeremiads, such as the assertion that software is not technology ${ }^{76}$ and that patents were unnecessary to create productive incentives in the software industry, ${ }^{77}$ foreshadowed similar censures of business method patents. Pamela Samuelson stated that the most profound problem with using patent law to protect software is that innovation in the field is usually accomplished in increments too small to be viewed as inventive steps. ${ }^{78}$ On the whole, however, complaints about software as patentable subject matter were less one-sided, less varied, and less strident than later rebukes of business method patents. ${ }^{79}$

Detractors of software patents expressed similar wariness about the adequacy of prior art. The idea that software patents were insufficiently supported by prior art references was proffered early on by some members

places, as well, sometimes alongside criticisms of software patents generally. See, e.g., Jesse Walker, Cyberspace's Legal Visionary: Lawrence Lessig on the fate of copyrights and computer networks in the digital future, REASONONLINE, June 2002, available at http://reason.com/0206/fe.jw.cyberspaces.shtml (last visited Nov. 21, 2003).

75. Lawrence Lessig, Patent Problems, The Industry STANDARD, Jan. 21, 2000, available at http://www.lessig.org/content/standard/0,1902,8999,00.html (last visited Nov. 21, 2003).

76. See, e.g., Gleick, supra note 58 (observing that patents on both software generally and software-embodied business methods showed that patents were now being issued on thought and abstraction). But cf. Durham, supra note 11, at 1525-28 (stating that software programming is technology, but business methods are not).

77. See, e.g., Pamela Samuelson, Benson Revisited: The Case Against Patent Protection for Algorithms and Other Computer Program-Related Inventions, 39 EMORY L.J. $1025,1142-43$ (1990) (contending that the most powerful argument against software patentability was that "the industry has grown from being a nonexistent industry to a major, flourishing, and highly innovative industry without patent protection").

78. Pamela Samuelson et al., A Manifesto Concerning the Legal Protection of Computer Programs, 94 CoLUM. L. REV. 2308, 2344-46 (1994) [hereinafter Samuelson et al., Manifesto].

79. Although opinion on the wisdom of patenting software was mixed, opponents were clearly in the majority. See, e.g., Pamela Samuelson, Once Again, Patents, 35 COMMUN. OF THE ACM 15 (1992) (noting correctly that her negative view of software patents was in the ideological mainstream, and then arguing that software is sufficiently different from previous technologies, and that Congress should act after having heard from economists, computer professionals, and others with varied perspectives). For an early minority view that software should be patentable subject matter, see Donald S. Chisum, The Patentability of Algorithms, 47 U. PITT. L. REV. 959 (1986). 
of the industry and the technical academic community, ${ }^{80}$ and later by many others. Julie Cohen's observations in 1995 are illustrative:

[I]n the field of computers and computer programs, much that qualifies as prior art lies outside the areas in which the PTO has traditionally looked-previously issued patents and previous scholarly publications. Many new developments in computer programming are not documented in scholarly publications at all. Some are simply incorporated into products and placed on the market; others are discussed only in textbooks or user manuals that are not available to examiners on line. In an area that relies so heavily on published, "official" prior art, a rejection based on "common industry knowledge" that does not appear in the scholarly literature is unlikely. ${ }^{81}$

Contemporaneously with Professor Cohen, Kenneth Dam noted the prior art problem with software patents in the course of a theoretical economic analysis of intellectual property rights in software. ${ }^{82}$ Although numerous others have concurred, ${ }^{83}$ they never provided empirical support

80. Randall Davis, professor of computer science at the Massachusetts Institute of Technology, chaired a broadcast panel discussion of software patents on Oct. 30, 1990, at MIT in which both the inherent patentability of algorithms and prior art concerns were significant topics of discussion. Michael D. Ernst, Intellectual Property in Computing: (How) Should Software Be Protected? An Industry Perspective (May 1992), available at http://pag.lcs.mit.edu/ mernst/pubs/ (last visited Nov. 28, 2003). One of the panelists, Mitchell Kapor, founder of Lotus Development Corporation, which was at the time embroiled in software copyright litigation regarding its Lotus 1-2-3 spreadsheet software, observed: "The real problem is not in copyright; it's in patents ... . So what we've got is a kind of Bhopal of software patents. There are all of these terrible patents that should never have been issued because there's prior art." Id.

81. Cohen, Electronic Vigilantism, supra note 13, at 1178.

82. Kenneth W. Dam, Some Economic Considerations In The Intellectual Property Protection of Software, 24 J. LEGAL STUD. 321,369 (1995).

83. See, e.g., Thomas P. Burke, Software Patent Protection: Debugging the Current System, 69 NoTRE DAME L. Rev. 1115, 1164-65 (1994); Cohen \& Lemley, Patent Scope and Innovation, supra note 57, at 12; Lemley, Rational Ignorance, supra note 4, at 1495 96 \& nn.1-2 (2001); Mark A. Lemley \& David W. O'Brien, Encouraging Software Reuse, 49 STAN. L. REV. 255, 300-04 (1997); Peter S. Menell, The Challenges of Reforming Intellectual Property Protections for Computer Software, 94 COLUM. L. REV. 2644, 2653 (1994); Maureen A. O'Rourke, Toward a Doctrine of Fair Use in Patent Law, 100 COLUM. L. REV. 1177, 1240-41 (2000); Samuelson et al., Manifesto, supra note 78, at 2363 \& nn.221-24; Chad King, Note, Abort, Retry, Fail: Protection for Software-Related Inventions in the Wake of State Street Bank \& Trust Co. v. Signature Financial Group, Inc., 85 CORNELL L. REV. 1118, 1172 \& n.336 (2000); Garfinkel, supra note 13; Brian Kahin, The Software Patent Crisis, TECH. REV., Apr. 1990, at 52; Joseph Milizzo, Computer Industry Fears Patent Wave, COMP. \& SOFTWARE NEWS, May 22, 1989, at 4; Rachel Parker, Refac's Unworthy Patent May Rally the Rest of the Industry, INFOWORLD, 
for the assertion that software patents cite less prior art than other kinds of patents. $^{84}$

Critics have pointed to problems with the PTO classification system as adding to the prior art problems allegedly plaguing software patents. ${ }^{85}$ It is true that patents on software have been strewn among many PTO classifications. There appear to be two reasons. First, PTO classifications and subclassifications focus on detailed function, not conceptual definition. They focus at a very low level of abstraction on what inventions achieve rather than on how they achieve it, giving PTO classifiers no reason to conceptually identify an invention as covering software. ${ }^{86}$ Second, and relatedly, a great many inventions touch upon multiple technology areas. These difficulties with using PTO classifications clearly are not limited to software.

Aug. 7, 1989, at 42; Richard Stallman \& Simson Garfinkle, Against Software Patents; Software Should Be Copyrighted, Not Patented, COMM. OF THE ACM, Jan. 1992, at 17; Jeff Ubois, The Case Against Software Patents, MidRANGE SySTEMS, Jan. 7, 1992, at 44.

84. Only commentator Gregory Aharonian, a well-known critic of the PTO generally and software patents particularly, has amassed data on the issue. On his website and through his e-mail patent newsletter, one can see that for a number of years he has consistently excoriated software patents for the inadequacy of their prior art, especially nonpatent prior art. See Gregory Aharonian, Bad Patents Home Page, http://www.bustpatents. com (last visited Nov. 30, 2003). Instructions for subscribing to his newsletter are at http://www.bustpatents.com/ipns.htm (last visited Nov. 30, 2003). In February 2003, he began sending his newsletter from patnews@nsl.patenting-art.com. In 1998, he reported in his newsletter that software patents averaged fewer than five references to the prior art. 17,500 Software Patents to Issue in 1998, INTERNET PATENT NEWS SERVICE (Gregory Aharonian). Oct. 18, 1998, available at http://lpf.ai.mit.edu/Patents/ipns/ipns-19981018 .txt (printed copy on file with authors) (last visited Nov. 30, 2003); see also Robert P. Merges, As Many as Six Impossible Patents Before Breakfast: Property Rights for Business Concepts and Patent System Reform, 14 Berkeley Tech. L.J. 577, 589 \& n.31 (1999) [hereinafter Merges, Six Impossible Patents] (referring to this statistic from Aharonian's Oct. 18, 1999 newsletter). Ultimately, however, Aharonian's data appeared to combine disparate categories into larger ones, introducing data comparability problems too serious for reliable statistical analysis. Our present study does not examine software patents overall, so we cannot comment on this finding, but we certainly did not find similarly small numbers of prior art citations in Internet business method patents.

One study of the characteristics of patents in general that also included a category for software patents, found that software patents cited somewhat less patent prior art than the average patent, more nonpatent prior art, and about the same amount of total prior art when compared with the average patent and with patents in most other areas of technology. Allison \& Lemley, Who's Patenting What?, supra note 40, at 2131-32, 2149, 2158-60.

85. See, e.g., Garfinkel, supra note 13.

86. The International Patent Classifications ("IPCs") operate in the same manner, and, as a consequence, neither system works well as a means for identifying areas of technology. 


\section{Prior Art-Related Criticisms Migrating from Software to Business Method Patents}

Business method patents likewise have been repeatedly indicted for failing to cite sufficient prior art. These patents may have been more susceptible than software patents to prior art-based criticisms because of the belief, true or not, that much evidence of prior business practices is unlikely to have found its way into written sources. By and large, it is said, these things have just been "done," and if a company perceived that a particular business practice gave it a competitive advantage, it would have protected it as a trade secret. As with software patents, only a few writers have initially offered reasoned arguments along these lines, ${ }^{87}$ and many others have simply agreed. ${ }^{88}$ Charles Cella, a former patent attorney, Jeff

87. See Dreyfuss, supra note 59, at 268-69; Rebecca S. Eisenberg, Analyze This: $A$ Law and Economics Agenda for the Patent System, 53 VAND. L. REV. 2081, 2090 (2000); Merges, Six Impossible Patents, supra note 84, at 577, 589-90; Thomas, Collusion and Collective Action, supra note 21, at 318-19.

88. See, e.g., Kevin M. Baird, Business Method Patents: Chaos at the USPTO or Business as Usual?, 2001 U. ILL. J.L. TECH. \& POL'Y 347, 347-48, 354-56, 359-64 (2001) (repeating arguments about prior art inadequacies and offering several suggestions for improvement, including mandatory prior art searching by applicants); Sandra Szczerbicki, Comment, The Shakedown on State Street, 79 OR. L. REV. 253, 273-82 (2000) (stating, incorrectly, that many commentators believe that interest in business method patents will be short-lived, criticizing business method patents, and observing that prior art inadequacies are likely); Brett Dorny, Intellectual Piracy, CIO MAG., Feb. 15, 2001, available at http://www.cio.com/archive/021501/fine_content.html (repeating prior art criticism); Kris Frieswick, Are Business Method Patents a License to Steal?, CFO MAG., Sept. 1, 2001, available at http://www.cfo.com/printarticle/0,5317,4803|A,00.html (last visited Nov. 25, 2003) (repeating prior art criticism); David Ignatius, Firestorm in Cyberspace, WASH. PoST, Mar. 19, 2000, at B07 (reporting that Internet patent "rebels" at PC Forum conference had agreed to create a prior art database to prevent future issuance of business method patents that inadequately refer to prior art); Michael Mahoney, Patents: The Weapon of Choice for E-Biz Giants, E-COMMERCE TIMES, Apr. 6, 2001, available at http://www.ecommercetimes.com/perl/story/8757.html (repeating prior art criticism) (last visited Nov. 25, 2003); Seth Shulman, Software Patents Tangle the Web, TECH. REV., Mar./Apr. 2000, at 68 (observing prior art inadequacies in both software and business method patents); see also Raymond Van Dyke, E War-Episode One: The Patent Menace, 6 COMPUTER L. REV. \& TECH. J. 1, 6-7 (2001) (noting inadequacy of prior art, but opining that time should rectify the problem); Gleick, supra note $58, \S 6$, at 44 (noting serious prior art problems in the examination of business method patent applications, placing these patents side-by-side with patents on such inventions as a method for exercising a cat and a method for determining bra size by measuring the breasts).

We make this statement only as an observation and do not intend it to be judgmental. Of course, the relatively few individuals expressing sanguinity about business method patents have also relied on assumptions and impressionistic judgments rather 
Bezos, CEO of Amazon.com and co-inventor of the one-click patent, ${ }^{89}$ and Tim O'Reilly, a well-known Internet publisher, went so far as to found the now-defunct BountyQuest.com in 2001. BountyQuest.com allowed patent challengers to post patents for which someone was seeking invalidating prior art. By providing relevant prior art, BountyQuest.com users could receive a bounty. ${ }^{90}$ Although the venture subsequently posted patents in several technology fields, the publicity surrounding business method patents clearly provided the impetus for its creation. ${ }^{91}$

As with software patents, prior art-related criticisms of business method patents were almost exclusively based on impressionistic judgment without the benefit of empirical analysis. There have been references in the literature to numbers of software and business method patent applications and grants, but no systematic data collection and analysis. ${ }^{92}$

As of this writing, Josh Lerner is the only one to our knowledge who has done in-depth research on business method patents. He found 445 financial patents in five subclasses of classification 705 issued from the

than data. See Greg S. Fine, Note, To Issue or Not to Issue: Analysis of the Business Method Patent Controversy on the Internet, 42 B.C. L. REV. 1195, 1206-09 (2001) (relating the arguments of the few supporters of these patents who have spoken up).

89. Yes, the irony is palpable. Bezos applied for another Internet business method patent on March 1, 2001, the application for which was published on February 14, 2002. See U.S. Patent App. No. 20020019856, Ser. No. 797503 (published Feb. 14, 2002) ("Method and System for Information Exchange Between Users of Different Web Pages"). Earlier, however, Bezos had posted an open letter on Amazon.com stating that, although it was his duty to protect his company's intellectual property to the fullest extent possible, he believed that Internet business method patents should be singled out for different treatment than other patents, including a shorter term of protection. See Posting of Jeff Bezos, An Open Letter from Jeff Bezos on the Subject of Patents, originally posted to $\mathrm{http}: / / \mathrm{www} . a m a z o n . c o m$ on Mar. 9, 2000, available at http://www.oreilly.com/news/ amazon_patents.html (last visited Nov. 28, 2003); see also Bezos Calls for Patent Reform, ZDNET U.K. NEWS, Mar. 10, 2000 (providing further discussion regarding BountyQuest.com), available at http://news.zdnet.co.uk/story/0,,t269-s2077612,00.html (last visited Nov. 28, 2003).

90. See Every Patent is a Double-Edged Sword, Bus. WK. OnLINE, Mar. 5, 2001 (report compiled from e-mail correspondence between Business Week correspondent and Charles Cella), available at http://www.businessweek.com/bwdaily/dnflash/mar2001/ nf2001035_724.htm (last visited Nov. 25, 2003); Q\&A: Junk-Patent Perps, Beware of BountyQuest, BUS. WK., Apr. 30, 2001, at 30, available at http://www.businessweek. com/magazine/content/01_18/b3730038.htm.

91. See BountyQuest: Our Vision and Our History, at http://www.bountyquest. $\mathrm{com} / \mathrm{bqcorp} / \mathrm{bqcorp}$.htm. (The BountyQuest website is no longer available.).

92. As with software patents, Greg Aharonian has been the main exception. His effort has been laudable, but as previously noted, his data are not such as to allow for reliable statistical testing. 
early 1970s through February 2000, and analyzed the prior art in a sample of $100 .^{93}$ Among other findings, he determined that (a) patents had increasingly issued in fields of finance in which there is highly relevant academic finance literature, particularly in asset allocation, risk management, and valuation; ${ }^{94}$ (b) some of the work published by finance academics was suitable subject matter for patenting; ${ }^{95}$ (c) financial patents are characterized by a lower ratio of examiner-added prior art to applicantsubmitted prior art than is the case in other areas of patenting involving academic research; ${ }^{96}$ and (d) an apparent lack of sufficient examiner familiarity with academic research in finance has probably contributed to an overall inadequacy of citation to relevant academic research in financial patents. ${ }^{97}$

Although Professor Lerner's research is valuable and interesting, it does not address our concern as to the largest and most controversial segment of business method patents, those targeting Internet-related uses. His comparison of finance patents with patents in other technologies in which academic research is important, such as biotechnology, was quite appropriate because finance is the one clearly identifiable area in business that appears distinctly in issued patents and has been the subject of highly focused academic research for a substantial period of time. Patents on financial tools and techniques are also a special case among business method patents in that one is not likely to know how to find and understand the relevant research without a Ph.D. in finance or economics. A person with a doctorate in a field such as math or physics could

93. Josh Lemer, Where Does State Street Lead? A First Look at Finance Patents, 1971-2000, 57 J. FIN. 901, 904-05 (2002) [hereinafter Lerner, Where Does State Street Lead?].

94. Id. at 913-14.

95. See id. at 918 .

96. Id. at 927-28. To determine which references were cited by the applicant and which were added by the examiner, one must go through the "file wrapper," or prosecution history of each patent. This is, as Lerner admits, a very slow and laborious task, which is the reason why he limited his study to 100 of the 445 financial patents. Id. at 905. Such an undertaking was simply not feasible for our comparison of 1,093 Internet business method patents with 1,000 patents-in-general, and we primarily relied on circumstantial evidence to draw an inference that most prior art references are submitted by the applicant rather than being added by the examiner. However, in 2001, the PTO began identifying on the face of the patent which prior art references had been added by the examiner, and we are now able to cite statistics firmly supporting the non-empirical evidence. See infra at Part V.A.

97. Lerner, Where Does State Street Lead?, supra note 93, at 927-28. 
understand the math if she were taught how to find the relevant literature. $^{98}$

\section{RESPONSES BY CONGRESS AND THE PTO}

\section{A. Congressional Responses}

\section{The First Inventor Defense Act}

Faced with mounting complaints characterized by a "how-could-thePTO-do-such-a-thing?" tone, Congress and the PTO answered with measures targeting business method patents for special treatment. Congress passed the First Inventor Defense Act in 1999 to create a new defense to an accusation of patent infringement for a prior inventor of a business method that is later patented by another. ${ }^{99}$

Unlike patent systems in many other countries, there is no "prior user right" ("PUR") in U.S. patent law that protects a first inventor who has kept her invention secret ("prior secret user") from being sued for infringement by a second inventor who patents the same invention. If the first inventor makes a nonsecret use of the invention (for example, a public use, demonstration or disclosure), or if she sells the invention (whether secretly or not), she creates prior art that should prevent a second inventor from obtaining a patent in the first place or invalidate the patent if issued and later challenged by an accused infringer. On the other hand, a first inventor keeping the invention secret does not create prior art that prevents the second inventor from patenting, and remains vulnerable to an infringement suit by the patenting second inventor. ${ }^{100}$

98. Professor Lerner at Harvard Business School and the colleagues in finance whom we contacted at the University of Texas expressed their belief that a person having an MBA degree with a finance concentration could not adequately understand the academic finance literature.

99. First Inventor Defense Act of 1999, Pub. L. No. 106-113, 113 Stat. 1536 (codified as amended at 35 U.S.C. $\S 273(2000)$ ).

100. Despite the fact that state trade secret law and federal patent law may constitutionally coexist, the knowledge disclosure and dissemination policies underlying the latter disfavor the former. Kewanee Oil Co. v. Bicron Corp., 416 U.S. 470, 491 (1974). One example is illustrative. Suppose that $\mathrm{X}$ invents a novel and nonobvious machine or process, and keeps it secret. $X$ then uses the invention to make a product and markets the product commercially. Assuming that the product does not reveal the secret machine or process (which it is very unlikely to do), X's invention does not lose its status as a protectable trade secret. If $X$ decides to patent her invention, however, she must do so within one year after first marketing the product commercially, despite the fact that $\mathrm{X}$ never actually disclosed the invention itself. The patent law policy discouraging secrecy and favoring disclosure leads to the result that X's sale of a product made by her secret inven- 
In contrast, patent laws in many other nations have long provided for PURs that provide an infringement defense for a first secret user-the first inventor who creates no prior art and does not patent - in the event she is later sued by a second inventor who obtained a patent. ${ }^{101}$ PUR creates a personal defense that merely allows the prior inventor to continue practicing the invention within her business to the extent she had been doing so before the patent issued. Even though the U.S. patent regime has never included PUR, in 1999 Congress created such a defensive right for business methods out of the fear that a substantial number of business method patents might have reflected techniques previously developed and practiced in secrecy. ${ }^{102}$ However, Congress made no attempt to define the term "business method." Nor did Congress make any findings that business methods are practiced in secrecy to any greater extent than processes or techniques in other fields. ${ }^{103}$ To date, there has been no reported case in which the First Inventor Defense Act was at issue, and we thus have not yet had a chance to sympathize with the plight of a court seeking to ascertain what a business method actually is. ${ }^{104}$

tion is a "public use" of that invention. See Metallizing Eng'g, Co. v. Kenyon Bearing \& Auto Parts, Co., 153 F.2d 516, 518 (1946).

101. All nations except the United States employ a first-to-file system for determining which inventor has priority for patenting purposes. Thus, in other countries the presence of PURs can add some of the assumed fairness of a first-to-invent system to the greater efficiency of a first-to-file system. This does not mean, however, that PURs will not work under the U.S. first-to-file rule for determining priority between contemporaneous inventors seeking patents on the same invention. Indeed, if PURs are a good idea in general, they should work equally well in the United States for all types of inventions.

102. For more detail on the First Inventor Defense Act and an argument that congressional failure to define business methods may open the door to a more generally applicable PUR, see Jeffrey P. Duke, Comment, The First Inventors Defense Act (35 U.S.C. \$ 273) Have Prior User Rights in Patent Law Been Resurrected?, 20 ST. LouIS U. PUB. L. REv. 223, 242 (2001). See also Thomas, Collusion and Collective Action, supra note 21, at 337-40 (discussing the First Inventor Defense Act and arguing that it increases the probability of collusion between the first secret inventor and the subsequent patentee to suppress invalidating prior art). See generally James R. Barney, Comment, The Prior User Defense: A Reprieve for Trade Secret Owners or a Disaster for the Patent Law?, 82 J. PAT. \& TRADEMARK OFF. SOC'Y 261 (2000) (criticizing the First Inventor Defense Act of 1999).

103. In all areas of technology, trade secrets are preferred over patents by research and development executives as a means of generating returns from R\&D investments. See generally COHEN ET AL., WhY U.S. MANUFACTURING FIRMS PATENT, supra note 51; Levin et al., supra note 51. Thus, if creating PUR for business method patents is a good idea, it should be an equally good idea for patents in all areas.

104. In common parlance, a business method is a method, technique, or process that has something to do with the practice of business. We wonder whether, for example, a chemical refining process would be a business method for a firm in the business of refin- 
Although it is not entirely unheard of for Congress to single out a particular field for different protective scope under patent law, it is quite rare. In 1996, Congress granted immunity to medical practitioners and health-care entities so that they are no longer liable for infringing medical and surgical procedure patents. ${ }^{105}$ That action by Congress has been criticized, though not widely, because of the difficulties likely to be encountered in defining "medical or surgical procedures." 106 Even if one believes that it was socially optimal to remove the threat of an infringement action so as to give physicians the freedom to use any procedure they choose, it is unlikely that a reasonable estimate of costs and benefits would lead to the same conclusion for business methods.

ing petroleum products. Although probably not within the contemplation of most people who have given thought to business methods, why would the refining process not be included within such a definition? Other examples are innumerable.

105. Omnibus Consolidated Appropriations Act, 1997, Limitation On Patent Infringements Relating To A Medical Practitioner's Performance Of A Medical Activity, Pub. L. No. 104-208, 110 Stat. 3009, $\S 616$ (codified as amended at 35 U.S.C. $\S 287$ (c) (2000)). The act immunizes "medical activity" performed by a "medical practitioner," $i d$. $\S 287(\mathrm{c})(1)$, defines "medical activity" as a "medical or surgical activity performed on a body," id. $\S 287(\mathrm{c})(2)(\mathrm{A})$, and does not include as an immunized activity "(i) the use of a patented machine, manufacture, or composition of matter in violation of such patent, (ii) the practice of a patented use of a composition of matter in violation of such patent, or (iii) the practice of a process in violation of a biotechnology patent," id. $\$ 287$ (c)(A)(i)(iii). "Medical practitioner" is unhelpfully defined as "a natural person who is licensed by a state to perform the medical activity." Id. $\S 287(\mathrm{c})(2)(\mathrm{B})$. Related health care entities would include hospitals, nursing homes, and similar places where patients are treated and with which the medical practitioner has a professional affiliation. Id. $\S 287(\mathrm{c})(2)(C)$. Several bills sought the outright exclusion of such procedures from the definition of patentable subject matter, and the ultimately adopted legislation immunizing physicians from liability represented a compromise. See Brett G. Alten, Note, Left To One's Devices: Congress Limits Patents on Medical Procedures, 8 FORDHAM INTELL. PROP. MEDIA \& ENT. L.J. 837, 859-97 (1998).

106. See Alten, supra note 105 , at 359-97,; see also Steve Dirksen, A Reconsideration of the Physicians' Immunity Statute, 2001 DUKE L. \& TECH. REV. 27 (2001) (arguing that, to adequately recompense physician research and create incentives for medical procedure innovation, a licensing scheme should replace the physician exemption); Cynthia M. Ho, Patents, Patients, and Public Policy: An Incomplete Intersection at 35 U.S.C. $\S 287(c), 33$ U.C. DAVIS L. REV. 601 (2000) (generally critiquing the exemption); Scott D. Anderson, Comment, A Right Without a Remedy: The Unenforceable Medical Procedure Patent, 3 MARQ. INTELL. Prop. L. REv. 117, 117 (1999) (referring to Congress's action as a "radical amendment" that was "buried within an appropriations measure" and "passed as an impetuous response to a single lawsuit"); Joel J. Garris, Comment, The Case for Patenting Medical Procedures, 22 AM. J.L. \& MED. 85, 104 n.186 (1996) (critiquing congressional proposal to completely exclude medical and surgical procedures from patentability, and observing the problematic nature of defining a term like "surgical procedure"). 
Business practices lack the social imperative of medical treatments. ${ }^{107}$ Moreover, treating different technologies differently places too great a premium on ex ante definitions, such that the definitional scheme will be at least partially defeated because of the significant transaction costs associated with attorney efforts to opt into or out of a definition by carefully tailoring invention descriptions and patent claims. ${ }^{108}$

\section{H.R. 5364}

On October 3, 2000, Representatives Howard Berman and Rick Boucher introduced H.R. 5364, "The Business Method Patent Improvement Act of 2000." 109 Berman and Boucher admittedly did not expect the measure to pass so late in the session, but they intended to promote discussion of the issue. Congressman Boucher observed, in what we now consider to be classic political hyperbole, that "few issues in the 107 th Congress will be more important than deciding whether, and under what conditions, the government should be issuing 'business method' patents." 110

H.R. 5364 proposed to increase the difficulty of moving business methods from application to issuance, and to make them easier to challenge once issued. The 2000 Berman-Boucher bill proposed means for restraining the issuance of business method patents, which included (1) requiring publication of business method patent applications eighteen months after filing, regardless of whether the applicant also contemplated

107. There have been a few other instances in which Congress has treated particular technology areas differently. These are briefly discussed supra at note 19.

108. Although this will not always be successful, it can be done, and undoubtedly will be done if a significant premium is placed on whether an invention is defined as a business method. See, e.g., Jeffrey R. Kuester \& Lawrence E. Thompson, Risks Associated with Restricting Business Method and E-Commerce Patents, 17 GA. ST. U. L. REV. 657, 678-79 (2001) (practitioners are adept at drafting patent claims so as to avoid penalties based on categorization). Further, the concept of a "business method" is likely to prove exceptionally difficult to define. In its 1996 revised guidelines to assist examiners with software inventions, the PTO observed that its personnel had experienced "difficulty in properly treating claims directed to methods of doing business," and further stated that patent "[c]laims should not be categorized as methods of doing business," but "should be treated like any other process claims." Examination Guidelines for Computer-Related Inventions, 61 Fed. Reg. 7478-79 (USPTO Feb. 28, 1996).

109. H.R. 5364, 106th Cong. (2000).

110. 146 CONG. REC. E1,651-52 (daily ed. Oct. 3, 2000) (statement of Rep. Boucher). Congressman Boucher also stated that "[s]omething is fundamentally wrong with a system that allows individuals to get patents for doing the seemingly obvious .... We're introducing this legislation in an effort to repair the system before the PTO awards more monopoly power to people doing the patently obvious." Id. at 1651 . 
filing in another country; ${ }^{111}$ (2) allowing the public to submit prior art after application publication and protest the issuance of the patent; ${ }^{112}$ (3) instituting a post-grant administrative opposition procedure for challenging the patent's validity that closely resembles opposition procedures employed in countries that do not allow courts to invalidate issued patents; ${ }^{113}$ (4) requiring applicants for these patents to disclose whether and to what extent they have conducted a search of the prior art; ${ }^{114}(5)$ presuming that the invention is obvious if the business method is previously known and the only new feature is computer implementation; ${ }^{15}$ and (6) imposing a preponderance of the evidence burden of proof for the challenger to a business method patent's validity rather than the clear and convincing evidence standard employed for other patent validity challenges. ${ }^{116}$ In the first attempt to legally define a business method, H.R. 5364 described it as: "(1) a method of-(A) administering, managing, or otherwise operating an enterprise or organization, including a technique used in doing or conducting business;

111. H.R. $5364 \S 3$. As part of the American Inventors Protection Act of 1999 (of which the First Inventors Defense Act was also a part), Congress amended the Patent Act to provide for publication of patent applications eighteen months after filing, unless the application declared that it would not also file in a foreign country. 35 U.S.C. $\S 122$ (b) (2000). Previously, the PTO maintained U.S. patent applications in confidence until issuance of the patent. In other nations, however, patent applications traditionally were published at the eighteen-month point after filing, although usually not in English. Allowing an exception to eighteen-month publication in the United States for applicants not filing outside the United States was seen primarily as a bow to individual inventors and small businesses who are less likely to file overseas and thus less likely to have faced eighteenmonth publication in another nation. The PTO began implementation of the new publication measure in March 2001.

Requiring eighteen-month publication of all applications for business method patents possibly could have had noticeable effects because applications for such patents rarely would be subject to the more general publication requirement since such applications are unlikely to be filed in other countries, given the fact that most other countries do not recognize patents on business methods. If publication of all applications is a good idea, however, there is no good reason to limit the practice to a single ill-defined technology area.

112. H.R. $5364 \S 3$.

113. Id.

114. Id at $\S 5$. There is no requirement in patent law that an applicant conduct a prior art search. Instead, there is only a requirement that the applicant disclose to the PTO any relevant material prior art of which the applicant is aware. 37 C.F.R. $\S 1.56$ (2002); see also Upjohn Co. v. Mova Pharm. Corp., 225 F.3d 1306, 1315 (Fed. Cir. 2000). The combination of no required prior art search and a severe penalty if one is conducted but results not disclosed can have perverse effects. See infra text at Part V.A.1.

115. H.R. $5364 \S 4$.

116. Id. at $\S 3$. 
or (B) processing financial data; (2) any technique used in athletics, instruction, or personal skills; and (3) any computer-assisted implementation of a method described in paragraph (1) or a technique described in paragraph (2)." 117 This definition has been criticized on several grounds, including the likelihood that it also could apply to patents on computer hardware, ${ }^{118}$ and more importantly, that its fluidity could logically encompass process inventions in many fields. Greg Aharonian observes, for instance, that if "part of the definition is 'a technique used in doing or conducting business' . . . isn't using toluene instead of benzene in a chemical reaction a technique used in doing or conducting chemical engineering business?"119 $\mathrm{He}$ also provides an example of how the Amazon.com one-click patent can be redrafted so that it would be placed into one of the PTO's software engineering subclasses and escape special treatment as a business method patent. ${ }^{120}$

\section{H.R. 1332}

After Congress had expectedly taken no action on H.R. 5364, Congressmen Berman and Boucher introduced H.R. 1332, "The Business Method Patent Improvement Act of 2001" on April 3, 2001. The bill, which also received no action by Congress, defined a business method similarly to the previous year's bill. The definition in the second bill, however, emphasized the inclusion of only software-implemented business methods. ${ }^{121}$ Although almost everyone thinks only of softwareembodied business methods whenever the subject comes up, the previous definition could have been interpreted more expansively. Two observers

117. Id. at $\S 2$.

118. Kuester \& Thompson, supra note 108 , at 678.

119. Gregory Aharonian, Business Method Law Proposed, InTERnET PAT. NewSLETTER, Oct. 6, 2000 (on file with author). Aharonian's publicly available archive of newsletters has an end point shortly before the date of this one, but will be updated in the future. See www.bustpatents.com (last visited Nov. 25, 2003) (including link to list of articles in archive, the text of which are available on a CD-ROM). In his comments about H.R. 5364, Aharonian uses his characteristically subtle style to state: "In short, IT IS UTTERLY IDIOTIC TO TRY TO DEFINE 'BUSINESS METHODS' AS A CLASS OF PATENT APPLICATIONS TO BE TREATED DIFFERENTLY." Id. (capitalization original).

120. Id.

121. H.R. 1332 defined a business method as: "(1) a method-(A) of-(i) processing data; or (ii) performing calculation operations; and (B) which is uniquely designed for or utilized in the practice, administration, or management of an enterprise; (2) any technique used in athletics, instruction, or personal skills; and (3) any computer-assisted implementation of a method described in paragraph (1) or a technique described in paragraph (2)." H.R. 1332, 107th Cong. $§ 2$ (2001). 
criticized H.R. 1332's definition as "similarly inexact." 122 Hearings on H.R. 1332, although naturally displaying some of the unease with business method patents that prompted the bill's introduction in the first place, ${ }^{123}$ also revealed concerns that the question whether an invention can be characterized as a business method would impose unnecessary burdens on the federal judiciary. ${ }^{124}$ Additionally, the hearings revealed observations that an initial onslaught of questionable biotechnology patents in the 1980s had ameliorated with time and experience; ${ }^{125}$ that the application of traditional novelty and nonobviousness concepts would increase the quality of business method patents over time; ${ }^{126}$ and that more fundamental problems such as improving general PTO funding and prior art databases needed to be addressed. ${ }^{127}$

No business method patent bill was introduced in the 2002 session, perhaps because previous sponsors concluded that most members of Congress believed the issue to be a tempest in a teapot; because their attention was diverted by terrorism and a deepening economic recession; or because interested members like Berman and Boucher were able to tell those pressuring them to tighten the screws on business method patents that the PTO had taken up the cause.

\section{B. PTO Responses}

In March 2000, the PTO unveiled a new program making it more difficult to obtain a business method patent. The PTO's March 2000 initiative included a program to establish a formal Customer Partnership with the software, Internet, and electronic commerce industries similar to an earlier biotechnology industry outreach. ${ }^{128}$ Part of the program consisted of a "Roundtable Forum" to discuss issues and possible solutions surrounding business method patents. The PTO envisioned that

122. Kuester \& Thompson, supra note 108 , at 679 n. 125 .

123. See Hearings on H.R. 1332, supra note 23, at 13, 19-20, 62 (statements of Rep. Howard L. Berman, Rep. John Conyers, and Andrew B. Steinberg, Executive Vice President, Travelocity.com, a web-based travel agency).

124. Id. at 51-53 (statement of Ronald E. Myrick, President, Intell. Prop. Owners Ass'n).

125. Id. at 51-53.

126. In the congressional hearings on H.R. 1332, Nicholas P. Godici, Acting Director of the USPTO at the time, testified that the PTO was flexible and could adapt, whereas changes in the law itself would prove much less flexible. Id. at 27 (statement of Nicholas P. Godici, Acting Under Sec'y of Com. for Intell. Prop. and Acting Dir. of the U.S. Pat. and Trademark Off.).

127. Id. at 34-50 (statement of Michael K. Kirk, Executive Director of the Am. Intell. Property Law Ass'ns (AIPLA)).

128. Id. at 48 . 
the Forum would also facilitate its effort to obtain industry feedback on the PTO's existing prior art databases and other information sources, with a view towards ultimately expanding its prior art collection. ${ }^{129}$

Another effort was designed to make examination of patents in Class 705 more robust. The PTO created Class $705^{130}$ ("Data Processing: Financial, Business Practice, Management, or Cost/Price Determination") in 1997 from the business and cost/price subclasses of Classes 395 and 364. ${ }^{131}$ The predecessors to Class 705 were originally dominated by computerized postage metering and cash register systems, but by 1994 , financial transaction systems commanded the largest share of patents in the predecessor classes. Since the creation of Class 705, patents on electronic shopping, advertising management systems, records management, and many other software-embodied methods relating to business enterprises have gradually become the majority in this category. ${ }^{132}$

As part of its stated goal of enhancing the quality of issued business method patents, the PTO greatly increased the number of examiners for applications placed in Class $705,{ }^{133}$ emphasized the hiring of examiners with both software expertise and business experience, and vowed to provide additional business method training. ${ }^{134}$ The PTO identified online databases and periodicals that Class 705 examiners are required to

129. Id.

130. PTO classifications do not suggest different legal treatment for different technologies, but instead serve to aid the search for prior art.

131. See Business Method WhITE PAPER, supra note 24, at 6 . Class 705 is defined as follows:

This is the generic class for apparatus and corresponding methods for performing data processing operations, in which there is a significant change in the data or for performing calculation operations wherein the apparatus or method is uniquely designed for or utilized in the practice, administration, or management of an enterprise, or in the processing of financial data. This class also provides for apparatus and corresponding methods for performing data processing or calculating operations in which a charge for goods or services is determined.

USPTO, U.S. Patent Classification System-Classification Definitions as of June 30, 2000: Class 705, available at http://www.uspto.gov/web/offices/ac/ido/oeip/taf/def/705. htm (last visited Nov. 30, 2003). Class 705 includes approximately one hundred subclasses.

132. See BusIness METHOD WhITE PAPER, supra note 24 , at 7.

133. The number of examiners in Class 705 increased from seventeen in late 1997 to seventy-seven in April 2001. See Hearings on H.R. 1332, supra note 23, at 32 (statement of Nicholas P. Godici).

134. See Business Method WhITE PAPER, supra note 24 , at 12. 
search, ${ }^{135}$ established "Electronic Information Centers" that provide examiners with access to more than 900 databases - many of which include business and financial information, ${ }^{136}$ and instituted a second level of examiner review for applications in Class $705 .{ }^{137}$ From March 2000 to March 2001, the grant rate for business method patent applications declined from $56 \%$ to $36 \%$. ${ }^{138}$ According to PTO Director James Rogan, this allowance rate had stabilized at $35-40 \%$ by October $2002 .{ }^{139}$

\section{DATA ON INTERNET BUSINESS METHOD PATENTS AND GENERAL PATENTS}

\section{A. The General Patent Data Set}

Our investigation employs two data sets. The first, developed by John Allison and Mark Lemley in connection with previous studies, ${ }^{140}$ measures a large number of patent attributes for 1,000 randomly selected patents of

135. Id. at 15 .

136. Hearings on H.R. 1332, supra note 23, at 31 (statement of Nicholas P. Godici).

137. See BUSINESS METHOD WHITE PAPER, supra note 24, at 21.

138. Hearings on H.R. 1332, supra note 23, at 52 (statement of Ronald E. Myrick).

139. Declan McCullagh, Patent Office Swamped-"Hurting Technology", ZDNET NEws, Oct. 16, 2002, available at http://zdnet.com.com/2100-1106-962182.html (last visited Nov. 25, 2003). Mr. Rogan, a former congressman appointed by President Bush in late 2001 , stated, "We were granting 65 or 70 percent of these things. Now the rejection rate is around 65 or 70 percent." Id.

Although Director Rogan was comparing apples to apples and there apparently has been a real decline in the allowance rate for business method patents, one generally must be cautious in relying on the PTO's reported allowance rates because they do not properly take into account previous continuing applications in a chain leading to the patent in question. A significant number of patents relate back to one or more "parent" (or "ancestor") applications, and many of these ancestor applications result in their own patents on very closely related inventions. See Cecil D. Quillen, Jr. \& Ogden H. Webster, Continuing Patent Applications and Performance of the U.S. Patent and Trademark Office, 11 FED. CIR. B.J. 1, 3 (2001) (estimating the actual allowance rate as being far higher than the $66 \%$ reported by the PTO for $1993-98$, perhaps as high as $80-97 \%$ ) [hereinafter Quillen \& Webster, Continuing Patent Applications]; Cecil D. Quillen, Jr. et al., Continuing Patent Applications and Performance of the U.S. Patent and Trademark Office-Extended, 12 FED. CIR. B.J. 35 (2002) (adjusting assumptions from previous study to correct a probable flaw, but still producing an estimated allowance rate much higher than reported, and higher than in Japan and Germany). The effects of ancestor applications on the time patent applications spend in the PTO prior to issuance are discussed infra at Part V.E.1.

140. Allison \& Lemley, Growing Complexity, supra note 40 (statistically comparing variables in the 1996-98 data with counterpart variables in a set of one thousand randomly selected patents issued twenty years earlier, 1976-78); Allison \& Lemley, Who's Patenting What?, supra note 40 (statistically analyzing variables within the data set). 
all kinds issued during a two-year period between mid-1996 and mid1998. ${ }^{141}$ Some of the many patent attributes measured in that data set are not relevant to our current research on whether business method patents were of lower quality and value than others, and thus we report only the characteristics relevant to our study. ${ }^{142}$ For the current study we collected additional data for the set of general patents and made slight modifications to it for comparison with Internet business method patents. The parameters we compare are the number and type of prior art references, number of claims within the patents, number of inventors, and time spent in the PTO before issuance. ${ }^{143}$

\section{Defining the Technology Areas}

In developing the general patent data set, we placed each of the 1,000 patents in one or more of fourteen technology areas. We did not use the PTO's classification system for our definitions because, as anyone who is familiar with that system knows, it identifies most classes and subclasses at a very low level of functional abstraction and is not especially helpful in conceptually defining technologies from a science or engineering perspective. PTO classes and subclasses also are frequently entwined in rather cryptic ways. ${ }^{144}$ The system is designed to assist patent examiners in

141. A complete description of that data set is found elsewhere. Allison \& Lemley, Who's Patenting What?, supra note 40, at 2108-13.

142. For example, we developed extensive data on the geographic origin of patents in both data sets, by state and by country, but these data are not germane to the current study's objectives.

143. All of these data were extracted from the patents themselves. Additional data on the entity status of patent owners at issuance-individual, small business, nonprofit, or large business - were obtained from the PTO, but we decided not to use it in this Article because it strays a bit from our main focus. These data did show, however, that the portion of patents owned by large businesses and the combined small-entity types was essentially the same in both data sets. The only difference was that, in the case of Internet business method patents, there was a significant ownership shift from individuals to small corporations.

144. For example, Class 345 is defined as "Computer Graphics Processing, Operator Interface Processing, and Selective Visual Display Systems." The class definition states:

This class provides for processes and apparatus for selective electrical control of two or more light-generating or light-controlling display elements in accordance with a received or stored image data signal. The image data includes character, graphical information or display attribute data. The image data may include, for example, information data from a peripheral input device, from the reception of a television signal, from the recognition of image data, or from the generation or creation of image data by a computer. This class also provides for digital data processing systems or methods for data processing for visual presentation, wherein the processing of data includes the creation 
searching for prior art by invention function, not by technological concept. Nor did we find that the World Intellectual Property Organization's ("WIPO") system of International Patent Classifications ("IPCs") well suited for identifying technology areas at a conceptual level, because it also was designed for purposes quite different than ours, and similarly operates at too low a functionally oriented level of abstraction to serve our definitional objectives. We have traded the objectivity of a third-party classification scheme for the subjective but far more conceptually accurate taxonomy we have chosen. ${ }^{145}$ Although almost all of the fourteen areas are susceptible to more than one definitional approach, we believe ours to be at least as reasonable as other possible alternatives.

While it is possible to devise an almost endless list of categories and subcategories, these fourteen categories were chosen because they reflect the areas of technology into which inventions in the sample generally fell after a trial run involving the careful study of several hundred patents. The size of the sample further suggests that this is a reasonable approach to categorizing technology areas in patents generally.

\section{The Fourteen Technology Areas}

Following, in alphabetical order, are the technology areas we identified and the definitions we developed.

1) Acoustics: A process or product that consists solely or in critical part of an invention using sound waves. Such an invention may also be included in another classification, such as medical device or computer-related.

or manipulation of graphic objects (e.g., artificial images), text or use of an operator interface by a digital data processing system prior to use by or within a specific display system.

USPTO, U.S. Patent Classification System-Classification Definitions: Class 345, available at http://www.uspto.gov/go/classification/uspc345/defs345.htm (last visited Nov. 30, 2003).

Not only does the class combine different technology areas, such as computer hardware, software, and optics, but it also does so in a very function-oriented way rather than a concept-oriented way. To further illustrate, Subclass 74 within Class 345 is "Machine Element or Mechanism, particularly Subclass 471 for control elements which move in two planes," showing both the system's often bewildering structure and its focus on low-abstraction functionality. Id.

145. One must understand that the act of defining areas of technology in today's world is as much art as it is science, and that many inventions involve more than one technology, such as optics and electronics or acoustics and software. Some might reasonably disagree with these definitions. 
2) Automotive-related: An invention that is intended for use with automobiles or trucks. An invention in this classification necessarily will also be included within another classification, such as mechanics, electronics, or computer-related.

3) Biotechnology: A process involving advanced genetic techniques intended to construct new microbial, plant, or animal strains, a product created from such a process, or the way such a process or product is used in biotechnology research.

4) Chemistry: A process that consists solely of chemical reactions, a product resulting from such a process, or an invention of which a chemical process or product is a critical part. Closely related inventions such as those on novel metal alloys are also included. An invention in the field of chemistry may be included in one or more other classifications, such as electronics or optics.

5) Communications-related: An invention intended to improve the state of the art in communications. An invention placed in this classification necessarily will also be included within another classification, such as optics, electronics, or computer-related.

6) Computer-related: (a) A process or product for improving computer hardware (except for advances in semiconductor technology, which are in a separate, mutually exclusive classification). (b) An invention solely embodied in software. (c) An invention in which a microprocessor or other integrated logic circuit is expressed in the patent as being a critical part of the invention (again excluding advances in semiconductor technology itself). Any invention in part (c), and some inventions in parts (a) and (b), of the computer-related classification will necessarily also be classified in one or more other categories.

7) Electronics: A process or product in which the sole or a critical part of the invention makes use of traditional electronic circuitry or involves electric energy storage. An invention in this classification may also be included in other classifications, including chemistry, mechanics, or optics.

8) Energy-related: Any invention that intends to advance the state of the art in the production, processing, or transmission of energy. An invention is also included in this classification if its intended use is research into some aspect of the production, processing, or transmission of energy. The definition of "energy" includes that 
produced by any means from any source, including fossil fuels, nuclear power, electricity, and the many forms of radiation. An invention in this classification necessarily will also be included within another classification, such as mechanics, electronics, acoustics (for example, seismological inventions for detection of oil and gas), optics, chemistry, or computer-related.

9) Mechanics: A process or product that consists solely of the use of mechanical parts, sometimes combined with heat, hydraulics, pneumatics, or other power sources; or an invention in which the above is a critical part. Some inventions classified as mechanical also will be in one or more other classifications, such as electronics. While many different types of inventions fit into this category, it is not a catchall "other" category.

10) Medical devices: An apparatus to be used for the diagnosis or treatment of diseases in humans or animals including devices used in medical research. An invention classified as a medical device will also fall within at least one other classification, such as computer-related, electronics, mechanics, or optics.

11) Optics: A process or product intended to advance the state of the art in the use of light waves or imaging. This may be its sole purpose or it may be a critical part of an invention also having other purposes. Optics technology often will also be classified in one or more other areas, such as medical devices, semiconductors, electronics, or chemistry.

12) Pharmaceutical: A process or substance to be used in the diagnosis or treatment of diseases or other abnormal conditions in humans or animals, including processes or substances used in medical research. In this data set, a technology classified as pharmaceutical will also be within either the chemistry or biotechnology areas.

13) Semiconductors: A process or product intended to advance the state of the art in researching, designing, or fabricating semiconductor computer chips. Sometimes a semiconductor patent will also be placed in another classification, such as a semiconductor manufacturing process employing a purportedly new chemical process.

14) Software: An invention that is completely embodied in software, even if the claims of the patent refer to a system or article of manufacture. A pure software invention is also placed in the 
computer-related classification. The instructions embodied in software code can often be embodied in semiconductor chips in a device; this is done in the obvious instances of modern consumer electronic devices, automobiles, and other devices in which the instructions are very specific to a particular function of the device and the use of software for logic instructions simply is not practically feasible. Another researcher might include within the software classification those inventions in which the algorithms are embodied in chips, but we have chosen to include within our definition of software only those inventions that consist purely of software that is not embodied in hardware.

\section{B. The Internet Business Method Patent Data Set}

We set out to construct a database of all patents issued through the end of 1999 that were clearly targeted for use with the Internet. ${ }^{146}$ Our goal then was to extract from those patents the ones that could be characterized as "methods of doing business." Using Lexis-Nexis, we experimented with many search terms before settling on "Internet or World Wide Web."147 Although patents covering technological advancements ultimately contributing to the operability of the Internet undoubtedly issued before the term Internet became part of the American vernacular, and others having an impact on the Internet surely continued to issue after use of the term became widespread, we did not attempt to gather all patents that may have affected the Internet because the effort would have taken us into the realm of speculation. ${ }^{148}$ Instead, we sought only patents

146. We only sought patents issued through the end of 1999 because we began the effort in 2000 and, once the data set was in place, it was quite unwieldy to add to it piecemeal.

147. Search terms in LEXIS, of course, are not case-sensitive. Although we found it very unusual for a patent to use the term "World Wide Web" without also using the term "Internet," we also included the former because it might pick up a small number of Internet-related patents with little chance of including irrelevant ones.

148. After we had developed our operational search request and had done much of our data collection, a member of the review committee at NAS suggested that we add a search term such as "computer network." Although we were far enough into systematic study of the patents and data coding that doing a reconfigured search request would have caused substantial delay, we saw the suggestion as a reasonable one and experimented with it by searching for patents using the request "computer network! and not (Internet or World Wide Web)". The search did return a substantial number of patents, but after closely reading over 200 of them we concluded that even though a relatively small number of additional patents probably could be included in the data set, attempting to do so would force us into too much speculation about whether inventions were truly targeted at the Internet. Without seeing a substantial advantage to be gained from a reconfigured search, we decided that further delaying a long and arduous project was unjustified. 
on software inventions that clearly were aimed at use with the Internet. We then categorized the patents that made the cut.

\section{Constructing the Data Set}

Our initial search for all patents issued from the beginning of 1990 to the end of 1999 that included the terms "Internet or World Wide Web" yielded over 9,000, most of which used these terms in an incidental fashion (such as a cite to a piece of prior art on the Internet). ${ }^{149}$ Although a survey of these patents found a few initially promising candidates in older computer industry classifications such as $345,365,370$, and 375 , we found by far the heaviest concentration in the newer 700-series "data processing" or "electrical computer" classifications. ${ }^{150}$ In particular, most contenders for inclusion appeared in Class 705, 707, and 709. ${ }^{151}$ Although

149. Most of the patents we found had been issued in 1998 and 1999 , with a far smaller number in 1997 and only a few before 1997.

150. When it created the 700-series classes, the PTO did go back several years and add the newer class numbers to selected patents in the older classes. Patents often are placed in more than one PTO classification and it was not uncommon to find patents that had been placed in one or more of the newer classes as well as in an older class.

151. These class titles and definitions are:

Class 705: Financial, business, practice, management, or cost/price determination: This is the generic class for apparatus and corresponding methods for performing data processing operations, in which there is a significant change in the data or for performing calculation operations wherein the apparatus or method is uniquely designed for or utilized in the practice, administration, or management of an enterprise, or in the processing of financial data. This class also provides for apparatus and corresponding methods for performing data processing or calculating operations in which a charge for goods or services is determined.

This class additionally provides for subject matter described in the two paragraphs above in combination with cryptographic apparatus or method.

USPTO, U.S. Patent Classification System-Classification Definitions: Class 705, available at http://www.uspto.gov/go/classification/uspc705/defs $705 . \mathrm{htm}$ (last visited Nov. $30,2003)$.

Class 707: Data Processing: database and file management, data structures, or document processing: This is the generic class for data processing apparatus and corresponding methods for the retrieval of data stored in a database or as computer files. This class provides for data processing means or steps for organizing and inter-relating data or files (e.g., relational, network, hierarchical, and entity-relationship models). This class also provides for data processing means or steps for generic data, file and directory upkeeping, file naming, and file and database maintenance including integrity consideration, recovery, and versioning. 
some possibly relevant patents were also found in other 700 -series classes, a closer study of these showed that those potentially relevant to our study were also placed in 705,707 , or $709 .{ }^{152}$ Using our search terms, we retrieved over 2,800 patents in these three classes. ${ }^{153}$

USPTO, U.S. Patent Classification System-Classification Definitions: Class 707, available at http://www.uspto.gov/go/classification/uspc707/defs 707.htm (last visited Nov. 30, 2003).

Class 709: Electrical computers and digital processing systems: multiple computer or process coordinating: This class provides for an electrical computer or digital data processing system or corresponding data processing method including method or apparatus for transferring data or instruction information between a plurality of computers or processes wherein the computers or processes employ the data or instructions before or after transferring and the employing affects said transfer of data or instruction information. The class includes the following subject matter:

A. Process or apparatus for administrating process or job execution over a digital data processing system.

B. Process or apparatus for transferring data among a plurality of spatially distributed (i.e., situated at plural locations) computers or digital data processing systems via one or more communications media (e.g., computer networks)

C. Process or apparatus for exchanging data or messages between two executing programs or processes, generally independent of the hardware used in the communication.

D. Process or apparatus for synchronizing control or regulation of clocking or timing operations of two or more processors.

USPTO, U.S. Patent Classification System-Classification Definitions: Class 709, available at http://www.uspto.gov/go/classification/uspc709/defs709.htm (last visited Nov. 30, 2003).

152. For example, we found some patents that appeared not only in 705,707 , or 709 , but also in classes such as: "Class 700: Data processing: generic control systems or specific applications," USPTO, U.S. Patent Classification System-Classification Definitions: Class 700, available at http://www.uspto.gov/go/classification/uspc700/defs 700 .htm (last visited Nov. 30, 2003); "Class 703: Data processing: structural design, modeling, simulation, and emulation," USPTO, U.S. Patent Classification SystemClassification Definitions: Class 703, available at http://www.uspto.gov/go/ classification/uspc703/defs 703.htm (last visited Nov. 30, 2003); and "Class 713: Electrical computers and digital processing systems: support," USPTO, U.S. Patent Classification System-Classification Definitions: Class 713, available at http://www.uspto.gov/ go/classification/uspc713/defs713.htm (last visited Nov. 30, 2003).

153. The large difference between the nine thousand patents we first uncovered and the twenty-eight hundred we found after re-running the search only in Classes 705, 707, and 709 resulted from the far greater number of duplicate patents in the first exploratory search because many more classifications had been included and so many patents were in multiple classes. 
In our multiple readings to ascertain whether a given patent should be characterized as Internet-related, we focused mainly on the written description of the invention (not just the abstract), although we also examined the claims. ${ }^{154} \mathrm{We}$ approached the study of these patents with the attitude that we would take the inventors at their word about whether the inventions would be used in connection with the Internet. In the case of employed inventors, of course, these words presumably reflected not only the inventors' own visions for the inventions but also those of corporate managers and patent attorneys familiar with their clients' patenting strategies. If the written description of the invention clearly demonstrated that it was intended to be used with the Internet, it was included; otherwise, it was discarded. We eventually excluded approximately onehalf of these patents for a variety of reasons, yielding a data set of 1,423 patents. ${ }^{155}$

\section{Categorizing Internet Patents}

Our study of the more than 2,800 patents also revealed that Internetrelated patents fall into several discernible categories. Many described relatively broad models for doing business on the Internet and clearly were of the sort that comes to mind when most observers think about business method patents. The Priceline.com reverse auction model for purchasing airline tickets was prototypical of this type. Among the many others, there is U.S. Patent No. 6,006,265, "Hyperlinks resolution at and by a special network server in order to enable diverse sophisticated hyperlinking upon a digital network," a method for distributing hypervideo, i.e., digital video broadcasting incorporating hyperlinks. ${ }^{156}$ Other examples include U.S. Patent No. 6,009,412, "Fully integrated on-line interactive frequency and award redemption program," describing a system for Internet shopping

154. Had our inquiry dealt with questions of validity or infringement, we obviously would have given most of our attention to the claims.

155. Three examples of reasons for exclusion from the data set follow. First, the search produced a number of duplicate patents because some had been placed into two or sometimes even all three of these classifications $(705,707,709)$, although, as noted, the number of duplicates was far less than in our initial search. Second, and as in our first search, many patents in these classes that included the terms "Internet" or "World Wide Web" used the terms in only an incidental way and did not clearly envision use of the software invention with the Internet. For instance, there were substantial numbers of patents in which these terms were found only in a prior art reference to an item that had been found on the Internet, for example, a web page. Third, several patents described only software application products with some discussion of how they could be delivered over the Internet. Through this process we discarded approximately fifty percent, yielding a set of 1,423 .

156. U.S. Patent No. 6,006,265 (issued Dec. 21, 1999). 
incorporating an awards program, ${ }^{157}$ and the self-explanatory U.S. Patent No. 5,978,780, "Integrated bill consolidation, payment aggregation, and settlement system." 158 We labeled these as "Internet business model patents."

We also encountered inventions narrower in scope, intended not as business models, but only as means for solving specific business problems. The Amazon.com one-click patent is illustrative. Other examples include U.S. Patent No. 6,006,332, "Rights management system for digital media," which provides a method for controlling unauthorized access to copyrighted material distributed by content owners over the Internet, ${ }^{159}$ and U.S. Patent No. 6,009,382, "Word storage table for natural language determination," a method by which a company can distribute a document in multiple human languages and have a particular recipient's computer automatically select the recipient's language. ${ }^{160}$ We labeled these patents as "Internet business technique patents."161

Our study of Internet-related patents revealed a third type involving techniques that purport to make the Internet more efficient and effective for conducting electronic commerce by solving a technical software problem. These are easily distinguishable from broadly-described business methods, but are sometimes difficult to differentiate from narrowly drawn ones. One example of the third variety is U.S. Patent No. 6,003,077, "Computer network system and method using domain name system to locate MIB module specification and web browser for managing SNMP agents," 162 which was fairly easy to distinguish from a patent on a broad business model because of its very narrow, technical nature. Another, U.S.

157. U.S. Patent No. 6,009,412 (issued Dec 28, 1999).

158. U.S. Patent No. 5,978,780 (issued Nov. 2, 1999).

159. U.S. Patent No. 6,006,332 (issued Dec. 21, 1999).

160. U.S. Patent No. 6,009,382 (issued Dec. 28, 1999).

161. The PTO and most commentators have associated patents on business models and business techniques solely with Class 705 . Although Internet business model and business technique patents are more highly concentrated in Class 705 (especially models), they can also be found in 707 and 709 . As noted earlier, the PTO frequently places patents in more than one classification, the first one listed being the "main classification." We point this out because the PTO's March 2000 initiative, which includes a secondlevel review before issuance, applies only to patents with a main classification of 705 . Therefore, a substantial number of business method patent applications are not subject to this program of greater scrutiny because they either are not in 705 at all or because they are in 705 as a secondary classification. Although the end point of our Internet business method data set, December 31, 1999, is prior to the PTO's institution of this initiative, we make these observations to further substantiate our position that placing a premium on subject matter definition or classification creates its own set of problems.

162. U.S. Patent No. 6,003,077 (issued Dec. 14, 1999). 
Patent No. 6,005,939, "Method and apparatus for storing an Internet user's identity and access rights to world wide web resources," presented us with a definitional issue about which reasonable people could differ. We ultimately placed it with others of a similar nature in a category we called "Internet software technique patents," 163 because the invention description emphasized the solution to a software problem much more than it emphasized the solution to a business problem.

\section{Excluding the Last Category}

After finishing development of our taxonomy of three categories of Internet patents and placing all 1,423 into one of the three, we concluded that only the first two (business models and business techniques) should remain in our data set for comparison with the general patent data set. The third category more logically belongs in the larger universe of "software patents," of which software-implemented business method patents are a subset. Although the third category consists of Internet-related software patents, few knowledgeable observers would characterize them as business method patents. As a result, our final Internet business method data set includes 1,093 patents issued through the end of 1999. As one would expect, most of these patents issued in 1998 or 1999, with a much smaller number in 1997 and only a handful in 1996. Because the general patent data set includes patents of all types issued between mid-1996 and mid-1998, the two data sets are sufficiently contemporaneous for statistical comparison. ${ }^{164}$

\section{COMPARISON OF PATENT CHARACTERISTICS}

\section{A. Number of Prior Art References}

Aside from objections that business methods should not even be patentable subject matter, the most common reason for castigating them was the perception that they are granted with little attention to the prior art. In the examination of patent applications, prior patents and other printed publications ("nonpatent references") describing related

163. U.S. Patent No. 6,005,939 (issued Dec. 21, 1999).

164. Contemporaneity is very important for data comparability in statistical comparison of patent groups because the values of almost all patent variables such as references, claims, and inventors have increased significantly over time. See Allison \& Lemley, Growing Complexity, supra note 40, 97-103 (demonstrating this for the twenty years between the late 1970 s and late 1990s). 
technological advances are the two most important types of "prior art."165 There is a strong intuitive appeal to the idea that the number of prior art references in a patent may relate to patent quality, and thus to patent value. One reason for this appeal is the fact that uncited prior art-art that was not before the patent examiner-is the most common basis for court decisions invalidating U.S. patents. ${ }^{166}$ Therefore, a larger number of references in a patent should, on average, increase the probability that it would be held valid if challenged. Naturally, we are speaking only of statistical tendencies over a large group of patents.

When patent applicants spend more time, effort, and money conducting more thorough prior art searches to better differentiate their inventions from what others have done, they probably do so mainly out of a conviction that their innovations have greater value. More vigorous differentiation from the prior art leads, in turn, to more valuable patents because they have a better chance of withstanding validity challenges. We thus witness a likely relationship between the perception and the reality of greater patent value. This notion of self-selected value, which we revisit in other contexts, seems perfectly acceptable because applicants should have more relevant information than anyone else about the probable private value of their inventions. Moreover, applicants' inclusion of more prior art may result in more thorough examinations in the PTO, further contributing to stronger patents. ${ }^{167}$ Relating the number of prior art references to average patent value is thus an intuitively attractive concept. ${ }^{168}$

165. The other types of prior art consist of evidence that an invention had been in public use or had been placed on sale. 35 U.S.C. $\S \S 102(a)$, (b) (2000). Although evidence of a prior public use or of prior activity that placed an invention on sale often forms the grounds for a judicial invalidity finding, these types of prior art are far less likely to be a factor in the PTO examination process.

166. Allison \& Lemley, Validity of Litigated Patents, supra note 31, at 231-34.

167. Prior art references are listed in the patent by both the applicant and the examiner, but it is not feasible to determine for a large number of patents which references were cited by the applicant and which by the examiner because one must study the prosecution history in the PTO to make this determination. However, there are reasons to believe that the great majority of prior art referenced in patents have been cited by applicants rather than by the PTO examiner. See Allison \& Lemley, Who's Patenting What?, supra note 40 , at 2137. Allison and Lemley found that U.S. patents on foreign-origin inventions cite much more foreign-origin prior art and much less U.S.-origin prior art than do U.S. patents on U.S.-origin inventions. There is reason to believe that these foreign applicants for U.S. patents have better access to foreign-origin prior art in their language. However, if very much additional prior art were cited by the U.S. patent examiner, one would expect it to be English-language prior art. The fact that this did not appear to occur supports the inference that most of the prior art is cited by the applicant and not the examiner. 
One study found empirical support for the notion that the number of prior art references is positively correlated to independent measures of patent value, ${ }^{169}$ but two others were unable to find a statistically significant relationship. ${ }^{170}$ Those studies counted only references to prior

Another observation clearly provides strong support for this conclusion. One finds wild variations in the number of patent and nonpatent prior art references among U.S. patents in the same area of technology. We certainly found this to be true in the case of Internet business method patents. Unless all or most of this prior art is cited by applicants, then patent examiners in the same technology area do not have access to the same resources, they do not communicate with each other, there is little supervision by primary examiners, or all of the above. There is absolutely no reason to believe any of these possibilities and, therefore, most prior art is probably cited by applicants.

Moreover, the fact that the distribution of prior art references in a group of patents tends to be bimodal, as discussed infra at Part V.A.1, also provides strong support for an argument that most prior art is cited by applicants rather than examiners. The reasons for such a distribution relate only to applicants, not examiners.

Our theory that most prior art is cited by applicants rather than examiners was recently confirmed empirically. Beginning on January 1, 2001, the PTO began placing an asterisk beside each prior art reference that was cited by the examiner. Bhaven Sampat found that, between January 1, 2001 and June 25, 2002, 40\% of the citations to prior U.S. patents, $13 \%$ of foreign prior art (foreign patents, foreign search reports and published foreign patent applications), and 3\% of nonpatent prior art was cited by examiners. Bhaven N. Sampat, Analysis of Examiner Inserted Citations, Patent Information User Group (PIUG) Discussion List Archives, Mar. 7, 2003, available at http://www.questel. orbit.com/piug/current/0173.html (last visited Nov. 11, 2003).

168. As with other variables we measure, the relationship may or may not hold in the case of any particular patent. We speak of statistical relationships in large groups of patents. To ascertain whether references in a given patent strengthen it, one must be knowledgeable in the technical area and study the difference between the patent's claims and the prior art.

169. Dietmar Harhoff et al., Citations, Family Size, Opposition and the Value of Patent Rights (Working Paper 1999), available at http://emlab.berkeley.edu/users/bhhall/ harhoffetal99.pdf (last visited Nov. 11, 2003).

170. Lanjouw \& Schankerman, Stylized Facts of Patent Litigation, supra note 38, 15; Lanjouw \& Schankerman, Characteristics of Patent Litigation, supra note $34,138$.

There is stronger empirical evidence that the number of forward citations is a predictor of patent value. The term "forward citations" has been used by some economists to describe what most people would call "citations received," that is, the number of citations received by a patent in later issued patents. The proposition that patents receiving much more attention as prior art in later patents have more value has both instinctive attraction and strong empirical support. See generally BRONWYN HALL ET AL., MARKET VAlUE AND PATENT Citations: A FiRST LOOK, (Nat'l Bureau of Econ. Research, Working Paper No. 7741, 2000), available at http://www.nber.org/papers/w7741 (last visited Nov. 11, 2003); Dietmar Harhoff et al., Citation Frequency and the Value of Patented Inventions, 81 REV. OF ECON. \& STAT. 511 (1999); Trajtenberg, supra note 29. We did not measure forward citations because the patents in our data sets were so recent, those in one set issuing from mid-1996 to mid-1998 and those in the other set almost all issuing 
patents, however, and not references to nonpatent prior art, a somewhat glaring omission given the importance of nonpatent prior art in many fields. ${ }^{171}$ Removing some of the ambiguity in previous research, a recent study in which one of the authors participated found that patents involved in patent infringement litigation have significantly more prior art references of all kinds than the general population of patents. ${ }^{172}$ Litigated patents, in turn, have been shown to be more valuable than patents in general. ${ }^{173}$ In addition to the existence of empirical support for the existence of a relationship between the number of prior art references and patent value, as well as the intuitive appeal of an argument that such a relationship exists, we heavily emphasize prior art in the present study because prior art has served as a centerpiece of business method patent criticism.

\section{Internet Business Method Patents Compared With the Average Patent}

The following table shows the results of our comparison of patent, nonpatent, and total references in Internet business method patents and general patents, including the untransformed means. ${ }^{174}$

during 1998-99. Our study design and data collection began early in 2000 and ended before the middle of 2001. Collection of data on forward citations should be done when sufficient time has passed for these data to be meaningful for the entire data set. The NBER database compiled by Bronwyn Hall and her colleagues, supra, reports citations received only through December 31, 1999 for patents issued between 1963 and 1999.

171. The probable reason that prior studies may have failed to take account of nonpatent prior art is that extracting these data is extremely tedious and time-consuming.

172. Allison et al., Valuable Patents, supra note 30 (manuscript at 25-26 \& tbl.1). Indeed, using the term "significant" is an understatement. The study found that litigated patents had more prior art references by a margin that far exceeded the typical .05 level for statistical significance. Id.

173. See generally Lanjouw \& Schankerman, Enforcing Intellectual PropERTY RIGHTS, supra note 33; Lanjouw \& Lerner, Literature Survey on I.P. Rights Enforcement, supra note 33 .

174. Although we used log-transformed means to smooth out extreme variations in the distributions for most statistical tests in this study, we report untransformed means in the summary tables for ease of understanding. 
Table 1: Prior Art References: Internet Business Method Patents

Compared with General Patents

\begin{tabular}{|c|c|c|c|c|c|c|c|}
\hline & $\mathbf{N}$ & Variable & Mean & Median & Std. Dev. & Min. & Max. \\
\hline \multirow[t]{3}{*}{$\begin{array}{l}\text { Internet } \\
\text { Business } \\
\text { Method } \\
\text { Patents }\end{array}$} & 1093 & Patent Refs & 14.90 & 10 & 23.76 & 0 & 314 \\
\hline & & NonPat Refs & 10 & 2 & 38.56 & 0 & 391 \\
\hline & & Total Refs & 24.90 & 13 & 53.15 & 0 & 457 \\
\hline \multirow[t]{3}{*}{$\begin{array}{l}\text { General } \\
\text { Patents }\end{array}$} & 1000 & Patent Refs & 12.79 & 9 & 14.13 & 0 & 154 \\
\hline & & NonPat Refs & 2.37 & 0 & 6.56 & 0 & 68 \\
\hline & & Total Refs & 15.16 & 10 & 16.29 & 0 & 163 \\
\hline
\end{tabular}

Statistical comparison of these means showed that Internet business method patents had significantly more patent references, nonpatent references, and total references than general patents. ${ }^{175}$ The null hypothesis of "no difference" was rejected with a confidence level of over $99.99 \%$ in the case of total references and nonpatent references $(p<$ $0.0001)$, and over $97 \%$ in the case of patent references $(\mathrm{p}<0.0235)$.

175. Based on the descriptive analysis of the distributions of the three types of prior art references, $\log$ transformations were useful for normalizing the number of patent references and total references, but not for nonpatent references because it was not necessary. Although our standard for statistical significance is $95 \%$ or greater, i.e., a $p$-value of 0.05 or less, p-values were often far lower than 0.05 , thus signifying very high levels of significance. Reported p-values are always two-tailed. These and almost all other comparisons in this study used independent-groups t-tests with means that had been adjusted by performing logarithmic transformations to adjust for extreme values in the data distributions. The data distributions for all of our variables, except the number of inventors, were substantially influenced by extreme upper outliers, i.e., very long right-hand tails in the distributions. A simple comparison of untransformed means would thus have not provided reliable results because those means were not good indicators of central tendencies. As an additional check on our results, we employed Wilcoxon nonparametric tests in almost all instances. 
The distribution of prior art references in a large group of patents is bimodal, with many applicants citing either very few or a large number. ${ }^{176}$ Bimodality is even more pronounced in a distribution of nonpatent references, where one often finds none at all, because it is more timeconsuming and thus more expensive to search for nonpatent prior art than it is to search for relevant prior patents. Overall, this phenomenon is easily explainable by the fact that patent law does not require applicants to conduct a prior art search at all, but PTO Rule 56 does require applicants to cite all material prior art of which they are aware. ${ }^{177} \mathrm{~A}$ violation of this duty of candor regarding known prior art can result in a judicial finding that the patentee committed "inequitable conduct," " which may render an otherwise valid and infringed patent unenforceable. Indeed, such a finding can produce consequences substantially more severe than an invalidity finding. Both infringement and validity are determined on a claim-byclaim basis, leading to situations in which certain claims in a patent may be invalid while others remain valid. A patentee's inequitable conduct, however, renders the entire patent unenforceable, ${ }^{179}$ as well as entitling the accused infringer to successfully raise inequitable conduct as a defense to attorney fees. ${ }^{180}$ Furthermore, related patents springing from the same original application may also become unenforceable. ${ }^{181}$ The absence of a duty to search the prior art and the cost of doing so, coupled with potentially severe penalties for not citing what has been found, tends to cause many applicants to take extreme approaches, conducting either minimal searches or painstakingly thorough ones. ${ }^{182}$

176. As explained at supra note 167 , most prior art references are almost certainly cited by applicants rather than examiners.

177. 37 C.F.R. $\S 1.56$ (2002).

178. See, e.g., Kingsdown Med. Consultants, Ltd. v. Hollister Inc., 863 F.2d 867, 872 (Fed. Cir. 1988) (en banc) (discussing inequitable conduct defense).

179. See, e.g., J.P. Stevens \& Co. v. Lex Tex, Ltd., 747 F.2d 1553, 1561 (Fed. Cir. 1984).

180. See, e.g., Gentry Gallery, Inc. v. Berkline Corp., 134 F.3d 1473, 1480 (Fed. Cir. 1998).

181. Consol. Aluminum Corp. v. Foseco Int'l, Ltd., 910 F.2d 804, 809-10 (Fed. Cir. 1990) (finding six related patents unenforceable because of inequitable conduct in intentionally failing to adequately disclose the best mode for one of them). See generally Scott D. Anderson, Comment, Inequitable Conduct: Persistent Problems and Recommended Solutions, 82 MARQ. L. REV. 845 (1999) (discussing the various consequences of inequitable conduct).

182. We confirmed the existence of bimodality by examining the distributions of each outcome including references (patent, nonpatent, and total) using histograms and Quantile-Quantile (“QQ") plots. 
In addition to bimodality, the distribution of the numbers of prior art references is also characterized by extreme upper outliers. ${ }^{183}$ Some patent applicants cite a large amount of prior art. These distribution characteristics existed in both data sets. In addition to performing logarithmic transformations of the means to adjust for the skewed distributions before comparing them, ${ }^{184}$ we compared the median number of prior art references in the two data sets to further ensure that patents with extremely large numbers of references did not over-influence our finding that Internet business method patents cited significantly more prior art than patents in general. Nonparametric tests of medians confirmed our finding that Internet business method patents contain significantly more patent, nonpatent and total prior art references than patents overall.

One may gain further insight into the data by comparing the proportion of patents in the Internet and general patent data sets that cited no prior art at all. We were unable to conduct statistical comparisons between the number of patents in each data set containing zero references to prior patents, or between the number of patents in each data set containing zero total prior art references, because the number of such patents was too small for statistical testing. ${ }^{185}$ Far more telling, however, was a comparison of the proportion of patents in each set having no references to nonpatent prior art, that is, to articles in periodicals and other types of documents. The data revealed that $62.1 \%(621$ of 1,000$)$ of general patents cited no nonpatent prior art, whereas only $32.2 \%(352$ of 1,093$)$ of the Internet business method patents cited none, a difference that is not just significant but truly striking. In sum, using various methods, we found that Internet business method patents cited substantially more prior art than did the average patent during the late 1990s.

183. Extreme values on the right side of the distribution characterized all of the other variables we studied, except for the number of inventors. The distributions for other variables were not characterized by bimodality, however.

184. The number of references was transformed using natural logs. Based on visual inspection of the log-transformed distribution, this appeared very effective in reducing the influence of the small subset of patents with exceptionally large numbers of references. The independent groups $t$-tests using the log-transformed values provides a valid test of the central tendencies (e.g., mean) of each distribution after minimizing the effect of upper outliers.

185. In the general patent data set, 14 out of 1,000 patents $(1.4 \%)$ cited no patent prior art. In the Internet business method data set, 23 out of 1,093 patents $(2.1 \%)$ cited no patent prior art. In the general patent data set, 2 out of 1,000 patents $(0.2 \%)$ cited no prior art of any kind. In the Internet business method data set, 3 out of $1,093(0.3 \%)$ cited no prior art of any kind. 


\section{Internet Business Method Patents Compared With Patents in Individual Technology Areas}

We also compared the number of prior art references in Internet business method patents with the number in each of the fourteen areas of technology identified in the general patent data set. Such comparisons are important because patenting strategies and practices probably show some variations among different fields. ${ }^{186}$ Furthermore, previous economics research exploring possible relationships between certain patent characteristics and patent value did so within technology areas or industries. $^{187}$

The results of comparing the log-transformed mean number of patent, nonpatent, and total prior art references in Internet business method patents with those in each of the fourteen technology areas follows in Table 2. ${ }^{188}$ In the table, "more," "fewer," and "equal" refer to situations in

186. As means for protecting investments in research and development, the relative importance of patents, in contrast with other means such as secrecy and lead-time, varies among industries and technology fields. See generally COHEN ET AL., WHY U.S. MANUFACTURING FIRMS PATENT, supra note 51; Bronwyn H. Hall \& Rosemarie Ham Ziedonis, The Patent Paradox Revisited: An Empirical Study of Patenting in the U.S. Semiconductor Industry, 1979-1995, 32 RAND J. ECON. 101 (2001) (exploring patenting strategies in the semiconductor industry); Levin et al., supra note 51; Edwin Mansfield, Patents and Innovation: An Empirical Study, 32 MGMT. SCI. 173 (1986); Ariel Pakes \& Margaret Simpson, Patent Renewal Data, in 1989 BroOKINGS PAPERS ON ECON. ACTIVITYMicroeconomiCs 331 (Martin Neil Baily \& Clifford Winston, eds., 1989).

187. See generally LANJOUW \& SCHANKERMAN, STYLIZED FACTS Of PATENT LitIGATION, supra note 38 (finding that litigated patents are more valuable than unlitigated ones and that the incidence of patent litigation varies significantly among technology fields); Jean O. Lanjouw, Patent Protection in the Shadow of Infringement: Simulation Estimations of Patent Value, 65 REV. ECON. STUD. 671 (1998) (correlating incidence of decisions to pay patent renewal fees in Germany with simulated litigation propensity within each of four industries); Lanjouw \& Schankerman, Characteristics of Patent Litigation, supra note 34 (comparing total number of claims in litigated and unlitigated patents within same 4-digit IPC); Lerner, The Importance of Patent Scope, supra note 30 (correlating the number of IPCs into which patents were placed with value of patent-owning start-up firms within biotechnology industry); Schankerman \& Pakes, supra note 29 (identifying incidence of patent renewal decisions in the United Kingdom, France, and Germany within particular industries as an indicator of patent value); Trajtenberg, supra note 29 (finding citations received by a patent in later patents to be an indicator of patent value within the field of computer tomography scanners).

188. There are two major differences between comparing Internet business method patents with patents in general and comparing them with patents from individual technology areas. One difference is that the number of patents in each area is necessarily smaller than the whole, meaning that any variance must be greater to demonstrate statistical significance. The other difference is that the distribution of values in a particular technology area sometimes may be even more skewed than the distribution in general patents as a 
which Internet business method patents have significantly more, significantly fewer, or an insignificantly different number of references than patents in the particular technology area, respectively. To illustrate, Internet business method patents had significantly more patent references than acoustics patents, significantly fewer patent references than medical device patents, and an insignificantly different number of patent references than automotive-related patents.

Table 2: Prior Art References:

Internet Business Method Patents Compared with Patents in Each Technology Area

\begin{tabular}{|c|c|c|c|c|c|}
\hline & \multicolumn{2}{|l|}{ Pat Refs } & \multicolumn{2}{|l|}{ NonPat Refs } & Total Refs \\
\hline $\begin{array}{l}\text { Internet Business } \\
\text { Methods Compared } \\
\text { With }\end{array}$ & i & & के & 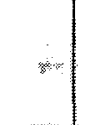 & $\beta$ \\
\hline Acoustics & & More & & More & More \\
\hline Automotive-Related & Equal & & & More & More \\
\hline Biotechnology & \multicolumn{4}{|c|}{ More Fewer } & Equal \\
\hline Chemistry & Equal & & & More & More \\
\hline Communications-Related & Equal & & & More & More \\
\hline Computer-Related & & More & & More & More \\
\hline Electronics & & More & & More & More \\
\hline Energy-Related & Equal & & & More & Equal \\
\hline Mechanics & Equal & & & More & More \\
\hline Medical Devices & Fewer & & & More & Equal \\
\hline Optics & & More & & More & More \\
\hline Pharmaceutical & & More & Equal & & More \\
\hline Semiconductors & & More & & More & More \\
\hline Software & & More & & More & More \\
\hline
\end{tabular}

whole. Thus, the use of log-transformed means for comparison and the use of nonparametric tests is likely to be even more important because unadjusted means in some technology areas may be less reliable indicators of central tendencies than are the unadjusted means in the entire set of general patents. 
It is apparent that Internet business method patents had significantly more patent references than patents in eight technology areas, an insignificantly different number than in five areas, and significantly fewer in only one. They had more nonpatent references than patents in twelve technology areas, an insignificantly different number than in one area, and fewer in one. The comparison of total references yielded similar results, with more references in eleven technology areas and an insignificantly different number in three.

These findings do not support the conventional wisdom that Internet business method patents inadequately cite the prior art, when compared either with the average patent or with patents in particular technology areas. These findings appear, in fact, to support the contrary position that Internet business method patents cite more prior art.

\section{B. Types of Nonpatent Prior Art References}

Because the universe of potential sources for nonpatent prior art is so expansive, any evidence that applicants may have simply "dumped" large numbers of inferior references into Internet business method patent applications would be more likely to show up in references to sources other than prior patents. This is especially true in view of the fact that the margin by which Internet business method patents cite more nonpatent prior art references than general patents far exceeds the margin by which Internet business method patents cite more patent prior art references than general patents. Thus far, all of our measures have been purely quantitative. Although it would be desirable to precisely assess and compare the relevance, objectivity, and reliability of information in all of the prior art in our two data sets, the reasons why this is impossible are too obvious to require explanation.

There cannot be even a rough assessment of informational relevance, objectivity, and reliability in the case of references to prior patents, because there is no feasible way to segregate these references into different categories on the basis of their probable informational quality. In the case of nonpatent prior art, however, it is possible to make at least a rough appraisal of quality, because these types of prior art references can be placed into categories based on their likely informational objectivity and reliability (but not relevance). ${ }^{189}$ Such an appraisal is necessarily subjective and thus must be interpreted with caution, but it can nonetheless be worthwhile.

189. To assess the relevance of nonpatent prior art references, we would have to employ an expert in the particular area of technology (or technologies) involved in each patent. 
After a trial run in which we closely studied the types of nonpatent prior art in more than 100 Internet business method patents and an equal number of general patents, we classified nonpatent references based on the nature of the sources we found in those patents. After deciding on the categories and their definitions, we categorized the nonpatent prior art in a random twenty percent sample of Internet business method patents (219 out of 1,093$)$ and a random twenty percent sample of general patents $(200$ out of 1,000). Following are explanations of the eight categories of nonpatent prior art we identified and the tabular results of our comparisons. ${ }^{190}$

1) Acad/Trade: Academic or trade books, book chapters, articles, and proceedings papers. This category represents publications of a type for which there is an independent intermediating influence such as one or more editors or referees to increase the probability of accuracy and objectivity. We did not differentiate between academic and trade publications, because there is much overlap, collaboration and cross-fertilization between academic and industry research efforts. We also often found them difficult to distinguish, and decided to focus on whether a publication is likely to have been independently screened for accuracy and objectivity.

2) Comp/Indus: Company/industry publications, press releases, web sites, and advertisements. This category includes publications that were produced by individual companies or industry groups and published with no independent intermediating influence to increase the probability of accuracy and objectivity. Publications in this category are, therefore, likely to be less reliable on average than those in the first category. It does not include software and software documentation, however, because we believed the latter to be sufficiently distinct from and probably more reliable than other types of publications from companies or industry groups.

3) Univ Pubs: Publications from universities or consortia of universities, such as those from university research labs, particular departments (such as computer science), and individual faculty, as well as theses and dissertations. Although originating with

190. When we were uncertain about how to categorize a given source or when it was of unknown origin, we did a considerable amount of research on the Internet in addition to speaking with knowledgeable colleagues to better understand what particular sources were and who was responsible for them. There naturally remained a small number that we could not characterize. 
universities, these are not peer-reviewed publications. They nevertheless are likely to be of relatively high average quality compared with many other sources.

4) Gov Doc: Government documents/publications and websites, except for published patent applications and search reports. This category includes U.S. and foreign government publications, plus those of international government organizations such as the WIPO.

5) SW: Software programs and software documentation. These are separated from other company or industry sponsored publications because of their functional nature and obvious need for a high degree of accuracy and reliability.

6) PP: Popular press. Includes not only newspapers, magazines, and other publications of general interest, but also news publications aimed at general business and legal audiences.

7) Pat Apps/Search Rpts: Published patent applications and patent office search reports, such as Patent Cooperation Treaty ("PCT") and European Patent Office ("EPO") search reports.

8) Oth: Other publications. Includes varied items such as individual web pages, but most references placed in this category are those in which we found insufficient information to determine the exact identity of the item, even after we conducted a web search of key names and terms in the incomplete reference. One example is a reference to a partial title of an item, followed by "found on the web on $\mathrm{x}$ date." 


\section{Internet Business Method Patents Compared With the Average Patent}

In Table 3, we present descriptive statistics based on our analysis of the different types of nonpatent prior art references in each data set. ${ }^{\text {.9 }}$

191. In Tables 3 and 4 we report only descriptive statistics. We did not formally test for statistical significance in our comparison of nonpatent prior art categories, for several reasons. First, Table 3 reflects the fact that taking a $20 \%$ patent sample in each data set and dividing the nonpatent prior art into 8 categories produced numbers too small for statistical testing, except in the case of Acad/Trad and Comp/Ind nonpatent prior art references. We possibly could test the difference between the percentage of Acad/Trade references in the two data sets, and the difference between the percentage of Comp/Ind references in the two data sets, but the results would be suspect. The reason is that, when formal statistical testing is done, each observation should be independent of other observations.

When, for example, we compared the mean number of claims in the two sets of patents, each observation was a number of claims in a specific patent. This patent was independent of other patents, one observation not influencing another observation. Or, when we compared the mean number of patent and nonpatent prior art references in the two sets of patents, each observation was a number of references in a specific patent. In the set of general patents, the assumption of independence of observations can be made with exceptionally high confidence because, when taking a random sample of one thousand patents out of a population of approximately 235,000 patents issued during a twoyear period from mid-1996 to mid-1998, the chance that any two of those patents were, for example, drafted by the same attorney for the same client and perhaps deriving from the same original patent application is close to zero. The assumption of independence cannot be made with the same exceptionally high level of confidence in the case of our data set of 1,093 Internet business method patents, because we sought to include the entire population of Internet business method patents issued through the end of 1999. In this data set, there is a somewhat greater probability that, in a small number of instances, two of these patents may have originated from the same original application drafted by the same attorney for the same client. Thus, there is a chance that, in a few instances, the number of claims or references in two patents may not be totally independent of one another. After carefully examining all of the Internet business method patents to check for this possibility, however, we found that this was a rare occurrence, so the assumption of observation independence is still very strong, and our results untainted, despite the somewhat greater probability of some interdependence.

With this understanding of the importance of observation independence to valid statistical testing, one can see that the validity of such testing would be very questionable when the unit of study is the qualitative type of nonpatent prior art reference in a patent. Here, the unit of study is not a number of something in a patent, as compared with the number of something in another distinct patent. Instead, the unit of study is the qualitative and subjectively determined category of nonpatent prior art that has been chosen by the inventor and patent attorney for citation. There often will be hundreds of potential sources for nonpatent prior art, and no one can check them all. A perfect prior art search is impossible, and a hit-or-miss prior art search is far more typical. Within a given patent, the types of nonpatent prior art references cited by the applicant's patent attorney are almost certainly not independent of one another. The attorney's decisions, presumably 
Table 3: Types of Nonpatent Prior Art References: Internet Business Method Patents Compared with General Patents

\begin{tabular}{|c|c|c|c|c|c|c|c|c|c|}
\hline & $\begin{array}{l}\text { Acad/ } \\
\text { Trade }\end{array}$ & $\begin{array}{l}\text { Comp/ } \\
\text { Indus }\end{array}$ & $\begin{array}{l}\text { Univ } \\
\text { Pubs }\end{array}$ & $\begin{array}{l}\text { Gov } \\
\text { Docs }\end{array}$ & SW & PP & $\begin{array}{c}\text { Pat } \\
\text { Apps/ } \\
\text { Search } \\
\text { Rpts }\end{array}$ & Oth & Total \\
\hline $\begin{array}{l}\text { Internet } \\
\text { Business } \\
\text { Method } \\
\text { Patents }\end{array}$ & & & & & & & & & \\
\hline Number & 1084 & 308 & 29 & 34 & 106 & 206 & 22 & 30 & 1819 \\
\hline Percentage & $59.6 \%$ & $16.9 \%$ & $1.6 \%$ & $1.9 \%$ & $5.8 \%$ & $11.3 \%$ & $1.2 \%$ & $1.6 \%$ & $100 \%$ \\
\hline Mean & 4.95 & 1.41 & 0.13 & 0.16 & 0.48 & 0.94 & 0.10 & 0.14 & 8.31 \\
\hline Median & 1 & 0 & 0 & 0 & 0 & 0 & 0 & 0 & 3 \\
\hline Std. Dev. & 18.88 & 4.21 & 0.47 & 0.73 & 2.09 & 8.56 & 0.50 & 0.56 & 30.72 \\
\hline \multicolumn{10}{|l|}{$\begin{array}{l}\text { General } \\
\text { Patents }\end{array}$} \\
\hline Number & 373 & 109 & 5 & 6 & 0 & 5 & 22 & 12 & 532 \\
\hline Percentage & $70.1 \%$ & $20.5 \%$ & $1 \%$ & $1 \%$ & $0 \%$ & $1 \%$ & $4.1 \%$ & $2.3 \%$ & $100 \%$ \\
\hline Mean & 1.86 & 0.55 & 0.03 & 0.03 & 0.00 & 0.03 & 0.11 & 0.06 & 2.66 \\
\hline Median & 0 & 0 & 0 & 0 & 0 & 0 & 0 & 0 & 0 \\
\hline Std. Dev. & 5.61 & 3.30 & 0.23 & 0.24 & 0.00 & 0.19 & 0.56 & 0.65 & 7.74 \\
\hline
\end{tabular}

As expected from the much larger number of overall nonpatent prior art references in Internet business method patents, these patents also have far more of each category of nonpatent reference except for published patent applications and search reports. ${ }^{192}$ A comparison of the percentages

aided by the inventor, about which items of nonpatent prior art to cite in the patent are almost certainly influenced by some common factors, such as which academic or trade journals the inventor was in the habit of checking, perhaps because of more convenient availability. Although patent examiners rarely add citations to nonpatent sources of prior art, the same lack of independence will characterize an examiner's selection of any such references.

192. The PTO did not begin publishing patent applications (eighteen months after filing) until March 2001. Our data thus could not include references to U.S. patent applications in either of our data sets. To our knowledge, only Japan recognized business methods as patentable subject matter at the end of 1999 (the end point of our Internet business method data). The source of search reports is typically Europe (where business 
of cited prior art in each category reveals nothing particularly odd. The fact that Internet business method patents cite proportionately more references to the popular press $(11.3 \%$ of total nonpatent prior art references) than do general patents $(1.0 \%)$ is arguably a detraction from the overall quality of this prior art in the former. The negative connotation of "popular press" as a source of prior art is ameliorated by two factors, however. First, the newsworthiness of business method patents during the relevant years suggests that at least some references to other developments in the field would show up in the popular press. Second, our definition of the term popular press includes some sources that are likely to be more accurate and reliable than magazines and newspapers for general readership. ${ }^{193}$

Aggregating the different types of nonpatent prior art into two broad classes based on the probable quality of the prior art reveals even more about the general quality of prior art citations in Internet business method patents. Those that, on average, are likely to be the most objective and reliable-Acad/Trade, Univ Pubs, Gov Docs, SW, and Pat Apps/Search Rpts - can be combined into a "higher quality" category. Those that, on average, are likely to be the least objective and reliable-Comp/Indus, PP, and Oth-can be combined into a "lower quality" category. The result of the aggregation is that $70.2 \%$ of the nonpatent prior art in Internet business method patents is in the higher quality category, and $29.8 \%$ in the lower quality category. On the other hand, $76.1 \%$ of the nonpatent prior art in the average patent is in the higher quality category, and $23.9 \%$ in the lower quality category. An argument thus can be made, albeit a weak one, that nonpatent prior art in Internet business method patents was of lower quality than that cited in the average patent.

\section{Internet Business Method Patents Compared With Patents in Individual Technology Areas}

The weakness of the argument that general patents cite higher quality nonpatent prior art than Internet business method patents was prominent when we compared Internet business method patents with those in each of the fourteen individual technology areas within the set of general patents. Before proceeding, we note that triple division in the general patent data set-taking a twenty percent sample, dividing into eight categories of nonpatent prior art, and further dividing into fourteen technology areas-

method patents are not recognized) or Japan, so it is surprising that our Internet business method data set included any references at all in this category.

193. We included not only newspapers, magazines, and similar publications for the general population, but also news publications targeted at business and legal audiences. 
produced numbers too small in some instances for meaningful comparison between Internet business method patents and patents in individual technology areas. ${ }^{194}$ In several cases, however, the number of patents in a sample of a particular technology area and the number of nonpatent prior art references in some categories were adequate for rough comparison. Moreover, comparison becomes more meaningful if we aggregate the types of nonpatent prior art into "higher-quality" and "lower-quality" categories as we did when comparing Internet business method patents with the average patent.

In Table 4, we denote the combined group of higher quality reference types as "Higher Quality P.A.," and denote the combined group of lower quality reference types as "Lower Quality P.A." Beside each technology area, we note the number of patents within that area in the twenty percent sample.

Table 4: Types of Nonpatent Prior Art References:

Internet Business Method Patents Compared with Patents in Each Technology Area

\begin{tabular}{|l|c|c|}
\hline & $\begin{array}{c}\text { Higher } \\
\text { Quality } \\
\text { P.A. }\end{array}$ & $\begin{array}{c}\text { Lower } \\
\text { Quality } \\
\text { P.A. }\end{array}$ \\
\hline Internet Business Methods & $70.2 \%$ & $29.8 \%$ \\
\hline General Patents & $76.1 \%$ & $23.9 \%$ \\
\hline & & \\
\hline Chemistry (59) & $96.4 \%$ & $3.6 \%$ \\
\hline Computer-Related (30) & $61.7 \%$ & $38.3 \%$ \\
\hline Electronics (30) & $24.5 \%$ & $75.5 \%$ \\
\hline Mechanics (82) & $27.3 \%$ & $72.7 \%$ \\
\hline Medical Devices (14) & $60.3 \%$ & $39.7 \%$ \\
\hline Optics (23) & $74.0 \%$ & $26.0 \%$ \\
\hline Pharmaceutical (22) & $97.4 \%$ & $2.6 \%$ \\
\hline Semiconductors (16) & $86.6 \%$ & $13.4 \%$ \\
\hline
\end{tabular}

194. The number of patents and/or the number of references in the $20 \%$ sample was too small for any kind of comparison in the acoustics (four patents), automotive-related (fourteen patents but very few nonpatent references), biotechnology (four patents), communications-related (two patents), energy-related (four patents), and software (four patents) technology areas. 
The data reported in Table 4 suggest that only patents in the areas of chemistry, pharmaceuticals, and semiconductors cite nonpatent prior art of higher quality than Internet business method patents. The observation of probable higher quality is most meaningful in the case of chemistry patents because the number of such patents in the sample of that category is much larger (fifty-nine) than the number of patents in the pharmaceutical (twenty-two) and semiconductor (sixteen) areas. In these three areas, however, chemistry and semiconductor patents contain a substantially lower quantity of nonpatent prior art references than Internet business method patents, while pharmaceutical patents do not cite a significantly different quantity of nonpatent prior art than Internet business method patents. These findings do, however, support an argument that pharmaceutical patents (equal quantity, greater quality) and chemistry patents (lower quantity, greater quality, and a relatively large number of patents in the sample) cited better nonpatent prior art than Internet business method patents.

Overall, we find little basis for concluding that the nonpatent prior art cited in Internet business method patents was substantially inferior to that cited in most other kinds of patents. One should, however, take any findings from our data on the different types of nonpatent prior art with caution, because these particular comparisons are much less precise than our other findings.

\section{Total Patent Claims}

Claims delineate the boundaries of the property right granted to the patentee. Even without empirical support, one can logically argue that a larger number of claims may be an indicator of patent value. When a patent owner sues for infringement, she does not sue for infringement "of the patent." Instead, she sues for infringement of one or more identified claims in the patent. Each patent has at least one independent claim, and usually has several. ${ }^{195}$ The invention is defined in its broadest sense by the independent claims. Although $\S 121$ of the Patent Act calls for only one distinct invention per patent, ${ }^{196}$ a patent may contain two or more independent claims because (a) it is possible to claim some inventions using different formats, ${ }^{197}$ (b) a patent may claim a process and a product

195. For example, the average number of independent claims in the general patent data set was 2.75 .

196. 35 U.S.C. $\S 121$ (2000).

197. Software patents are an example. A software invention may be claimed as a device (or machine) itself, a device incorporating software, a system, a process, or any combination of the above. See, e.g., AT\&T Corp. v. Excel Communications, Inc., 172 
made from that process, (c) a patent may claim a product and a process for using the product, or (d) a patent may claim closely related versions of the invention. ${ }^{198}$

Typically, a series of successively narrower dependent claims follows each independent claim. Dependent claims are narrower because they contain further restrictions or limitations on the scope of the independent claim from which they flow. ${ }^{199}$ Because of the one-invention-per-patent rule, the average number of independent claims does not vary across technology areas or across time nearly as much as dependent claims. Research has shown, for instance, that a dramatic increase in the average number of total claims over a recent twenty-year period is almost entirely attributable to an increase in dependent claims. ${ }^{200}$

Because independent claims are broader, any given independent claim should encompass more potentially infringing behavior or products made by others. This does not mean, however, that the total number of claims is not an indicator of patent value. Broader claims run a greater risk of encompassing uncited prior art and being held invalid in court than narrower ones, which could still leave the patent owner with quite a few narrower claims that are valid and infringed. Thus, the larger the number of total claims, the more opportunities there are for the activities of others to infringe. This fact of more claims thus should translate into greater value for the patent owner.

F.3d 1352 (Fed. Cir. 1999) (describing a process); In re Alappat, 33 F.3d 1526 (Fed. Cir. 1994) (en banc) (describing a machine). The "means-plus-function" claim drafting format, which is allowed by 35 U.S.C. $\$ 112$, \6 (2000), is also used in some instances and has been employed frequently in software patents. However, even identifying, much less interpreting, claims of this type is fraught with much uncertainty and the topic is far beyond the scope of the present Article. See generally Fidel D. Nwamu, Does Your Claim Conform To Means-Plus-Function Format Under Section 112, Paragraph Six?: O.I. Corp. v. Tekmar Co., 6 J. INTELL. PROP. L. 189 (1999).

198. For example, U.S. Patent No. 5,566,752 (issued Oct. 22, 1996) ("High heat density transfer device"), includes an independent claim on a diamond substrate semiconductor chip device (followed by a series of successively narrower dependent claims), and another independent claim on a module comprised of several of these devices working together (again followed by a series of dependent claims).

199. See 35 U.S.C. $\S 112$, $\uparrow$ 2-5. Dependent claims may depend on an independent claim or on another dependent claim.

200. Allison \& Lemley, Growing Complexity, supra note 40, at 103-04. The average number of independent claims in the general patent data set was 2.75 and the average number of dependent claims was 12.12 . In contrast, the average numbers of independent and dependent claims in an identical data set from twenty years earlier were 2.09 and 7.85 , respectively. 
We compare only total claims in this study, because previous research finding a positive relationship between the number of claims and value used total claims as the metric and did not differentiate between independent and dependent claims. ${ }^{201}$ Furthermore, previous research in economics has found a significant correlation between the total number of claims and the probability that the patent will be the subject of litigation. $^{202}$ A new study comprehensively comparing litigated and unlitigated patents finds that litigated patents have far more claims than unlitigated ones. ${ }^{203}$ That study also finds a clear association between other measures of patent value and the incidence of infringement litigation. ${ }^{204}$ Thus, the number of claims may be indicative of patent value.

The litigation-value relationship also makes intuitive sense. Patent litigation is one of the most, if not the most, expensive forms of litigation, and a rational patent owner would be expected to pursue litigation only when the perceived value of the patent is high. ${ }^{205}$ We therefore believe

201. See, e.g., Lanjouw \& Schankerman, Characteristics of Patent Litigation, supra note 34 , at 141 .

202. Lanjouw \& SchankeRman, Stylized Facts of Patent Litigation, supra note 38, at 18; Lanjouw \& Schankerman, Characteristics of Patent Litigation, supra note 34 , at 141 . This research compared litigated and unlitigated patents only within the same areas of technology. The research by Lanjouw and Schankerman used the 4-digit International Patent Classification ('IPC') to define areas of technology, and made comparisons between litigated and unlitigated patents within particular four-digit IPCs.

203. Allison et al., Valuable Patents, supra note 30 (manuscript at 22-23).

204. Id. One other factor that may predict a greater average propensity toward litigation is the degree of information asymmetry, or divergence in the parties' expectations about the likely outcome. The magnitude of information asymmetry is likely to be greater in the case of emerging technologies and technologies in which patent protection is relatively new. LANJOUW \& SCHANKERMAN, STYLIZED FACTS OF PATENT LiTIGATION, supra note 38 , at 4 . To the extent that this is true, one should expect a higher probability of litigation involving Internet business method patents independent of other variables. Tracking actual litigation rates for the patents in our current data set was not within the envisioned scope of this study and, indeed could not have been because of their recencymost were issued during 1998-99.

205. See AIPLA, 2003 ECONOMIC SURVEY, supra note 33, for recent estimates of patent infringement litigation costs. Patent litigation may be initiated by either the patent owner or a challenger (accused infringer). When the owner sues for infringement, the defendant typically counterclaims for a declaratory judgment of non-infringement and invalidity. When patent litigation is initiated by a challenger, the challenger seeks a declaratory judgment of non-infringement and invalidity (the same thing sought by the defendant in a patent infringement suit brought by the patent owner), and the patent owner typically counterclaims for infringement. The challenger has standing to act as a plaintiff to seek a declaratory judgment only when it has been threatened with an infringement action, however, so the value-litigation relationship should apply equally to litigation initiated by a challenger. 
that the potential private value of innovations perceived by patent applicants and owners will frequently produce higher actual value. More claims also cost the applicant more money. PTO fees increase with the number of claims, and attorney fees increase with the additional time necessary for drafting and prosecuting more claims. ${ }^{206}$ Choosing to devote these additional resources is within the control of the applicant.

The influence of patent applicants and owners on indicators of patent value also explains the commonly existing correlations among patent attributes that are used to measure patent quality and value. For example, this is not the only study to find that a set of patents having more average claims usually has more average references and more of certain other indicators. ${ }^{207}$ Correlation does not mean causation, of course, and there is no reason to believe that the existence of more references actually causes patents to have more claims, or vice-versa. Correlation, or "interaction," among variables cannot be ignored, however. Suppose that, in one data set, variables $\mathrm{X}, \mathrm{Y}$, and $\mathrm{Z}$ are each found to be significantly different from counterpart variables in a comparison data set. If there are correlations among two or more of these $\mathrm{X}, \mathrm{Y}$, and $\mathrm{Z}$ variables in one data set, such interactions may diminish or even destroy the earlier finding of significance. Multivariate statistical tests of several types can be used to ascertain not only the existence of these interactions among variables within the same data set, but also whether findings of significance remain valid after accounting for the correlations. In our study, such tests revealed that the significance of differences between the number of references in the two data sets, and the significance of differences between the number of claims in the two data sets remained after accounting for the correlations between these two variables within each data set.

Federal courts apply a two-step analysis to ascertain whether they have jurisdiction over a patent challenger's declaratory judgment action for non-infringement or invalidity: "(1) an explicit threat or other action by the patentee, which creates a reasonable apprehension on the part of the declaratory plaintiff that it will face an infringement suit, and (2) present activity which could constitute infringement or concrete steps taken with the intent to conduct such activity." See, e.g., Cygnus Therapeutic Sys. v. ALZA Corp., 92 F.3d 1153, 1159 (Fed. Cir. 1996), overruled in part on other grounds by Nobelpharma AB v. Implant Innovations, 141 F.3d 1059, 1068 (Fed. Cir. 1998); see also 28 U.S.C. $\S 2201$ (2000) (stating that a federal district court has jurisdiction to hear a declaratory judgment action by a plaintiff when there is an independent basis for federal jurisdiction-such as the patent statute-and when there is an actual "case or controversy").

206. We later show that the number of claims significantly correlates positively with the time patents spend in the PTO. See infra note 240 and accompanying text.

207. This correlation is found, and strongly so, in a new study comparing litigated and unlitigated patents. See Allison et al., Valuable Patents, supra note 30 . These correlations existed in both the Internet business method data set and the general patent data set. 
Moreover, the existence of these correlations further supports the theory that a significant part of private patent value is a self-fulfilling prophecy-"self-selected value"-because applicant perceptions of greater value are probably a common cause of both the larger number of references and the larger number of claims.

One additional fact provides yet more support for the idea that the total number of claims, like the number of prior art references, is an indicator of patent value. The number of references and claims in a patent are largely within the control of the applicant - the contributions of the examiner have only minor effects on these numbers in most cases. Other studies have found that the number of "forward citations"--the number of times a patent is itself cited as prior art in later patents-is a significant predictor of litigation propensity, and thus is also a probable value indicator. ${ }^{208}$ Recent research comparing litigated and unlitigated patents not only confirms the relationship between the number of forward citations and litigation propensity (and indeed finds the relationship to be even stronger than discovered in previous research), but also finds that litigated patents have far more references and claims than unlitigated patents. ${ }^{209}$ Thus, value indicators over which the applicant has much control are confirmed by a value indicator over which the applicant has very little direct control after the patent issues. ${ }^{210}$

208. See Lanjouw \& Schankerman, Stylized Facts of Patent Litigation, supra note 38; Allison et al., Valuable Patents, supra note 30; Lanjouw \& Schankerman, Characteristics of Patent Litigation, supra note 34.

209. Allison et al., Valuable Patents, supra note 30.

210. Patent owners may, however, cite their own previous patents as prior art in their later ones, and the study by Allison et al., did not exclude these self-citations. See Allison, et al., Valuable Patents, supra note 30 (manuscript at 36). Others have found, however, that more valuable litigated patents not only receive more self-citations in later patents with the same owners but also in later patents owned by others. Moreover, the greater number of self-citations in more valuable litigated patents is even more pronounced than the larger number of citations by others. See id. Self-citations may themselves be a value indicator by revealing that a given patent is part of a group of related ones owned by the patentee, and the whole can be more valuable to the owner than the sum of its parts.

Moreover, patent owners may have some very indirect control over how often their patents are later cited as prior art because there is evidence that their filing of infringement actions sends signals causing others to cite their patents more often. Lanjouw \& Schankerman, Characteristics of Patent Litigation, supra note 34 . Such signaling adds yet more value to a patent. Thus, there is no reason to exclude self-citations from the total of citations received by a patent unless one wishes to explore the differential contributions to patent value of self-citations and citations by others. 


\section{Internet Business Method Patents Compared With the Average Patent}

Table 5 reports the results from our comparison of total claims in Internet business method and general patents. ${ }^{211}$

Table 5: Total Number of Claims: Internet Business Method Patents Compared with General Patents

\begin{tabular}{|l|c|c|c|c|c|}
\hline & Mean & Median & Std. Dev. & Min. & Max. \\
\hline $\begin{array}{l}\text { Internet } \\
\text { Business } \\
\text { Method } \\
\text { Patents }\end{array}$ & 26.26 & 20 & 22.45 & 1 & 375 \\
\hline & & & & & \\
$\begin{array}{l}\text { General } \\
\text { Patents }\end{array}$ & 14.87 & 12 & 11.47 & 1 & 120 \\
\hline
\end{tabular}

Using several statistical techniques, we found that the Internet business method patents contain a far larger number of total claims than the average patent. The results were highly significant. ${ }^{212}$

\section{Internet Business Method Patents Compared With Patents in Individual Technology Areas}

We then compared average total claims in Internet business method patents with average total claims in each of the fourteen technology areas within the general patent data set. Here, too, the results were notable, with Internet business method patents having far more claims than patents in each area. ${ }^{213}$ Table 6 shows the untransformed means and other descriptive statistics for claims in Internet business method patents and patents in each technology area.

211. Again, we report untransformed means in the table although we used logtransformed means in testing.

212. As before, we performed an independent-groups $t$-test using log-transformed total claims and a Wilcoxon nonparametric test, the results of both tests being $p<0.0001$.

213. These findings were highly significant statistically except in the area of acoustics. Although Internet business method patents also had many more claims than acoustics patents, the fact that there was a relatively small number of patents in the acoustics category and that these patents had substantially more claims than other areas caused the difference to be not statistically significant. 
Table 6: Total Number of Claims:

Internet Business Method Patents Compared with Patents in Each Technology Area

\begin{tabular}{|l|c|c|c|c|c|}
\hline & Mean & Median & Std. Dev. & Min. & Max. \\
\hline $\begin{array}{l}\text { Internet Business } \\
\text { Methods }\end{array}$ & 26.26 & 20 & 22.45 & 1 & 375 \\
\hline & 19.24 & 17 & 9.32 & 7 & 43 \\
\hline Acoustics & 14.99 & 13 & 10.03 & 2 & 55 \\
\hline Automotive-Related & 13.30 & 9 & 9.42 & 3 & 36 \\
\hline Biotechnology & 15.19 & 13 & 10.96 & 1 & 82 \\
\hline Chemistry & 15.82 & 10 & 13.11 & 1 & 49 \\
\hline Communications & 16.43 & 12.5 & 14.31 & 1 & 120 \\
\hline Computer-Related & 15.11 & 13 & 11.07 & 1 & 57 \\
\hline Electronics & 15.83 & 13 & 9.41 & 3 & 40 \\
\hline Energy-Related & 13.20 & 11 & 9.25 & 1 & 55 \\
\hline Mechanics & 17.48 & 14 & 12.57 & 1 & 61 \\
\hline Medical Devices & 16.83 & 14 & 14.53 & 1 & 120 \\
\hline Optics & 14.68 & 11 & 12.93 & 1 & 82 \\
\hline Pharmaceutical & 15.34 & 12.5 & 11.57 & 2 & 64 \\
\hline Semiconductors & 17.75 & 12 & 17.82 & 1 & 120 \\
\hline Software & & & & & \\
\hline
\end{tabular}

\section{Number of Inventors}

Prior research has not suggested using the average number of inventors as an indicator of patent value. One can argue plausibly, however, that the number of inventors may be related to the amount of costly resources devoted to the inventive enterprise. As already noted, it is likely that, on average, patent applicants who perceive greater innovation value commit greater resources to obtaining stronger and broader patents, and that this resource commitment may translate into greater actual patent value. Various human resource costs presumably rise with the number of inventors. The number of inventors may also affect patenting costs in several ways. A larger number of inventors can mean increased attorney fees because patent attorneys must interview and work with the inventors; while an attorney may not need to work closely with each of a group of 
multiple inventors in every case, the average number with whom the attorney must work surely increases as the total increases. The attorney may have to spend more time determining who the true inventors actually are, ${ }^{214}$ and there may be more uncertainty in the determination of various facts such as the best mode for carrying out the invention. ${ }^{215} \mathrm{~A}$ larger number of inventors likely affects litigation costs, as well. The presence of

214. Inventors must make an oath in the patent application that they are the true inventors. 35 U.S.C. $\S 116(2000)$. A patent attorney must determine whether those named as inventors really are such, and whether anyone else should also be named as an inventor. Incorrect inventorship may be corrected if inadvertent, but the deceptive omission of someone who should be named, or inclusion of someone who should not be, invalidates the patent See id. $\S 256$. It can be far from obvious who is entitled to assert inventor status. The fact that one is entitled to inventor status if, when he is working with another inventor, he makes a significant contribution to conception in at least one of the patent's claims, but not if he assists with the inventive process but does not make such a contribution, coupled with the common complication of multiple patents on related inventions, can cause inventorship questions to be quite difficult. See, e.g., Trovan, Ltd. v. Sokymat SA, 299 F.3d 1292 (Fed. Cir. 2002). In Trovan, the Federal Circuit remanded the question of inventorship to the district court because of an error caused by incorrect claim interpretation. Claim interpretation, a dicey proposition itself, is prerequisite to resolution of this and most other issues in patent litigation. The court observed:

When two or more persons make an invention jointly, they must apply for a patent jointly. Co-inventors need not physically work together or at the same time, make the same type or amount of contribution, or make a contribution to the subject matter of every claim of the patent. Because conception is the touchstone of inventorship, each joint inventor must generally contribute to the conception of the invention. Conception is the formation in the mind of the inventor, of a definite and permanent idea of the complete and operative invention, as it is hereafter to be applied in practice. Conception is complete when one of ordinary skill in the art could construct the apparatus without unduly extensive research or experimentation. An inventor may solicit the assistance of others when perfecting the invention without losing any patent rights. However, the basic exercise of ordinary skill in the art, without an inventive act, does not make one a joint inventor.

Id. at 1301-02 (internal quotation marks and citations omitted).

215. In addition to disclosing enough detail in the patent application to enable an ordinarily skilled practitioner in the art to make the invention and put it into practice ("enablement"), the inventor(s) must also disclose the best mode contemplated for carrying out the invention. 35 U.S.C. $\S 112 \uparrow 1$. The best mode requirement has both subjective and objective elements. First, the requirement applies only if the evidence indicates that the inventor(s) had in fact contemplated, or envisioned, a best mode (or "preferred embodiment") at the time the application was filed. Second, the disclosure of the best mode must be objectively adequate. See, e.g., Chemcast Corp. v. Arco Indus. Corp., 913 F.2d 923 (Fed. Cir. 1990). As the number of inventors increases, so does the possibility of disagreements among them about whether a particular method of putting the invention into practice is the best mode, or even whether there is an envisioned best mode at all. 
more inventors means more depositions, more time spent on trial testimony, and the increase of other costs associated with litigation. ${ }^{216}$

Furthermore, prior research has found that inventions in certain fields, namely, pharmaceuticals, biotechnology and chemistry, which require more advanced science and engineering and thus more expensive inventive processes than average, also tend to involve more than the average number of inventors. Conversely, the average number of inventors is smaller in fields such as pure mechanics and acoustics that typically involve lower-level skills and less expensive inventive processes. ${ }^{217}$ Furthermore, inventors in areas such as pharmaceutical, biotechnology, and chemistry are likely to be better paid than most because of their skill and training, and they or their employers are likely to have higher opportunity costs than average. Therefore, there is sufficient theoretical reason to believe that the average number of inventors in a group of patents could have an association with patent value to warrant statistical testing.

\section{Internet Business Method Patents Compared With the Average Patent}

Table 7 summarizes the results of our comparison of the number of inventors in Internet business method patents and general patents, using untransformed means. ${ }^{218}$

216. More trial witnesses also may translate to larger attorney fees, and may increase many other incidental costs such as those related to travel.

217. Allison \& Lemley, Who's Patenting What? supra note 40, at 2129, 2157-58. Allison and Lemley found that inventions in fields of pharmaceuticals (2.81), biotechnology (2.84), and chemistry (2.85) had significantly more inventors than the average for patents-in-general (2.25). Id. Mechanical inventions (1.77) and those in the area of acoustics (1.86) had significantly fewer inventors than average. Id. Inventions in the other fields, such as those in the clearly more complex area of semiconductors and the clearly less complex area of traditional electronics, had numbers of inventors that were not significantly different than average, and thus, neither confirmed nor disconfirmed the proposition. Id.

218. Because the distributions of number of inventors in both data sets looked very similar and were not heavily influenced by upper outliers as were other distributions in our study, logarithmic transformation of the means was not necessary. 
Table 7: Number of Inventors:

Internet Business Method Patents Compared With General Patents

\begin{tabular}{|l|c|c|c|c|c|c|}
\hline & $\mathbf{N}$ & Mean & Median & Std. Dev. & Min. & Max. \\
\hline $\begin{array}{l}\text { Internet } \\
\text { Business } \\
\text { Method } \\
\text { Patents }\end{array}$ & 1093 & 2.43 & 2 & 1.82 & 1 & 14 \\
\hline $\begin{array}{l}\text { General } \\
\text { Patents }\end{array}$ & 1000 & 2.26 & 2 & 1.52 & 1 & 11 \\
\hline
\end{tabular}

The average number of inventors in Internet business method patents was greater than in general patents by a statistically significant margin. ${ }^{219}$

\section{Internet Business Method Patents Compared With Patents in Individual Technology Areas}

We also compared this variable in Internet business method patents with patents in each of our fourteen technology areas. Table 8 reports the results of this comparison. ${ }^{220}$ Because this comparison is with patents in the individual technology areas rather than with the entire sample of general patents, the differences necessarily must be larger to be statistically significant.

219. Although we are confident of the result, it must be taken with a bit of caution because it was confirmed by only one of the two follow-up tests. The Independent Groups $t$-test resulted in $p<0.0185$. However, a Wilcoxon nonparametric test showed no significant difference $(p<0.1756)$. We also employed the Savage test, another nonparametric test that analyzes Savage scores-the expected order statistics for the exponential distribution. This test was chosen because these Savage scores tend to cluster at a single score with only a small percentage of subjects with scores in between the minimum and the maximum. This distribution of values closely approximates an exponential distribution. Unlike the nonparametric Wilcoxon test, the Savage test yielded results that were statistically significant $(p<0.0178)$.

220. As before, the table relates untransformed means. Unlike the comparison of number of inventors between Internet business method patents and patents in general, log transformation of the means was necessary when the comparison was made with patents in individual technology areas because the distributions were characterized by more extreme variations. 
Table 8: Total Number of Inventors: Internet Business Method Patents Compared with Patents in Each Technology Area

\begin{tabular}{|c|c|c|c|c|c|}
\hline & Mean & Median & Std. Dev. & Min. & Max. \\
\hline $\begin{array}{l}\text { Internet Business } \\
\text { Methods }\end{array}$ & 2.43 & 2 & 1.82 & 1 & 14 \\
\hline Acoustics & 1.81 & 2 & 0.98 & 1 & 4 \\
\hline Automotive-Related & 2.05 & 2 & 1.29 & 1 & 7 \\
\hline Biotechnology & 2.84 & 2 & 1.91 & 1 & 11 \\
\hline Chemistry & 2.86 & 2 & 1.69 & 1 & 10 \\
\hline Communications-Related & 2.23 & 2 & 1.39 & 1 & 7 \\
\hline Computer-Related & 2.25 & 2 & 1.47 & 1 & 10 \\
\hline Electronics & 2.37 & 2 & 1.54 & 1 & 10 \\
\hline Energy-Related & 2.70 & 2 & 2.08 & 1 & 9 \\
\hline Mechanics & 1.79 & 1 & 1.22 & 1 & 9 \\
\hline Medical Devices & 2.29 & 2 & 1.67 & 1 & 10 \\
\hline Optics & 2.59 & 2 & 1.72 & 1 & 10 \\
\hline Pharmaceutical & 2.92 & 2 & 1.94 & 1 & 11 \\
\hline Semiconductors & 2.17 & 2 & 1.39 & 1 & 7 \\
\hline Software & 2.52 & 2 & 1.61 & 1 & 10 \\
\hline
\end{tabular}

Overall, these results reveal more similarity than dissimilarity. Internet business method patents had significantly more inventors than patents in one technology area (mechanics), significantly fewer inventors than patents in three areas (biotechnology, chemistry and pharmaceuticals), and an insignificantly different number of inventors than patents in the other ten technology areas. It is difficult to draw any meaningful conclusions from these data. Although Internet business method patents had significantly more inventors than patents in general, that result was not as compelling as in comparisons of other variables, and the theory largely falls apart when the number of inventors in individual technology areas is examined. We can say, though, that to the extent that the average number of inventors has something to say about the value of patents, there is 
nothing in these data to suggest that Internet business method patents are clearly worth less. ${ }^{221}$

\section{E. Time Spent in the Patent Office}

The time that an application spends in the PTO before patent issuance is often referred to as "time-in-prosecution" or "pendency time." Although no prior research has sought to determine whether pendency time might be related to patent quality or value, Allison and Lemley surmised that one reason for the dramatic growth in the complexity of all aspects of patenting over time, including average pendency times, could be an increase in the value of patents to those who seek and obtain them. ${ }^{222}$ There is little doubt that patents have become more valuable assets in the past couple of decades. ${ }^{223}$ Moreover, the recent study by one of the authors comparing litigated and unlitigated patents finds that more valuable litigated patents spent much more time in the PTO before issuance than did unlitigated patents. ${ }^{224}$ We will discuss some of the factors that influence pendency times and the consequences of pendency variations before turning to comparisons between Internet business method patents on the one hand, and the average patent and patents in particular technology areas on the other.

\section{The Effect of Ancestor Applications on Average Pendency Times}

For many patents, pendency time is affected by the filing of copending "continuing" applications. Patent law in the U.S. allows an applicant to file another application covering a closely related invention while the first application is still pending. There are three types of continuing applications. The first, commonly called a "continuation," uses the same written description as its predecessor application, but makes changes in the claims. Continuation applications retain the priority date of the original filing as long as they are filed while at least one predecessor application in the chain is still pending, and as long as there is no material

221. Furthermore, the idea that this metric may be an indicator of patent value cannot be totally dismissed, and warrants further empirical research. However, the new study comprehensively comparing litigated and unlitigated patents finds that patents with more inventors are not more likely to be litigated, thus failing to support the hypothesis that the number of inventors is an indicator of value. Allison et al., Valuable Patents, supra note 30 (manuscript at 47).

222. See Allison \& Lemley, Growing Complexity, supra note 40, at 98-99, 139-41.

223. Id.

224. Allison et al., Valuable Patents, supra note 30 (manuscript at 44). 
change in the written description of the invention. ${ }^{225}$ An applicant may do this on her own initiative in order to get a shot at receiving another patent on a closely related invention-some continuation applications are abandoned and some result in their own separate patents-or she may do so in response to a rejection or limitation by the patent examiner. A patent applicant may also file a continuing application to reconfigure the claims so that they are more likely to encompass a competitor's activities, thus increasing the universe of potential infringers. ${ }^{226}$

The second type of continuing application is a "continuation-in-part" ("CIP"). Although a CIP also claims a closely related invention, the written description has been materially changed to support one or more changes in the claims. The inventor does not retain the original filing date for any claim in the CIP that draws its support from a material change in the description. Thus, when one receives a patent based on a CIP, it is possible for different claims in the patent to have different priority dates. Because the term of patent protection now dates from the original priority filing date, it is likewise possible for different claims in a patent to have different terms of protection.

The third type of continuing application is a "divisional." The Patent Act requires that there be only one distinct invention per patent. ${ }^{227} \mathrm{~A}$ divisional application represents an election by the applicant to keep only certain claims in the instant application and to put those claims representing the separate invention in a co-pending divisional application when the examiner issues a restriction based on finding more than one invention is found in an application. Here, again, the applicant retains the original priority filing date if no material change is made in the description of the invention. In other words, the original description is reused because it was adequate to support more than one distinct invention.

An applicant may file one or more of any type of continuing application while any other application deriving from the same original application is still pending. There can be a chain of such continuing applications, or even a tree when one or more of these applications

225. 35 U.S.C. $\$ 120$ (2000). See generally Quillen \& Webster, Continuing Patent Applications, supra note 139, at 4-6 (discussing the types of continuing applications and their effects). Retaining the earlier priority filing date can be crucial because it determines which prior art can be used against the patent applicant (or, later, the patent owner if its patent is challenged).

226. See id.

227. Id. $\S 121$. Although representing a fundamental precept of patenting, this requirement can be interpreted by patent examiners with varying degrees of rigidity or looseness. 
branches off into multiple others. Looking backward from a given patent, one can see that it sometimes has resulted from a series of prior related applications. Those related applications prior to the one that most immediately led to this patent are often called "ancestors" (or "parents," "grandparents," etc.). In our general patent data set, for example, patents resulted from an average of 1.535 U.S. applications. The median, however, was one application, because the majority of patents did not result from a chain. ${ }^{22}$

The PTO understates average pendency times in its reporting by only counting the time elapsed between the filing of the most immediate application and the issuance of a patent from it, even when that application is at the end of a chain. Such reporting is inaccurate for two reasons. First, the patent's origin and duration date back to the first filing with respect to all claims supported by the original written description. Second, when a patent is based not only on the most recent application but also on one or more ancestors, examination of the most recent one should require less of the applicant and the examiner because some of the work has already been done in connection with the ancestors.

\section{Other Reasons for Variation in Pendency Times}

Variations in patent pendency times are caused by several other factors, some of which reflect system-wide changes while others reflect idiosyncrasies in particular patents. Regarding the former, there have been dramatic increases in the number of patent applications in recent years, ${ }^{229}$ straining the PTO's resources and resulting in longer average pendency times in all technology areas. ${ }^{230}$ Beginning in mid-1995, the term of patent protection was changed from seventeen years counting from the date of patent issuance to twenty years counting from the original filing of the

228. We did not count the total number of applications in the Internet business method data set.

229. Utility Patent Applications Per Year: $2001=324,211 ; 2000=291,653 ; 1999=$ 259,$618 ; 1998=238,850 ; 1997=219,486 ; 1996=189,922 ; 1995=220,141 ; 1994=$ 185,087. USPTO, 2001 ANNUAL REPORT: OTHER ACCOMPANYING INFORMATION 107 (2002), available at http://www.uspto.gov/web/offices/com/annual/2001/01accompinfo. pdf (last visited Nov. 25, 2003).

230. See Allison \& Lemley, Growing Complexity, supra note 40, at 98-99 (average pendency times increased quite substantially from the late 1970 s to the late 1990 s). The fact that the PTO has had to deal with increasing numbers of applications is surely not the only reason for increasing pendencies in all technology areas during the past twenty years. Because patents have generally become more valuable assets during that period for variety of reasons, applicants also have probably spent more time in the PTO trying to get the broadest possible protection. $I d$. at 139 . 
application. ${ }^{231}$ It has been argued that the change would reduce overall pendency times because delay in the patent office would reduce the term of patent protection and applicants would push to get through the process faster. ${ }^{232}$ This has not turned out to be the case. If there nas been any such effect at all, it has been overwhelmed by the dramatic increase in the number of applications. Moreover, it is doubtful that the prospect of losing a relatively small portion of the patent term will motivate many patent applicants to push their applications through the PTO more quickly. ${ }^{233}$ The majority of patents do not create market power in the first place, and even in the case of those that do, the passage of time usually witnesses the introduction of various competing alternatives that reduce whatever market power the patent may have conferred. ${ }^{234}$

Thus, proportionately small increments in the term of protection will usually be worth little, except for pharmaceutical patents. Prior research has confirmed that patents are far more important in pharmaceuticals than in other areas. ${ }^{235}$ Also, pharmaceutical patents, unlike most patents in other fields (including Internet business methods), typically maintain their value throughout the term of protection.

231. 35 U.S.C. $\$ 154(a)(2)$ (stating that "such grant shall be for a term beginning on the date on which the patent issues and ending twenty years from the date on which the application for the patent was filed in the United States"). The term of seventeen years from issuance was changed to a term of twenty years from initial filing. Patents in force on June 8,1995 , or those issuing from applications still pending on that date, have the longer of these two terms. Those issuing from applications originally filed after that date have the twenty-year-from-filing term.

232. Mark A. Lemley, An Empirical Study of the Twenty-Year Patent Term, 22 AIPLA Q.J. 369, 392-93 (1994).

233. However, changing the way that the patent term is calculated undoubtedly did reduce the incentive to drag out the patenting process excessively, as had been done by a few who engaged in so-called "submarine" patenting. Submarine patenting consisted of intentionally dragging out the patenting process for an exceptionally long time so that the applicant could spring a patent as a fait accompli on members of an industry that had matured while the application had been lingering in the PTO. See, e.g., Allison \& Lemley, Growing Complexity, supra note 40, at $126 \mathrm{n} .108$.

234. See, e.g., Herbert HovenKamp, Economics AND Federal ANTITRust LaW $\S 8.3$, at 219 (1985) ("Many patents confer absolutely no market power on their owners ... . The economic case for 'presuming' sufficient market power . . . is very weak."); HERBERT HoVENKAMP ET AL., IP AND ANTITRUST ch. 4 (2003 ed.); Nat'1 Inst. on Indus. \& Intell. Prop., The Value of Patents and Other Legally Protected Commercial Rights, 53 ANTITRUST L.J. 535, 547 (1985) ("Statistical studies suggest that the vast majority of all patents confer very little monopoly power.").

235. See COHEN ET AL., Why U.S. MANufacturing FIRMS PATENT, supra note 51; Levin et al., supra note 51 . 
In addition to greater use of continuing applications and the increasing backlog of applications at the PTO during recent years, a number of other factors undoubtedly affect pendency times in either systematic or idiosyncratic ways. For example, we should expect individual examiners to work at varying speeds even if they are in the same field, because of different work habits or amounts of experience. Despite the fact that the impact of examiner heterogeneity on pendency time should be mitigated by PTO rules regulating the amount of time that patent examiners may work on applications, a recent study of patent examiners apparently found some variance among examiners in the time they take to allow the issuance of patents. ${ }^{236}$ As the PTO does, the authors of this study evidently considered only the time elapsed from the filing of the last application, failing to account for the effect of ancestor applications, and it is unknown whether the same type of time variances among examiners would exist if ancestor applications had properly been taken into account. Moreover, the study evidently used very rough estimates of filing and issuance datesthe year of filing and the year of issuance-to calculate pendency times. ${ }^{237}$ This study thus does not show the extent to which examiner identity may affect patent pendency times in a meaningful or systematic way, and an exploration of this variable is beyond the scope of our own study.

Recently, however, Doug Lichtman found that individual examiners do vary greatly in their tendencies to alter claim language during prosecution, even within the same field of technology. ${ }^{238}$ This fact in itself

236. IAIn M. Cockburn et Al., ARe All Patent EXaminers Equal? The IMPACT of Characteristics ON PATENT Statistics AND Litigation OUTCOMES 10 (Nat'l Bureau of Econ. Research, Working Paper No. 8980, 2002). We use words like "apparently" and "evidently" because the authors were not very clear in explaining their findings about the effect of examiner heterogeneity on pendency times.

237. We assume that the authors of the study did not take into account the effect of ancestor applications on pendency times because they used the NBER Patent Citation Data File, which reports the filing date of only the most immediate application, not the original priority filing date in the many cases in which there is a chain of ancestors. Moreover, this database measures the elapsed time between the year in which this most recent application was filed and the year in which the patent was granted, providing a measure of pendency time so rough as to be much less useful than we might like. See Bronwyn H. Hall et al., The NBER Patent Citations Data File: Lessons, INSIGHTS AND METHODOLOGICAL TOOLS 8 (Nat'l Bureau of Econ. Research, Working Paper No. 8498, 2001).

238. Douglas Lichtman, Rethinking Prosecution History Estoppel, U. CHI. L. REV. (forthcoming 2004), draft available at http://papers.ssrn.com/sol3/papers.cfm?abstract_ id $=455380$ (last visited Nov. 30, 2003). 
suggests that pendency times probably vary substantially from one examiner to another.

The area of technology undoubtedly has a significant impact on the time a patent spends in the PTO, probably in at least two ways. First, some technologies are just more complicated and difficult to decipher than others. ${ }^{239}$ Patents in some fields that are known to be more technically challenging, such as biotechnology and pharmaceuticals, spend much more time in the PTO than average. Second, the relative newness of some technologies or, relatedly, the recency of rules recognizing some technologies as patentable subject matter undoubtedly have an effect on pendency times in those fields. There surely must be a learning curve for inventors, patent attorneys, and patent examiners. It takes time for attorneys to develop and become comfortable with patent drafting techniques in new areas, and for examiners to understand these techniques. It takes time for the attorneys and the PTO to learn about the sources for nonpatent prior art in such areas, and for the PTO to make the sources available to examiners. Patent attorneys may encounter increased resistance from examiners not only because of uncertainty about prior art sources and claim drafting techniques, but also simply because of the vague feelings of unease that often accompany one's exposure to the unfamiliar. All of these factors are likely to create greater application backlogs in the PTO. It may also be that greater technical difficulty or the newness of the technology or the recency of its recognition as patentable subject matter tends to cause applicants in these areas to file more continuing applications. If so, we may find several causes for longer pendency times in some fields of inventive activity that sometimes work by themselves and sometimes interlink with other causes.

Finally, longer pendency times may also be due in part to applicants' perceptions of greater innovation value that lead them to devote greater resources to obtaining the strongest and broadest possible patents. First, we know that the filing of continuing applications accounts for a substantial portion of average pendency times, and that filing continuing applications adds substantially to patenting costs. Applicants perceiving greater value may tend to file more continuing applications. Second, we find evidence of sizable correlations between both claims and references on one hand, and pendency times on the other. Drafting and pursuing more claims costs more, and contributes quite significantly to the time that

239. Although patent examiners spend an average of about eighteen hours on a single application over a period of roughly two to three years, they take amounts of time ranging from eight to thirty-two in different technology areas. Lemley, Rational Ignorance, supra note 4 , at $1500 \&$ n. 19 . 
applications spend in the PTO.$^{240}$ Likewise, it costs more to carry out more thorough prior art searches, and larger numbers of prior art references, most of which originate with the applicant, correlate even more strongly with longer pendency times than the number of claims does. ${ }^{241}$ These high

240. Finding a claims-time correlation confirms the intuitive. Examination focuses on the claims because they define the invention. It is the claims that must show a novel and nonobvious advance over the prior art. In both data sets, we found that the number of claims was highly correlated with pendency times from both the original priority filing date and from the filing of the most recent application.

Because these were large samples, and because there is quite a bit of "noise" in the data on years in the PTO, there does not have to be a huge correlation coefficient to be highly significant. By noise, we mean that many factors probably affect pendency times, some of which we cannot measure and some of which we may not even know about. Nevertheless, we discovered some rather large Pearson $R$ values. The Pearson $R$ is the correlation coefficient, a number that falls between 0 and 1 , and if it is a positive number, it quantifies the extent to which increases in one variable correspond to increases in the other variable (and the extent to which decreases in one variable correspond to decreases in the other variable).

As with almost all of our other measures, we performed log transformations on the values to adjust for large right-hand skews caused by extreme upper outliers. For Internet business method patents, the results for claims and years in the PTO from the original filing date were: $R=0.09, p=0.003$. From the most recent application, the results were $R=0.11, p=0.0002$. For general patents, the results for claims and years in the PTO from the original filing date were: $R=0.08, p=0.01$. From the most recent application, the results were: $R=0.11, p=0.0004$.

241. In both data sets, the numbers of patent, nonpatent, and total prior art references were highly correlated with pendency times from the filing of the original application at the root of an application chain, nonpatent references being much more highly correlated than patent references.

Again, and for the same reasons as before, we performed log transformations on the values. For Internet business method patents, the results for references and years in the PTO from the original filing date were as follows. Patent References/Pendency: $R=$ $0.15, p<0.0001$; Nonpatent References/Pendency: $R=0.14, p<0.0001$; Total References/Pendency: $R=0.27, p<0.0001$. For general patents, the results for references and years in the PTO from the original filing date were as follows. Patent References/Pendency: $R=0.14, p<0.0001$; Nonpatent References/Pendency: $R=0.29, p<$ 0.0001; Total References/Pendency: $R=0.31, p<0.0001$.

We obtained similar results when measuring years spent in the PTO from the applications leading immediately to their corresponding patents, with one major exception in the case of patent references. In the case of both Internet business method patents and general patents, the number of nonpatent references and total references were highly correlated with pendency times from the most recent application, but the number of references to prior patents was not significantly correlated. For Internet business method patents, the results for references and years in the PTO from the most recent filing date were as follows. Patent References/Pendency: No significant correlation; Nonpatent References/Pendency: $R=0.10, p=0.0005$; Total References/Pendency: $R=0.16, p<0.0001$. For general patents, the results for references and years in the PTO from the most recent filing date were as follows. Patent References/Pendency: No significant correlation; 
positive correlations tell us nothing about the possible differences between Internet business method patents and general patents directly because the correlations were practically identical in the two data sets. They do seem to provide more support, however, for our self-selected value theory, particularly given that Internet business method patents did contain many more claims and references. ${ }^{242}$ Third, when applicants perceive greater innovation value, they are likely to spend more time and money trying to overcome objections to claims by the patent examiner instead of giving in, again producing longer pendency times. As we see below, Internet business method patents spent much more time in the PTO than we would have expected. ${ }^{243}$

\section{Method of Comparison}

First, we measure pendency times from the filing of the original patent application. This measure is affected by the substantial portion of patents in both data sets in which one or more continuing applications were filed. In our set of 1,093 Internet business method patents, $196(17.9 \%)$ were based on one or more ancestor applications prior to the filing of the most immediate application leading directly to the patent. In the set of 1,000 general patents, $293(29.3 \%)$ had one or more ancestor applications. At least a substantial portion of this difference is surely attributable to the fact that Internet business method patents have not been around as long as many other types. Therefore, the set of Internet business method patents fails to capture as many patents having a history of multiple continuing applications. $^{244}$ Also, a smaller portion of the original applications for

Nonpatent References/Pendency: $R=0.21, p<0.0001$; Total References/Pendency: $R=$ $0.17, p<0.0001$.

242. Our additional finding that claims and references also are significantly correlated with each other provides yet more support for the self-selected value theory. This interaction, almost certainly the result of applicants' willingness to invest more in innovations they believe to be worth more, was clearly observable from a simple visual inspection of the data. We have correlation coefficients and $p$-values for these relationships as well, but we do not report them here. We do not wish to glaze over readers' eyes any more than we probably already have.

243. The fact that pendency times are highly correlated with numbers of claims and references means that, when we used multivariate statistical tests to account for such interdependencies, the difference in years in the PTO between Internet business method patents and general patents ceased to be significant. The correlations themselves, however, lend support to the idea of value as a self-fulfilling prophecy.

244. Although the general patent data set had earlier average filing dates than the Internet business method data set, the two sets were contemporaneous in issue dates and overall were sufficiently contemporaneous such that our comparisons of references and claims are not measurably affected by temporal differences. 
Internet business method patents were filed before the time-mid-1995when delaying the examination process started counting against the term of patent protection. ${ }^{245}$ Both observations would cause us to expect, ceterus paribus, shorter pendency times for Internet business method patents from the original filing than for other kinds of patents. ${ }^{246}$

Our second set of comparisons looks at pendency times counting only from the filing of the most immediate application leading directly to a given patent. This second set of comparisons thus removes the effect of continuing applications so that we may focus on other factors.

4. Pendency Times from the Original Priority Filing Date: Internet Business Method Patents Compared With General Patents and With Patents in Each Technology Area

The following table reports the untransformed means of pendency times for Internet business method patents, general patents, and patents in each technology area, as well as the results of statistical comparisons.

245. For reasons previously discussed, we doubt that the prospect of relatively small reductions in patent terms in the case of applications filed after mid-1995 caused many applicants to push through the examination process much faster. The main effect on pendency times caused by this change is the removal of "submarine patents" with exceptionally long pendencies. Thus, the fact that the Internet business method patent data set had proportionately more patents based on applications filed after this date caused us to expect shorter pendency times for them because the effects of submarine patents should have been much less (or perhaps nonexistent).

246. One might even speculate that the rapidity of change in the Internet business sector during the period we studied to have induced patent applicants to have created an incentive for applicants to speed up prosecution and get their patents issued faster. 
Table 9: Patent Pendency Times From Original Filing:

Internet Business Method Patents Compared with General Patents and with Patents in Each Technology Area ${ }^{247}$

\begin{tabular}{|c|c|c|}
\hline & $\begin{array}{c}\text { Yrs in PTO From } \\
\text { Original Filing }\end{array}$ & $\begin{array}{c}\text { Significance of } \\
\text { Difference-- } \\
\text { Internet Business } \\
\text { Methods Spend } \\
\text { More, Less, or } \\
\text { Equal Time in PTO }\end{array}$ \\
\hline $\begin{array}{l}\text { Internet Business } \\
\text { Methods }\end{array}$ & 2.67 & \\
\hline General Patents & 2.77 & Less \\
\hline Acoustics & 2.69 & Equal \\
\hline Automotive & 2.19 & More \\
\hline Biotechnology & 4.72 & Less \\
\hline Chemistry & 3.42 & Less \\
\hline Communications & 2.77 & Equal \\
\hline Computer-related & 2.80 & Equal \\
\hline Electronics & 2.38 & More \\
\hline Energy & 2.78 & Equal \\
\hline Mechanics & 2.29 & More \\
\hline Medical devices & 2.78 & Equal \\
\hline Optics & 2.85 & Equal \\
\hline Pharmaceutical & 4.44 & Less \\
\hline Semiconductors & 2.77 & Equal \\
\hline Software & 3.07 & Equal \\
\hline
\end{tabular}

Thus, Internet business method patents spent slightly less time in the PTO from the original priority filing date than general patents did (2.67

247. In the far right-hand column "more" means that Internet business method patents spent significantly more time in the PTO from the original filing date, "less" means that Internet business method patents spent significantly less time in the PTO from the original filing date, and "equal" means that there was no statistically significant difference in pendency times from the original filing date. As before, the statistical tests were done after performing log-transformations on the means to adjust for extreme upper outliers and other abnormal characteristics of the distributions. The results were confirmed by Wilcoxon nonparametric tests, with one exception we note below. 
and 2.77 years, respectively). After adjusting the means to account for extreme values in the distributions, the average pendency time for general patents was longer than that for Internet business method patents, but the difference was barely significant. Moreover, the statistical significance of the difference disappeared when multivariate tests were used that accounted for the large correlations between numbers of claims and references on one hand, and pendency times on the other. We were not surprised that general patents spent a bit more time in the PTO than Internet business method patents, given the average earlier filing dates for general patents and the larger portion of general patents that were based on one or more ancestor applications. In fact, it is rather surprising that the difference between pendency times from the original filing was not substantially larger. We suspect that the newness and recency of Internet business method patents may largely explain this unexpectedly small difference. In other words, the newness and recency of Internet business method patents probably lengthened their average pendency times, while their average earlier filing dates and fewer continuing applications probably shortened their average pendency times. Thus, the effect of the former served as at least a partial offset to the effect of the latter.

In congruence with what we have found in the case of references and claims, we also think it possible that applicant perception of greater private value may have played a part in making pendency times for Internet business method patents longer than expected. Aside from the fact that perceptions of greater innovation value may have generated more references and claims, such perceptions also may have led applicants to contest examiner objections more strenuously rather than accepting them.

The comparison between Internet business method patents and those in individual technology areas reveals no statistically significant difference between Internet business method patents and those in eight of the fourteen technology areas. Internet business method patents spent significantly more time in the PTO than did patents in three areas: automotive-related, electronics, and mechanics. Internet business method patents spent significantly less time in the PTO than those in three areas: biotechnology, chemistry, ${ }^{248}$ and pharmaceuticals. ${ }^{249}$ Overall, then, there is

248. As with other comparisons, we not only used $t$-tests comparing log-transformed means to account for the effect of extreme upper outliers, but also Wilcoxon nonparametric tests. These tests were in agreement in practically every instance. In the case of chemistry patents from the original filing date, however, the tests produced contrary results. The $t$-test showed that chemistry patents spent significantly more time in the PTO than Internet business method patents, but the Wilcoxon test showed no significant difference. We chose to report the $t$-test result for several reasons, the most important of which is 
no evidence that Internet business method patents were exceptional in the time they spent in the PTO from the original filing date, except that they had longer pendencies than we would have expected.

5. Pendency Times from the Most Recent Filing Date: Internet Business Method Patents Compared With General Patents and With Patents in Each Technology Area

If we then look at average pendency times counting only from the most immediate applications that led directly to the patents in question, we observe two interesting phenomena. First, both data sets are still characterized by upper outliers, but they are less extreme than they were when we measured pendency times from the original priority filing date, and thus are characterized by a less pronounced right-hand skew. This is entirely expected because we have removed the effect of multiple applications leading up to a substantial number of the patents in each set. Second, and very surprisingly, we found that Internet business method patents generally spent more time in the PTO than did other kinds of patents. Table 10 reports the outcomes of these comparisons in the same format as Table 9.

that it is the more conservative of the two in light of our overall assertion that Internet business method patents had much longer pendency times than expected. We do not want to be seen as making close judgment calls in favor of this assertion.

249. Despite the fact that the untransformed mean of software patent pendency times is quite a bit longer than that for Internet business method patents $(3.07,2.67)$, the actual difference was not significant after the appropriate adjustments for extreme values. Findings like this one increase in likelihood as distributions of data stray farther and farther from normality. The distribution of pendency times from the original filing for software patents was characterized by more extreme individual values, thus making the untransformed means less reflective of the true central tendency of this set of data. We found a lack of statistical significance not only when we used log-transformed means but also when we used a Wilcoxon nonparametric test. The number of software patents (ninetytwo) was clearly a large enough sample for valid statistical testing, although it is of course true that this magnitude of difference probably would have been significant even after adjustment had the software sample size been far larger. 
Table 10: Patent Pendency Times From Most Recent Filing:

Internet Business Method Patents Compared with General Patents and with Patents in Each Technology Area

\begin{tabular}{|c|c|c|}
\hline & $\begin{array}{l}\text { Yrs in PTO From } \\
\text { Most Recent Filing }\end{array}$ & $\begin{array}{c}\text { Significance of } \\
\text { Difference- } \\
\text { Internet Business } \\
\text { Methods Spend } \\
\text { More, Less, or } \\
\text { Equal Time in PTO }\end{array}$ \\
\hline $\begin{array}{l}\text { Internet Business } \\
\text { Methods }\end{array}$ & 2.39 & \\
\hline General Patents & 2.02 & More \\
\hline Acoustics & 2.10 & More \\
\hline Automotive-related & 1.98 & More \\
\hline Biotechnology & 2.60 & Equal \\
\hline Chemistry & 2.13 & More \\
\hline Communications-related & 2.17 & More \\
\hline Computer-related & 2.06 & More \\
\hline Electronics & 1.90 & More \\
\hline Energy-related & 1.99 & More \\
\hline Mechanics & 1.85 & More \\
\hline Medical devices & 2.03 & More \\
\hline Optics & 1.89 & More \\
\hline Pharmaceutical & 2.64 & Equal \\
\hline Semiconductors & 2.13 & More \\
\hline Software & 2.30 & Equal \\
\hline
\end{tabular}

The most important finding is that, when the effect of continuing applications is purged from our data, Internet business method patents spent much more time in the PTO than the average patent. This difference remained highly significant even after taking into account the strong 
influence that the number of references and the number of claims each had on pendency times. ${ }^{250}$

Moreover, Internet business method patents spent significantly more time in the PTO from the most recent filing than patents in eleven of the fourteen individual technology areas, and an insignificantly different amount of time than patents in three areas: biotechnology, pharmaceuticals, and software. Patents in the first two of these three fields had significantly longer pendency times than Internet business method patents when counting from the original filing date, and we would have intuitively expected the same to be true when counting only from the most recent applications. They did not, however, probably because the proportion of their average pendency times from the original filing date that had resulted from continuing applications was larger than average within the set of general patents and certainly larger than for Internet business method patents. The fact that both types of patents continued to be on the high end of the set of general patents again substantiates the idea that patents are more important in these areas and applicants perceive them as having more value than in most areas. In the case of biotechnology patents, as with Internet business method patents, newness and recency could also have played a role.

When we measured from the filing of the most immediate application, the unadjusted averages for biotechnology and pharmaceutical patents certainly looked as though they should be significantly greater than those for Internet business method patents. However, the differences here are not statistically significant after appropriate adjustments. Even after removing the large effects of continuing applications in biotechnology and pharmaceuticals, average pendency times in these areas continued to be severely affected by a relatively small number of applications that took a very long time to issue as patents, rendering these unadjusted means a misleading indicator of the true center points in their respective distributions. ${ }^{251}$

250. We performed log transformations on the means of the number of claims, number of prior art references, and years in the PTO, and then performed a multiple regression to determine whether Internet business method patents still spent significantly longer in the PTO from the most recent filing when accounting for the fact that numbers of references and claims heavily influenced pendency times. The $p$-value was $<0.0001$.

251. Results from both $t$-tests using log-transformed means and Wilcoxon nonparametric tests confirmed the lack of significance in the differences between the means of pendency times in these two areas and those in Internet business method patents. The differences undoubtedly would have been significantly different had the sample sizes in these areas been as large as that for the set of general patents as a whole, but these samples were sufficiently large for valid statistical testing. To reiterate, the distributions of 
After purging the effect of continuing applications from the pendency time data, thus focusing on the process of getting a particular patent issued directly from a particular application, the two possible explanations mentioned earlier appear to gain strength. The newness of the technology in Internet business method patents and the recency of the technology's legal recognition as patentable subject matter almost certainly played a part. The other factor-applicant perception of greater potential value leading to the commitment of greater resources to the patenting enterprise and thus increasing actual value-also remains as a probable partial explanation.

\section{SUGGESTED EXPLANATIONS FOR THE GAP BETWEEN CONVENTIONAL WISDOM AND REALITY}

Most observers who have written or spoken publicly about Internet business method patents do not like them, to say the least. Our data, on the other hand, suggest that these patents were of a quality and value at least as high as most other patents. We were naturally led to wonder about the reasons for such a chasm.

\section{A. Possible Explanations}

One possible explanation is that Internet business method patents are indeed deficient in some ways, and that these deficiencies were a natural consequence of the patent system attempting to grapple with a new technology only recently recognized as patentable subject matter, and that these patents will get better with time. Although superficially appealing, this argument quickly implodes in the face of our data. We studied Internet business method patents when they were still new, compared them with patents in fields that were not so new, and could not find anything that was objectively wrong with them.

The approach used by the PTO and the courts for addressing the requirement of nonobviousness arguably could provide another explanation. Instead of looking at the invention from the perspective of subjective hindsight, PTO examiners and federal judges must use particularized prior art to demonstrate that an invention is undeserving of a patent because it represents an insufficient advance over what has gone before. ${ }^{252}$ Although there is no evidence that patent examiners have

data points for pendency times in these two areas were still affected a lot by upper outliers even when measuring only from the most recent applications.

252. See, e.g., Panduit Corp. v. Dennison Mfg. Co., 774 F.2d 1082 (Fed. Cir. 1985), vacated by 475 U.S. 809 (1986), remanded to 810 F.2d 1561 (Fed. Cir. 1987). 
commonly used subjective hindsight to reject applications, there have been periods when the courts clearly did so. Gone are the days, however, when courts routinely invalidated patents on the ground that inventions did not reveal a "flash of creative genius." 253 The approach to the nonobviousness inquiry may explain why one can find many patents in all fields that seem to stand on very shaky ground, but it does not support an inference that patents in one area are more trivial than in other areas. ${ }^{254}$

One may contend, as many have, that a disproportionate share of Internet business method patents were obvious because many such methods were previously practiced but kept secret during the years in which most people thought that they were not patentable subject matter and that there was thus a failure to create prior art as occurs in most fields. The fact of the matter is, however, that businesses in almost all industries have for a long time strongly preferred trade secret protection to patents as a means for securing the best return on their research and development investments. ${ }^{255}$ Thus, there has always been a lot of "secret" prior art in all fields. Admittedly, the percentage of the total volume of prior art that was kept secret in the field of business methods was probably greater than the percentage of the total in many other fields because of the recency with which business methods were deemed eligible for patent protection. In the end, however, the data must speak for themselves. Internet business method patents cited far more prior art than other patents.

The possibility also exists that our analysis of the prior art cited in patents overemphasizes quantity measures and fails to adequately account for variations in the relevance and content quality of those references. We believe that we have shown, however, that the quantity measures we use have much to say about patent quality and value, and we also attempted a reasonably thorough assessment of the caliber of the nonpatent prior art cited in the patents we studied. Our quality assessment revealed nothing to indicate that the quality of nonpatent prior art in Internet business method patents was substantially inferior to that found in other patents.

253. See, e.g., Cuno Eng'g Corp. v. Automatic Devices Corp., 314 U.S. 84, 90-92 (1941). See generally 2 Donald S. CHISUM, Chisum on PATENTS: A TREATISE ON THE LAW OF PATENTABILITY, VALIDITY AND INFRINGEMENT $§ 5.02$ (1999).

254. Although no knowledgeable observer would wish a return to a paradigm of subjective hindsight for obviousness decisions, we personally believe that patent applicants rather than examiners should bear the burden of proof during patent prosecution. Analysis of such a fundamental overhaul of the patent examination system is beyond the scope of this Article.

255. Cohen et AL., Why U.S. MANufacturing Firms PATENT, supra note 51; Hall \& Ziedonis, supra note 186; Levin et al., supra note 51. 


\section{B. An Information Cascade of Negative Opinion}

We are still left with questions about the gap between the accepted wisdom and what we believe to have been the reality. We believe that negative opinions about business method patents swelled to a classic information cascade. Part of a large body of theoretical and empirical work on collective behavior and an outgrowth of game theory, research on information cascades confirms the fundamental notion that people react to their environment, and that this environment includes other people's reactions to their environments. ${ }^{256}$ Information can cascade to the point (the "tipping point") that people's actions are increasingly influenced by the information conveyed through the actions of others, regardless of the accuracy of that information. ${ }^{257}$ This is sometimes called the "bandwagon effect," as seen in fads and fashions in apparel, toys, and academic research paradigms, and also accounts for phenomena such as herd behavior in the stock market, riots in the streets, and graffiti on the walls. It is possible for the cascade to reach a point that some people base their

256. See generally Lisa R. Anderson \& Charles A. Holt, Information Cascades in the Laboratory, 87 AM. ECON. REV. 847 (1997) (reporting that information cascades develop consistently in behavioral laboratory experimentation); Abhijit V. Banerjee, A Simple Model of Herd Behavior, 107 Q.J. ECON. 797 (1992) (modeling how subsequent actors increasingly rely on information signaled by the decisions of others to act, producing information cascades); B. Douglas Bernheim, $A$ Theory of Conformity, 102 J. POL. ECON. 841 (1994) (explaining how thought and behavior tend to converge and form social norms); Sushil Bikhchandani et al., Learning from the Behavior of Others: Conformity, Fads, and Informational Cascades, 12 J. ECON. PERSP. 151 (1998) (observing the critical role of "fashion leaders" in information cascades and that such cascades often fade because of shocks - sometimes slight ones - such as the arrival of better informed individuals or public release of new information); Bikhchandani et al., Theory of Fads, supra note 52 (showing how information cascades can often be mistaken even though individuals are acting rationally, how a few early individuals can have a disproportionate effect on the development of a cascade, and how people's beliefs and actions can depend to an increasing degree on information learned from the decisions of others); Stephan Fuchs, A Sociological Theory of Scientific Change, 71 SOCIAL FORCES 933 (1993) (describing movement from one area of inquiry in a scientific discipline to another area within that discipline in a way that closely resembles models of innovation diffusion by the way in which "fashion leaders" create conditions that ultimately lead to herding); Yali Peng, Intellectual Fads in Political Science: The Case of Political Socialization and Community Power Studies, 27 PS: POL. SCI. \& POLS. 100 (1994) (using two fields of study within political science to illustrate the development and decline of intellectual fads in academic circles); Cass R. Sunstein, On Academic Fads and Fashions, 99 MicH. L. REv. 1251 (2001) (applying the teachings of information cascade theory to fads and fashions in academic legal theories and models). For a popular treatment, see MALCOLM GLADWELL, THE TIPPING POINT (2000), discussing what he calls "social epidemics," or abrupt changes in social phenomena resulting from cascading information.

257. Banerjee, supra note 256, at 799. 
actions almost exclusively on information received in this manner rather than information they have discovered for themselves.

A combination of factors contributes to information cascades. The novelty of the phenomenon about which information is being transmitted is probably the most important. Internet business method patents were new and very different looking to almost everyone. Some of them struck informed observers as palpably ridiculous. ${ }^{258}$ The identity of the actors and the means by which they act and speak are also important. More than a few of those voicing adverse opinions about Internet business method patents were luminaries, whose opinions are highly regarded by others. On some occasions they spoke through prominent outlets. Then at some point the sheer volume of information caused the cascade to develop a life of its own, which is manifested by the decisions to produce even more negative commentary and reportage and to single out these patents for different treatment in Congress and in the PTO.

Many of the commentators, especially the academics, were not merely intellectual gadflies but were exceptionally capable people of keen discernment and good judgment. Although they are almost certainly not as prone to jumping on bandwagons as are the less capable, they are not exempt from long-evolved psychological tendencies.

A related theory may help further explain the persistence of the perception-reality gap. Aided by observers' repetition of a few striking examples such as Amazon.com's decision to sue Barnesandnoble.com for infringement of the patent on one-click Internet shopping check-out method, ${ }^{259}$ many people developed firm beliefs about these patents, namely, that they were bad. Although some people develop beliefs only after seeing substantial evidence, many others form them much more easily. Research in behavioral decision theory shows that, once people develop relatively firm beliefs, they tend to cling to them. Most people tend to then pay greater attention to further information confirming these beliefs, and even to seek out confirming evidence while paying little attention to contrary evidence. This "confirmation bias," sometimes called

258. Some probably were rather silly, because one can find many patents in all areas that seem silly. See, e.g., U.S. Patent No. 6,311,639 (issued Nov. 6, 2001) ("Dog Bone Holder"). Others of this ilk are legion. Most, of course, are never asserted against anyone. We admit that a few obvious-looking Internet business method patents were asserted, but we find no reason to believe that, over time, such patents in other areas are asserted less frequently in infringement litigation than Internet business method patents.

259. We have one colleague who said that all of this is explained by two words: "one" and "click". There is an element of truth in this observation, although we think that it is overly simplistic. Besides, we could not get a long article out of that observation. 
"belief perseverance," is a widespread psychological phenomenon even among scientists and others who have been trained to do otherwise. ${ }^{260}$ This is not to say that beliefs never change, of course. These are simply strong tendencies.

\section{CONCLUSION}

We have found no evidence to support the idea that Internet business method patents were of inferior quality or of lower value than most other patents. They were not exceptional. There is even a possibility that the opposite was true. The idea that Internet business method patents never should have been made eligible for patent protection in the first place, or that they are in fact inferior to others, led the PTO and Congress to treat them differently. We do not believe that there were any good reasons for singling them out, but we also see a much more fundamental problem. As Judge Newman observed in In re Shrader, ${ }^{261}$ the concept of "business methods" is probably undefinable. Why, for example, would a method used for applying a photo-resistant layer to a silicon wafer in semiconductor chip manufacturing not be a method of conducting the

260. Such an approach is not the logical way to test a belief (or a hypothesis in statistical testing) and is diametrically opposed to sound scientific method that seeks falsification of hypotheses. For discussions of the confirmation bias, see, for example, HOGARTH, supra note 53, at 116-21; RICHARD NISBETT \& LEE ROSS, HUMAN INFERENCE: STRATEGIES AND SHortcomings IN Social Judgment 167-92 (1980); SCOTT Plous, The PSYCHOlOGY OF Judgment AND Decision MAKING 231-40 (1993); Lee Ross \& Craig A. Anderson, Shortcomings in the Attribution Process: On the Origins and Maintenance of Erroneous Social Assessments, in JUDGMENT UNDER UNCERTAINTY: HEURISTICS AND BIASES 129, 144-52 (Daniel Kahneman et al. eds, 1982). See also MASSIMO PIATELLIPalmarini, InEVITABLE Illusions: How Mistakes OF REASON Rule OUR MindS 12023 (1994) (using different terminology but discussing the same subject matter).

261. 22 F.3d 290, 297-98 (Fed. Cir. 1994) (Newman, J., dissenting). In a dissenting opinion in which she responded to a request by the PTO's Board of Patent Appeals and Interferences for guidance from the Federal Circuit on whether business methods should be excluded from patentability, a request the majority declined to take up, Judge Newman stated:

The Board also relied on the "method of doing business" ground for finding Schrader's subject matter non-statutory under section 101. In so doing the Board remarked that the "method of doing business" is a "fuzzy" concept, observed the inconclusiveness of precedent, and sought guidance from this court. Indeed it is fuzzy; and since it is also an unwarranted encumbrance to the definition of statutory subject matter in section $101 \ldots$, my guidance is that it be discarded as errorprone, redundant, and obsolete. It merits retirement from the glossary of section 101.

Id. (Newman, J., dissenting) (footnote omitted). 
business of making computer chips? Although the enormous difficulty of defining an area of technology for the purpose of treating it differently at the patent system entry point is not limited to business methods, it could be especially acute in this case because all patents on any kind of method or process are presumably acquired for use in a business endeavor.

While it is true that legal decision makers often must work with definitions, it is also true that the greater the premium placed on how an activity is defined at the outset, the more skill and resources will be expended by affected parties to tailor descriptions of what they are doing to either opt into or out of that definition. When a technology is defined for the purpose of differential treatment in patenting, patent attorneys know this in advance of drafting the patent application. Skillful, experienced patent attorneys can often find ways to draft patent applications to make their clients' inventions fall within or outside a defined category. This is amply illustrated by the history of software patents, in which patent lawyers made software sound like a machine with nuts and bolts at a time when courts were still struggling with the idea of software as patentable subject matter and it was necessary that the functional ideas embodied in software be represented as accomplishing a transformation in the traditional physical world. ${ }^{262}$

The problem of definition is further illustrated by the PTO's March 2000 initiative providing an additional level of scrutiny to some business method patents. The program applies only to applications for patents in classification 705 and, indeed, only to a portion of those. ${ }^{263}$ As we noted earlier in this Article, we found many relevant patents in other classesmainly in 707 and 709-that looked very much like the ones in 705 . The PTO often places patents into more than one classification, and some of the patents we found were in two or more of these three classifications. However, many do escape the confines of category 705 and are found only in 707 or 709 , although they appear to be business method patents. ${ }^{264}$

262. See, e.g., In re Alappat, 33 F.3d 1526 (Fed. Cir. 1994) (en banc).

263. Those patents placed in Class 705 and one or more other classifications are subjected to additional scrutiny only if 705 is the first-listed, "main" classification.

264. U.S. Patent No. 5,659,742 (issued Aug. 19, 1997) ("Method for storing multimedia Information in an Information Retrieval System") (describing and claiming an Internet-based system for retrieving multi-media data in categories such as sports or movies and storing demographic data about users); U.S. Patent No. 5,617,565 (issued Apr. 1, 1997) ("Broadcast Interactive Multimedia System") (describing and claiming an Internetbased system for interactive television). Although both of these patents obviously cover Internet business methods, they were not placed in the classification designed for business method patents, Class 705 . Instead, the PTO placed them in Class 707 for inventions pertaining to data collection and retrieval. The patents were not misclassified and do in- 
Insurmountable definitional problems therefore reduce the effectiveness of any attempt to provide stricter scrutiny for business method patents, or indeed for almost any other type of subject matter.

The PTO's differential treatment of business method patent applications is likewise misguided as a matter of sound patent policy because transaction costs are likely to be increased by the definitional gerrymandering of patent lawyers. The PTO's action probably did serve an end that is worthwhile to the agency itself-easing public and congressional pressure from those who thought that business method patents were uniquely a problem-but it does not seem to serve broader policy ends. The one positive result of the PTO's experiment is that the experience gained in the effort could prove valuable were the agency ever given the resources and motivation to enhance scrutiny of patent applications in all fields of technology.

When we say that Internet business method patents were of a quality and value at least as high as most others, and arguably even higher, we do not mean that these patents were a godsend. We do not know whether they are likely to contribute to social welfare over the long term. We do claim, however, that efforts to treat them differently upon entry to the patent system will be ineffective at best and counterproductive at worst. ${ }^{265}$ When

deed belong in 707. See also U.S. Patent No. 6,009,458 (issued Dec. 28, 1999) ("Networked Computer Game System with Persistent Playing Objects") (describing and claiming an Internet-based system for making network game-playing available to users); U.S. Patent No. 6,009,457 (issued Dec. 28, 1999) ("Distributed Real-Time Communications System") (describing and claiming an Internet-based system for offering virtual jam sessions by musicians). Again, these two patents clearly involve Internet business methods, but were not placed in Class 705 . Both were placed, properly so, in Class 709 , the subject of which is computer communication networks, and the second one was also properly assigned to 707 . These represent additional examples of business method patents that were properly classified, but not in 705 .

265. This statement should not be read as suggesting that everything the PTO and the courts do should or can be the same for all patents on all occasions. Whether a patent should be granted and upheld depends mainly on whether the invention represents a novel and nonobvious advance over the prior art in the field. Questions such as which prior art should be considered, whether an invention is a nonobvious advance over the prior art, and whether the patent discloses enough information are all viewed through the lens of an ordinarily skilled practitioner in the particular art. When one realizes that an ordinarily skilled practitioner may range from an experienced mechanic or electrician to a person with a Ph.D. and much experience in molecular biology or computer science, the conclusion is inescapable that not all rules can be applied exactly the same in every case. This truism is very different, however, from saddling different types of subject matter with different rules before they enter the system. The former represents necessary flexibility in the application of rules while the latter invites manipulation of the rules themselves. See, e.g., Dan L. Burk \& Mark A. Lemley, Is Patent Law Technology-Specific?, 
we express the opinion that the PTO's initiative to examine them more thoroughly was misguided, we fully understand that the agency may have done so under duress. If business method patents were indeed of low quality and value, the conclusion is inescapable that a great many patents of other kinds are also questionable. We make no attempt here, however, to analyze all of the likely frailties in the patent system as a whole, because others have done this and will continue to do so. ${ }^{266}$

17 BERKELEY TECH. L.J. 1155, 1185-90 (2002) (exploring the idea that use of the ordinarily skilled person standard necessarily results in differences in the application of some of the basic patentability rules).

266. And besides, we've been working on this project a very long time, and we're tired. 